\title{
ANÁLISE DE VARIÂNCIA MULTIVARIADA COM A UTILIZAÇÃO DE TESTES NÃO-PARAMÉTRICOS E COMPONENTES PRINCIPAIS BASEADOS EM MATRIZES DE POSTOS
}

\section{ANTONIO CARLOS FONSECA PONTES}

Tese apresentada à Escola Superior de Agricultura "Luiz de Queiroz", Universidade de São Paulo, para obtenção do título de Doutor em Agronomia, Área de Concentração: Estatística e Experimentação Agronômica.

P I R A C I C A B A

Estado de São Paulo - Brasil

Junho - 2005 


\title{
ANÁLISE DE VARIÂNCIA MULTIVARIADA COM A UTILIZAÇÃO DE TESTES NÃO-PARAMÉTRICOS E COMPONENTES PRINCIPAIS BASEADOS EM MATRIZES DE POSTOS
}

\section{ANTONIO CARLOS FONSECA PONTES}

Bacharel em Estatística

Orientador: Prof. Dr. CARLOS TADEU DOS SANTOS DIAS

\begin{abstract}
Tese apresentada à Escola Superior de Agricultura "Luiz de Queiroz", Universidade de São Paulo, para obtenção do título de Doutor em Agronomia, Área de Concentração: Estatística e Experimentação Agronômica.
\end{abstract}

P I R A C I C A B A

Estado de São Paulo - Brasil

Junho - 2005 
Dados Internacionais de Catalogação na Publicação (CIP) DIVISÃO DE BIBLIOTECA E DOCUMENTAÇÃO - ESALQ/USP

Pontes, Antonio Carlos Fonseca

Análise de variância multivariada com a utilização de testes não-paramétricos e componentes principais baseados em matrizes de postos / Antonio Carlos Fonseca Pontes. - - Piracicaba, 2005.

$106 \mathrm{p}$.

Tese (doutorado) - - Escola Superior de Agricultura Luiz de Queiroz, 2005. Bibliografia.

1. Análise multivariada 2. Análise de variância 3. Estatística não-paramétrica I. Título

CDD 519.53 
Aos meus filhos, Antonio Carlos Jr, Carlos Eduardo e Ana Carolina e à minha esposa, Loide, por sua paciência e dedicação, eu dedico.

Especialmente à Professora Clarice Garcia Borges Demétrio, pelo incentivo e dedicação, exemplo de humanidade, educadora autêntica e amiga.

Ao meu pai (in memoriam), à minha mãe e aos meus irmãos Fábio e Rose, eu ofereço. 


\section{AGRADECIMENTOS}

Ao Prof. Dr. Carlos Tadeu dos Santos Dias, meu orientador, cuja paciência, cooperação e apoio foram fundamentais para a realização deste trabalho.

Aos professores do Departamento de Matemática e Estatística da Universidade Federal do Acre, pela confiança depositada.

Aos professores e funcionários do Departamento de Ciências Exatas da ESALQ/USP, em especial à Solange de Assis Paes Sabadin e Luciane Brajão pelo apoio nos momentos importantes desta caminhada.

Aos professores Humberto de Campos, Décio Barbin, César Gonçalves de Lima e Daniel Furtado Ferreira que contribuíram com sugestões valiosas, sem as quais não teria sido possível o término deste trabalho.

Aos funcionários das bibliotecas da ESALQ/USP pelo atendimento sempre pronto e na colaboração na aquisição de material bibliográfico.

À bibliotecária Eliana Maria Garcia pela colaboração e compreensão nos momentos finais. 


\section{SUMÁRIO}

Página

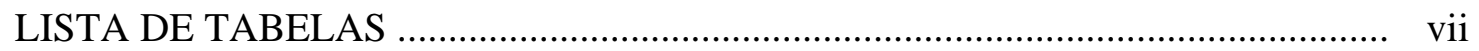

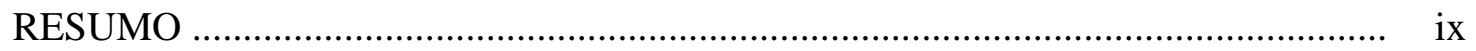

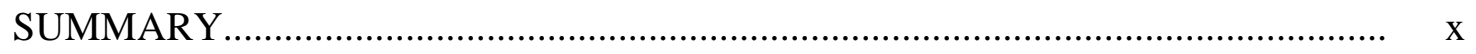

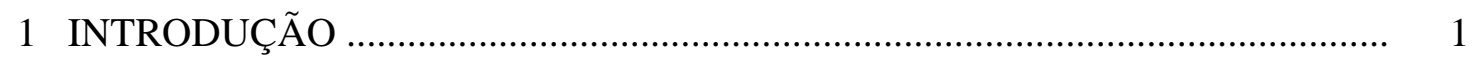

2 REVISÃO DE LITERATURA …........................................................................ 6

2.1 Testes de normalidade multivariada …......................................................... 14

2.2 Testes de aleatorização uni e multivariados .......................................................... 20

2.3 Testes não-paramétricos multivariados utilizando transformações de dados separadamente, para cada uma das variáveis .................................................... 22

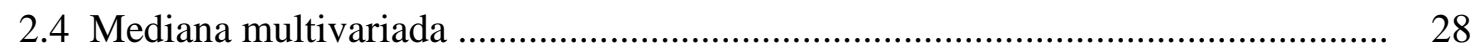

2.5 Combinação de testes independentes e testes de independência ........................... 31

2.6 Testes multivariados baseados na distância entre os dados .................................. 36

2.7 Análise de componentes principais (PCA) e assuntos correlacionados ................ 40

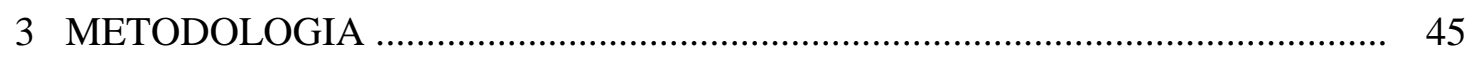

3.1 Notação ........................................................................................................... 46

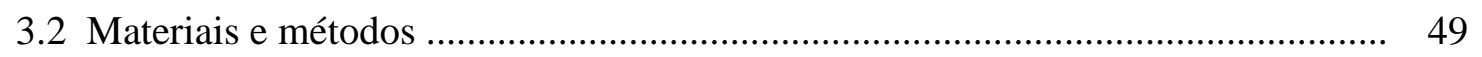

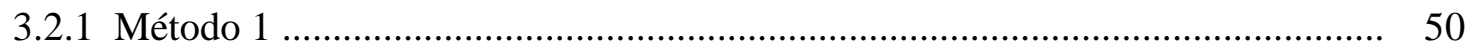

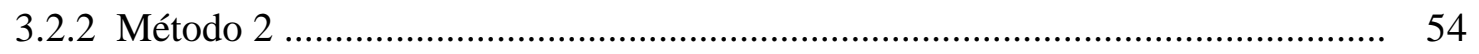

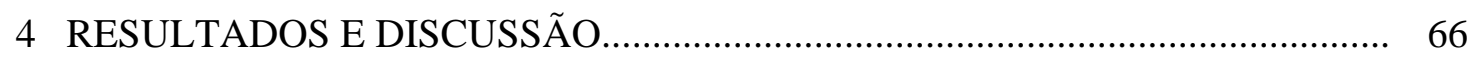

4.1 Exemplo 1. Dados fictícios (dois grupos e duas variáveis) ............................... 67 
4.3 Exemplo 3. Dados de Anselmo (2005)............................................................ 73

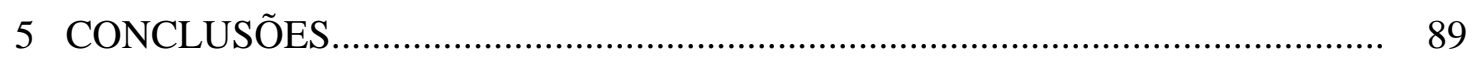

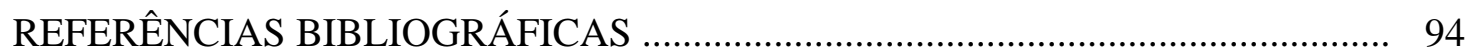




\section{LISTA DE TABELAS}

Página

1 Dados fictícios para uma amostra com dois grupos ...........................................6 68

2 Teste de Wilks para as configurações com dois grupos de três elementos ............ 70

3 Resultados do teste de Wilks $\left(\Lambda_{\mathrm{i}}\right)$ e do teste de Pillai $\left(\mathrm{V}_{\mathrm{i}}\right)$ para as configurações considerando três tratamentos, cada um com duas repetições .............................. 72

4 Tamanho da amostra e médias, para cada grupo, antes e depois do tratamento .... 75

5 Teste de normalidade, homogeneidade de variâncias e indicação da presença de valores discrepantes para as variáveis em estudo - sexo masculino ..................... 77

6 Teste de Normalidade, homogeneidade de variâncias e indicação da presença de valores discrepantes para as variáveis em estudo - sexo feminino ...................... 77

7 Teste de W-M-W comparando os grupos para o sexo feminino - antes .............. 78

8 Teste de W-M-W comparando os grupos para o sexo masculino - antes ............ 78

9 Valores de interesse para o teste de W-M-W para comparação entre os grupos

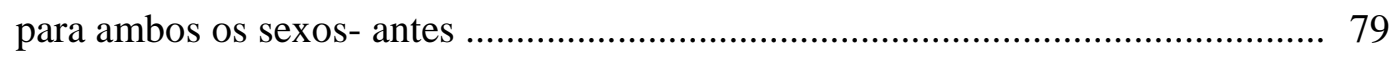

10 Teste W-M-W entre tratados e não tratados, ambos os sexos - Variáveis

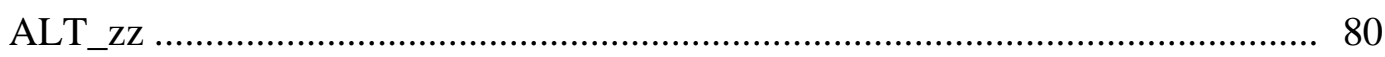

11 Teste W-M-W entre tratados e não tratados, sexo feminino - Variáveis

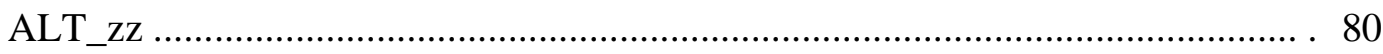


12 Valores de interesse para o teste W-M-W entre tratados e não tratados - sexo masculino - Variáveis ALT_zz

13 Valores de interesse para o teste $\mathrm{W}-\mathrm{M}-\mathrm{W}$ entre os sexos masculino e feminino e p-valores - Variáveis ALT_zz

14 Coeficiente de correlação de Spearman para as variáveis estudadas e respectivos valores-p

15 Resultados dos testes de Pillai e de Wilks para os dados transformados em postos e dados originais - variáveis ALT_zz e rALT_zz

16 Valores da decomposição do traço de Pillai e respectivos valores-p

17 Valores da decomposição de traço de Pillai, resultados obtidos através do programa e respectivos valores-p 


\section{ANÁLISE DE VARIÂNCIA MULTIVARIADA COM A UTILIZAÇÃO DE TESTES NÃO-PARAMÉTRICOS E COMPONENTES PRINCIPAIS BASEADOS EM MATRIZES DE POSTOS}

Autor: ANTONIO CARLOS FONSECA PONTES

Orientador: Prof. CARLOS TADEU DOS SANTOS DIAS

\section{RESUMO}

Métodos não-paramétricos têm aplicação ampla na análise de dados, tendo em vista que não são limitados pela necessidade de imposição de distribuições populacionais específicas. O caráter multivariado de dados provenientes de estudos nas ciências do comportamento, ecológicos, experimentos agrícolas e muitos outros tipos, e o crescimento contínuo da tecnologia computacional, têm levado a um crescente interesse no uso de métodos multivariados não-paramétricos. A aplicação da análise de variância multivariada não-paramétrica é pouco inacessível ao pesquisador, exceto através de métodos aproximados baseados nos valores assintóticos da estatística de teste. Portanto, este trabalho tem por objetivo apresentar uma rotina na linguagem $C$ que realiza testes baseados numa extensão multivariada do teste univariado de KruskalWallis, usando a técnica das permutações. Para pequenas amostras, todas as configurações de tratamentos são obtidas para o cálculo do valor-p. Para grandes amostras, um número fixo de configurações aleatórias é usado, obtendo assim valores de significância aproximados. Além disso, um teste alternativo é apresentado com o uso de componentes principais baseados nas matrizes de postos. 


\title{
MULTIVARIATE ANALYSIS OF VARIANCE USING NONPARAMETRIC TESTS AND PRINCIPAL COMPONENTS BASED ON RANK MATRICES
}

\author{
Author: ANTONIO CARLOS FONSECA PONTES
}

Adviser: Prof. CARLOS TADEU DOS SANTOS DIAS

\section{SUMMARY}

Nonparametric methods have especially broad applications in the analysis of data since they are not bound by restrictions on the population distribution. The multivariate character of behavioural, ecological, agricultural and many other types of data and the continued improvement in computer technology have led to a sharp interest in the use of nonparametric multivariate methods in data analysis. The application of nonparametric multivariate analysis is inaccessible to applied research, except by approximation methods based on asymptotic values of the test statistic. Thus, this work aims to presenting a routine in the $C$ language that runs multivariate tests based on a multivariate extension of the univariate Kruskal-Wallis test, using permutation technique. For small samples, all possible treatment configurations are used in order to obtain the p-value. For large samples, a fixed number of random configurations are used, obtaining an approximated significance values. In addition, another alternative test is presented using principal components based on rank matrices. 


\section{INTRODUÇÃO}

A incorporação de várias variáveis na análise de dados é, muitas vezes, imprescindível em muitas áreas da pesquisa. O inter-relacionamento de variáveis tomadas em uma mesma amostra ocorre naturalmente, em decorrência de sua natureza única. O uso de apenas uma variável pode ser uma simplificação grosseira em muitos casos, não espelhando de forma adequada o objeto em estudo. Esta simplificação ocorre, dentre outros motivos, com a finalidade de facilitar a análise dos dados, ou até mesmo como uma forma de torná-la possível.

Em geral, as diferenças existentes entre grupos ou populações, não é dependente de apenas uma variável e sim de um conjunto delas. A utilização de apenas uma variável nas pesquisas em geral pode tornar o trabalho falho. Existem alguns casos, por exemplo, em que o estudo univariado indica um determinado grupo (ou população ou tratamento) como sendo o melhor ou o mais adequado. Entretanto, quando se consideram outras variáveis, de forma conjunta, outros tratamentos podem ser mais adequados.

Existem situações ainda em que, quando analisadas separadamente, não são detectadas diferenças significativas entre as populações (ou tratamentos ou grupos) para as variáveis em estudo. Porém, quando a análise é feita de forma global, multivariada, as diferenças ficam evidenciadas e são detectadas pelos testes estatísticos. Isso pode ocorrer tanto pelo acúmulo de diferenças das variáveis individuais como por diferenças existentes entre combinações lineares dessas variáveis.

Esses fatores evidenciam a necessidade de se realizar análises multivariadas sempre que possível. Entretanto, como é natural na pesquisa científica, a adição de novas variáveis faz com que os problemas para a realização da análise se 
multipliquem. Um dos motivos para a não ampliação da utilização da análise de dados multivariados é a complexidade das análises. Outros fatores importantes são as fortes pressuposições necessárias para a correta avaliação dos tipos de dados envolvidos. A necessidade da multinormalidade dos dados, de ausência de pontos discrepantes e da homogeneidade das matrizes de covariância, pode fazer com que uma parte considerável das análises que deveria levar em conta múltiplas variáveis não possua as pressuposições adequadas para a execução de testes multivariados. Se, por um lado, tem-se uma visão global do problema ao analisar várias variáveis ao mesmo tempo, a não observação das pressuposições pode anular a vantagem adquirida, pois os testes podem se tornar imprecisos.

A análise de dados multivariados compreende, dentre outras, as técnicas de componentes principais, análise de agrupamentos, análise discriminante, análise fatorial, análise de variância multivariada (MANOVA - multivariate analysis of variance) e análise de correlação canônica.

A análise de dados através de técnicas não-paramétricas univariadas é bem difundida e tem grande utilidade. Testes como os de Wilcoxon-Mann-Whitney, Kruskal-Wallis, Friedman, Page e muitos outros são bem conhecidos e discutidos na literatura (Hollander \& Wolfe, 1999). Os softwares estatísticos mais conhecidos já incorporam estes testes, tanto na sua forma assintótica como na forma aproximada através de testes de permutação.

Por outro lado, técnicas multivariadas não-paramétricas não foram alvos prioritários de pesquisas até meados da década de 90 do século passado. Apenas algumas tentativas isoladas de pesquisadores ocorreram nos anos 70 com o intuito de criar técnicas adequadas à utilização de métodos não-paramétricos multivariados em pesquisas (Tamura, 1965; Sen, 1967; Sen 1969; Mantel \& Valand, 1970; Puri \& Sen, 1971). Na década de 80 aparecem alguns trabalhos isolados, com ênfase nas aplicações dos métodos multivariados não-paramétricos, especialmente nas áreas de biologia, sociologia e psicologia (Katz, 1980; Dietz \& Killeen, 1981; Zwick, 1985). Outros trabalhos dessa época enfocam medidas multivariadas (Gower, 1974; Oja, 1983) ou dão destaque às discussões teóricas referentes aos métodos (Negrillo, 1985). 
Com a ampliação da capacidade dos computadores e novas discussões referentes às transformações adequadas para a obtenção de postos na presença de múltiplas variáveis correlacionadas, a análise multivariada não-paramétrica tem tido destaque a partir dos anos finais do século passado e nos anos iniciais deste século, com a publicação de vários artigos relacionados e discussões bastante significativas a respeito da utilização dessa técnica em vários campos de pesquisa, tais como ecologia, sociologia, pesquisa agrícola em geral e economia, dentre outros. Destacam-se os trabalhos de Möttönen \& Oja (1995), Anderson (2001) e Möttönen et al. (2003), dentre outros.

A aplicação de testes de permutação na análise de dados também deu um impulso significativo na ampliação da discussão e análise de dados multivariados em sua forma não-paramétrica. Essa técnica permite a obtenção da probabilidade de ocorrência de valores menores ou iguais à estatística calculada (valores- $p$ ) sem a necessidade de utilização de resultados assintóticos que, em muitos casos, podem falhar grosseiramente (Anderson, 2001). Para grandes amostras, esses valores-p são aproximados e, no caso de amostras pequenas, pode-se obter valores- $p$ exatos sem que seja necessário recorrer a extensas tabelas.

O uso de técnicas multivariadas na análise de dados pode falhar devido às fortes suposições necessárias para a utilização dos testes multivariados paramétricos (Zwick, 1985; Anderson, 2001). As técnicas não-paramétricas tendem a ser ferramentas bastante úteis nestes casos, já que têm suposições menos restritivas e, portanto, são menos sensíveis aos desvios da multinormalidade, assimetria, existência de pontos discrepantes e heterogeneidade de variâncias.

De acordo com Rencher (1995), há pelo menos quatro argumentos para a abordagem multivariada para o teste de hipóteses:

a) o uso de um conjunto de testes univariados aumenta a taxa de erro tipo I $(\alpha)$, enquanto que o teste multivariado preserva o nível $\alpha$ exato;

b) os testes univariados ignoram as correlações entre as variáveis enquanto que os testes multivariados utilizam, em geral, a matriz de covariâncias de forma direta; 
c) em alguns casos, todos os p testes univariados falham para a obtenção da significância, mas o teste multivariado é significativo porque pequenos efeitos em algumas das variáveis combinadas tendem a indicar uma significância conjunta, o que torna o teste multivariado, em geral, mais poderoso que o conjunto de testes univariados;

d) muitos testes multivariados envolvendo médias têm como um produto derivado a construção de combinações lineares de variáveis que revela mais sobre como as variáveis são combinadas para a rejeição da hipótese.

Neste trabalho será feita uma discussão das técnicas multivariadas nãoparamétricas que têm sido apresentadas na literatura especializada, buscando confrontar algumas dessas técnicas e apresentar alternativas para a análise de dados multivariados. Serão tratados, em especial, o caso da análise de variância multivariada (MANOVA) com um e dois fatores (one e two-way) e os testes para detecção de diferenças entre tratamentos, bem como as técnicas de comparações múltiplas e discussão de contrastes não-paramétricos multivariados. Outra técnica multivariada, a análise de componentes principais, servirá de ponto de partida para a obtenção de um método para a análise de variância multivariada, não sendo, porém, o objeto de estudo principal nesse trabalho.

Assim, os principais objetivos deste trabalho são:

i) fazer uma revisão de literatura dos métodos utilizados na análise nãoparamétrica de dados multivariados;

ii) apresentar uma discussão sobre formas de obtenção de medidas de posição multivariadas, em especial a mediana multivariada, incluindo as transformações de dados em postos, baseadas nesses medianas multivariadas, para a utilização de métodos de análise de variância multivariada não-paramétrica;

iii) buscar um método alternativo, utilizando a técnica dos componentes principais, com o intuito de obter variáveis independentes que, combinadas, possam servir para a obtenção de respostas 
multivariadas, utilizando para isto um processo stepwise e métodos de combinação de estatísticas e/ou valores- $p$;

iv) utilizar a técnica de permutações, sistemáticas e aleatórias, na obtenção de valores críticos (valores- $p$ ) utilizando a transformação dos dados originais em postos e as estatísticas usuais da análise de variância multivariada;

v) implementar os métodos mencionados nos itens iii e iv em programas computacionais e analisar conjuntos reais de dados;

vi) comparar os resultados com aqueles obtidos através de técnicas que vêm sendo mais comumente utilizadas. 


\section{REVISÃO DE LITERATURA}

A estatística não-paramétrica pode ser considerada como a união de procedimentos estatísticos para os quais, não são relacionados parâmetros específicos. Esses procedimentos mantêm suas propriedades, independente da distribuição estatística subjacente aos dados. O termo não-paramétrico é o mais utilizado na literatura especializada, mas a denominação de métodos de distribuição livre é mais adequada tendo em vista que os métodos denominados não-paramétricos referem-se aos procedimentos de inferência estatística nos quais não são feitas suposições explícitas sobre a forma da distribuição dos dados. As exigências para a realização de procedimentos não-paramétricos são menores que as dos métodos paramétricos, mas algumas pressuposições ainda são necessárias para a construção desses testes.

Em relação à denominação dos testes, alguns autores utilizam os termos distribuição livre (distribution-free) e não-paramétrico, de formas distintas. Assim, nãoparamétrico seria a descrição do problema, enquanto que distribuição livre o método usado para a resolução do mesmo. Assim, mesmo num problema paramétrico, como, por exemplo, testar uma hipótese sobre um determinado parâmetro ou obter uma estimativa do mesmo, o método utilizado pode ser ou não de distribuição livre. Portanto, a denominação distribuição livre seria mais adequada no caso geral, mas, pelo uso corrente na literatura especializada, o termo não-paramétrico foi sedimentado.

Nos dias de hoje, ambos os termos (não-paramétrico e de distribuição livre), são usados para designar teses que são válidas sem a suposição de uma distribuição específica. Esses testes são baseados, em sua forma geral, na aleatorização e, em grande parte dos casos, em transformações dos dados em postos, ou seja, na ordenação desses dados em substituição aos dados obtidos no experimento realizado. Os 
testes de aleatorização formam uma classe ampla de testes, paramétricos ou não. Os testes não-paramétricos utilizam, em sua forma exata, a aleatorização para a obtenção dos níveis de significância para a realização de testes de hipóteses e estimativas de parâmetros.

No presente trabalho será considerada a denominação mais usual de testes não-paramétricos para cobrir a ampla classe de testes de permutação onde ocorrem transformações dos dados em postos. As atribuições de postos às observações podem ser feitas de diversas maneiras. Conover \& Iman (1981), discutindo os procedimentos nãoparamétricos, indicam formas através das quais os postos podem ser atribuídos às observações, sugerindo os seguintes tipos:

a) RT-1 (rank tranformation 1), na qual atribuem-se postos ao conjunto completo de observações, do menor ao maior, com a menor observação tendo o posto 1, a segunda menor o posto 2 e assim por diante; postos médios são atribuídos nos casos de empates de observações e esse é a maneira utilizada na execução do teste de Kruskal-Wallis, por exemplo;

b) RT-2 (rank transformation 2), em que, antes da atribuição de postos, as observações são particionadas em subconjuntos e, em dentro de cada uma dessas partições, os postos são designados às observações; ou seja, dentro de cada grupo atribuem-se os postos como na RT-1;

c) RT-3 (rank transformation 3), na qual antes de ser aplicada a transformação RT-1 aos dados, executa-se um realinhamento dos dados, ou seja, médias apropriadas, dentro de cada grupo, podem ser subtraídas dos dados, com a finalidade de retirar algum efeito indesejável ou que não se deseja mensurar;

d) RT-4 (rank transformation 4), em que se procede ao realinhamento e aplica-se a transformação RT-2.

Naturalmente, outras formas de transformações em postos podem ser planejadas e utilizadas, com o intuito de resolver casos específicos. Para a verificação de variabilidade de um conjunto de dados, por exemplo, pode-se atribuir postos dos 
extremos para o centro, fazendo com que os valores mais afastados do valor central tenham os menores postos ou vice-versa. Algumas outras formas de transformações de postos são apresentadas em Negrillo (1985).

No caso multivariado, ainda tem-se outras observações a serem feitas em relação à atribuição de postos. A atribuição de postos de forma conjunta a todas as observações esbarra na verificação de que, sob a hipótese nula, em geral, as permutações ocorrem entre os elementos amostrais e não entre as observações em si. Por outro lado, a atribuição de postos a cada variável, de forma individual, denominada atribuição componentwise, tem sido criticada por não levar em conta as correlações existentes entre as variáveis. Deve-se levar em conta, porém, que na análise multivariada paramétrica usual, a atribuição de valores às variáveis é feita de forma isolada, não havendo nenhuma menção à correlação entre as variáveis, já que ela é intrínseca ao próprio dado obtido. As relações existentes entre as variáveis são, assim, consideradas nas estatísticas de testes utilizadas para a verificação das hipóteses de interesse.

Outra crítica aos métodos que utilizam a atribuição de postos de forma isolada para cada variável refere-se ao tipo de mediana multivariada que está sendo considerada nessa atribuição, que é baseada na composição das medianas individuais relacionadas a cada uma das variáveis em estudo. Assim, várias outras formas vêm sendo discutidas para a mediana multivariada e, conseqüentemente, para a atribuição de postos às variáveis levando em conta essas novas medianas. Observa-se que nenhuma mediana multivariada apresentada na literatura é considerada ideal. Essas medianas são valores obtidos a partir de conceitos criados pelos pesquisadores, que vão desde a minimização de distâncias à minimização de simplexes (áreas, volumes, hiper-volumes) que, entretanto, não agregam todas as concepções desejáveis para uma medida de posição multivariada. Tais considerações serão abordadas com maiores detalhes nas Seções 2.3 e 2.4, onde são discutidos os métodos multivariados não-paramétricos apresentados na literatura.

A consideração de testes de postos (não-paramétricos) na presença de duas variáveis já é antiga. O coeficiente de correlação de Spearman, uma das mais antigas medidas de relacionamento de duas variáveis mostra essa preocupação. 
Basicamente, o coeficiente de correlação de Spearman é obtido a partir da idéia do coeficiente de correlação de Pearson. As simplificações decorrem das propriedades inerentes aos postos das variáveis, permitindo assim a fixação de alguns valores (Conover, 1999). Como em praticamente todos os testes não-paramétricos, o coeficiente de correlação de Spearman e os testes a ele inerentes são utilizados apenas nos casos em que os métodos paramétricos não são viáveis, seja motivado pela natureza das variáveis ou pelo fato das suposições para a execução de testes paramétricos não serem satisfeitas. Os testes não-paramétricos podem basear-se tanto na distribuição obtida através das permutações dos postos como na permutação dos valores originais (Pontes, 2000).

Na análise de dados univariados, os métodos não-paramétricos são, em geral, obtidos a partir de adaptações dos testes paramétricos para a situação em que os postos (ranks) substituem os dados reais. Para o caso multivariado, entretanto, algumas considerações devem ser feitas. Em primeiro lugar, deve-se atentar para a transformação de postos para dados com várias variáveis correlacionadas entre si. Outros dois fatores importantes são: a obtenção de uma medida de posição na forma multivariada e de uma matriz de variâncias e covariâncias para os dados na forma multivariada após a transformação de postos.

A obtenção de uma medida de posição quando se tem mais de uma variável, ou seja, uma mediana multivariada, e de uma matriz de variâncias e covariâncias baseada nessa medida tem sido objeto de alguns trabalhos na literatura (Gower, 1974; Oja, 1983; Plachky \& Rukhin, 1999; Visuri et al., 2000; Nadar et al., 2003; Ollila et al., 2003; Visuri et al., 2003; dentre outros). Por outro lado, alguns autores advogam o uso de uma matriz de distâncias entre pontos obtidos a partir dos dados amostrais, excluindo a necessidade de uma medida de posição. Essa matriz de distâncias pode ser obtida diretamente dos dados originais, sem a necessidade de cálculo de uma medida de posição e dessa forma, alguns tipos de medidas e de distâncias podem ser incorporadas (Anderson, 2001).

Nessa revisão bibliográfica serão apresentadas algumas das técnicas apresentadas na literatura especializada. Obviamente, tal discussão não é exaustiva, abrangendo parte dos métodos surgidos, especialmente nos últimos cinco anos, mesmo 
levando-se em conta que os primeiros trabalhos nesta área datam da década de 70 (Tamura, 1966; Sen, 1967; Sen, 1969). A abordagem da análise multivariada nãoparamétrica na literatura é bastante restrita, sendo encontrada em Puri \& Sen (1971) e Negrillo (1988). Algumas discussões relativas à permutação de dados multivariados podem ser encontradas em Edgington (1995), Good (1999) e Pesarin (2003).

A utilização de métodos não-paramétricos em análise de variância multivariada é resultante do fato que as pressuposições necessárias para a utilização dos métodos paramétricos tradicionais não são satisfeitas. As condições para a realização do teste multivariado podem não ser atendidas devido, dentre outros motivos, à natureza das variáveis. É comum, em estudos ecológicos e nas ciências sociais, por exemplo, variáveis oriundas de contagens, proporções, índices ou ainda algumas resultantes de ordenações dos dados, não passíveis de serem utilizados por uma escala de razão ou escala proporcional. Define-se escala proporcional ou escala de razão como sendo aquela em que os atributos são medidos de forma que os acréscimos em atributos são representados por acréscimos proporcionais em valores da escala. Pereira (1999) indica quatro tipos de escalas utilizadas na codificação de dados:

a) escala nominal, em que os atributos medidos só conhecem relações de igualdade ou desigualdade (relações de equivalência);

b) escala ordinal, que mede atributos que diferem em grau ou intensidade, na qual, além das relações de equivalência, é possível estabelecer relações de ordem (menor ou maior); apesar de ter sentido de direção definido, as unidades de mensuração são desconsideradas e não tem um valor nulo definido;

c) escala intervalar, que mede atributos de tal forma que, além da relação biunívoca entre atributos e código numéricos da escala e do sentido de orientação da medida, tem-se a definição de unidade de mesuração; o zero da escala é um valor arbitrário e assim, pode-se estabelecer relações numéricas entre intervalos de valores mas não entre os valores propriamente ditos; 
d) escala proporcional ou escala de razão, que engloba todas as propriedades das escalas anteriores e mais a existência de um zero real, que permite que a razão entre atributos e valores da escala bem como a razão entre intervalos de atributos e intervalos da escala sejam regulares.

Torabi \& Ding (1998) sugerem que a escolha entre as técnicas paramétrica e não-paramétrica pode ser feita pensando em três aspectos. No caso da hipótese poder ser testada por qualquer uma delas, o método a ser utilizado é aquele que é estatisticamente mais poderoso. Por outro lado, quando as amostras são pequenas, o teste não-paramétrico deve ser preferido, a não ser que a condição relativa à normalidade seja verificada. Nesse caso, o método paramétrico pode ser utilizado. Mundry \& Fischer (1998) apresentam alguns exemplos de utilização de testes não-paramétricos no periódico Animal Behaviour, enfatizando que o uso da distribuição assintótica na obtenção dos valores- $p$ para pequenas amostras pode levar a valores incorretos e, conseqüentemente, à conclusões errôneas a respeito da significância ou não de diferenças entre tratamentos. Os autores argumentam ainda que a escolha do método depende ainda da natureza dos dados.

Outra condição para a validade dos testes paramétricos multivariados é a igualdade, no sentido estatístico, das matrizes de variâncias e covariâncias dos grupos que estão sendo testados (tratamentos). Esta condição pressupõe, não só a igualdade das variâncias dos grupos, mas também uma estrutura de covariância semelhante entre os grupos. Obviamente, a dificuldade em satisfazer tais condições é bem superior ao caso univariado e, apesar do relaxamento de algumas condições, em especial da falta de multinormalidade ser bem tolerada, a necessidade dos métodos não-paramétricos na análise de dados multivariados é evidente. Em função disso, os pesquisadores vêm buscando alternativas aos tradicionais métodos paramétricos para as diversas técnicas multivariadas.

Os métodos multivariados da análise de variância, denominados na literatura MANOVA (Multivariate ANalysis Of VAriance) são aqueles em que, dados $C$ grupos ou tratamentos, procura-se verificar se existem diferenças entre esses grupos. No 
caso de delineamentos inteiramente casualizados, tomam-se por base amostras de tamanho $n_{i} \quad(i=1, \ldots, c)$ de cada grupo, totalizando $N\left(N=\sum_{i=1}^{c} n_{i}\right)$ elementos, sendo medidas $p$ variáveis. Restrições à aleatorização podem ocorrer, gerando assim outros delineamentos, como o aleatorizado em blocos e em quadrado latino, dentre outros.

A metodologia utilizada para verificar as diferenças entre tratamentos na análise multivariada considerando um delineamento inteiramente casualizado (one-way) pode ser a mesma dos métodos univariados, ou seja, a variabilidade total dos dados é subdividida, de tal forma que se obtém uma parte referente à variação devida às diferenças existentes entre tratamentos e outra referente à variação dentro dos tratamentos. No caso univariado, esta variabilidade é expressa pelas somas de quadrados enquanto que no caso multivariado tem-se uma matriz de somas de quadrados na diagonal principal e de somas de produtos fora dela. Outros delineamentos seguem a mesma metodologia, com a inclusão de novos fatores cujas somas de quadrados e de produtos serão expressas separadamente e retiradas da variabilidade total para a formação da matriz de variâncias e covariâncias residual.

No caso não-paramétrico, essa metodologia esbarra em obstáculos, alguns dos quais vêm sendo tratados na literatura. O primeiro deles refere-se ao tipo de medida central multivariada a ser utilizada. No caso paramétrico, o vetor de médias individuais das variáveis envolvidas é consistente, pois, obtém-se assim um ponto, denominado centróide, com as propriedades necessárias para sua aplicação. Entretanto, no caso não-paramétrico, a obtenção de uma mediana multivariada não é tão simples, já que existem diferentes definições do ponto mediano multivariado. Esse aspecto será abordado nas Seções 2.3 e 2.4, mas pode-se adiantar que o vetor das medianas individuais pode não ser equivalente ao ponto mediano multivariado. Assim, algumas formas para a mediana multivariada, como, por exemplo, o centro-mediano ou mediancenter (Gower, 1974) e a mediana de Oja (Oja, 1985) foram apresentadas.

Outro ponto a ser levantado é relativo à atribuição de postos no caso multivariado que depende da forma de mediana a ser considerada. Dentre as metodologias utilizadas para resolver esse problema tem-se a atribuição de postos às variáveis individualmente e a atribuição de postos centrados. Serão apresentadas nesta 
revisão de literatura algumas discussões a respeito da forma de tratamento utilizada na análise não-paramétrica de dados multivariados em diversos trabalhos publicados.

Diversos trabalhos apresentam métodos não-paramétricos e testes de permutações aleatórias na análise de dados multivariados, mas que não estão relacionados diretamente à análise de variância multivariada. Dentre eles, pode ser citado o trabalho de Huh \& Jhun (2001), em que os autores desenvolvem um método alternativo de permutação aleatória em regressão linear múltipla, e o de Thompson (1992), no qual é apresentada uma forma, uma forma alternativa de atribuição de postos, para a análise de dados em medidas repetidas. Denominando a atribuição de postos às variáveis individualmente como sendo intra-componentes, este último autor desenvolve um teste em que a atribuição é feita na forma inter-componentes. Nesse tipo de transformação, para a atribuição dos postos são combinadas as amostras e as variáveis, ou seja, no caso discutido pelo autor, em que se tem um teste bivariado com duas amostras, cada uma delas com $n$ dados, os postos variam de 1 a $4 n$. A partir dessa atribuição de postos, obtém-se a matriz de variâncias e covariâncias dos postos e um teste, semelhante ao $T^{2}$ de Hotteling é desenvolvido por Thompson (1992).

A presente revisão tem como intuito fazer um levantamento dos trabalhos que têm sido relevantes na discussão dos métodos não-paramétricos multivariadados, com ênfase na Análise de Variância Multivariada, discutindo os aspectos teóricos e práticos das metodologias propostas.

Com o intuito de melhor sistematizar e organizar a discussão dessas metodologias, o presente capítulo está subdividido em seções, referentes às técnicas multivariadas não-paramétricas presentes na literatura e a outros métodos, não diretamente ligados àquelas técnicas, mas que são importantes no desenvolvimento de metodologias alternativas.

Essas novas metodologias, propostas no presente trabalho, se baseiam, pois, na combinação de métodos já conhecidos, buscando soluções alternativas para a resolução de problemas na Análise de Variância Multivariada e proporcionar a utilização dessas técnicas por um número maior de pesquisadores. 


\subsection{Testes de normalidade multivariada}

Uma das fases mais delicadas no planejamento de experimentos é a fase inicial, quando são feitas as suposições a serem válidas para a análise dos dados, ou seja, determina-se um modelo ao qual supõe-se que se ajustem aos dados. Os métodos usuais nesta fase são os gráficos box-plot, esquemas de ramos e folhas e testes para detectar a possível distribuição dos dados, ou seja, a adequação, ou não, dos dados à uma determinada distribuição teórica. Na maior parte da metodologia utilizada nos trabalhos estatísticos, essa pressuposição refere-se à normalidade dos dados, homogeneidade de variâncias e não existência de dados discrepantes. A validade dos procedimentos a serem utilizados, em geral está associada à possibilidade de assumir uma determinada distribuição teórica, geralmente a distribuição normal. Quando isso não ocorre, transformações de dados podem ser utilizadas em alguns casos particulares. Andrews et al. (1971) apresentam uma extensão do método de Box e Cox para a obtenção de transformações de dados multivariados, mas tais transformações podem não ser adequadas devido à impossibilidade de se obterem conclusões confiáveis quando se realiza a transformação inversa. Os métodos apresentados pelos autores buscam não apenas a normalidade, mas também a aditividade e a homocedasticidade.

De acordo com Mardia (1970), os testes relacionados à análise de variância multivariada são, em geral, robustos mesmo quando a normalidade não ocorre, o mesmo não acontecendo com os testes de igualdade das matrizes de covariância. A rejeição do ajuste de um modelo teórico aos dados pode ainda levar ao uso de procedimentos que não são baseados em qualquer modelo específico, ou seja, aos métodos não-paramétricos (ou de distribuição livre), em que não se assume uma forma específica de distribuição dos dados e sim formas gerais para tal distribuição, como a simetria, por exemplo.

Vários métodos podem ser utilizados para verificar o ajuste de uma determinada distribuição (normal, Poisson, binomial, gama, dentre outras) a um conjunto de dados. Como grande parte dos métodos de inferência são baseados na suposição de normalidade dos dados, torna-se desejável então testar a hipótese de que 
uma amostra seja proveniente de uma população cujos membros podem ser estudados através de uma distribuição normal. De acordo com Johnson \& Wichern (1999), em Análise Multivariada, muitas das técnicas assumem que o vetor de observações $\boldsymbol{X}_{\boldsymbol{j}}$ tem uma distribuição normal multivariada. Por outro lado, em situações em que o tamanho da amostra é grande e as técnicas dependem somente da natureza do vetor de médias $\overline{\boldsymbol{X}}$ ou distâncias que envolvem esse vetor, a suposição de normalidade dos dados não é tão importante. Entretanto, a qualidade das inferências feitas por esses métodos depende de quão próximos da multinormalidade estão os dados sobre os quais serão feitas inferências.

Alguns métodos para detecção de multinormalidade foram discutidos na literatura. Dentre eles podem ser citados métodos gráficos tais como a representação através de stalactite plot (Atkinson \& Mulira, 1992) ou ainda generalizações dos métodos univariados (medidas generalizadas de simetria e curtose, por exemplo).

Para Johnson \& Wichern (1999), as pesquisas referentes à normalidade podem se concentrar apenas em variáveis isoladas ou grupos bivariados (distribuições marginais e scatterplots), pois é difícil construir um bom teste para normalidade conjunta em mais do que duas dimensões. No caso multivariado, os testes de normalidade univariada têm como principal objetivo verificar a normalidade de distribuições marginais. Dentre eles, tem-se o exame do histograma e das caudas da distribuição e a verificação de normalidade através de gráficos, como, por exemplo, o QQ Plot (quantile vs quantile plot). Entretanto, as verificações gráficas têm utilidade apenas nos casos em que o ajuste de uma determinada distribuição teórica a um conjunto de dados é graficamente óbvio, ou ainda quando existem dados muito discrepantes em relação à distribuição proposta. Nos casos em que há dúvidas a respeito do ajuste, a subjetividade do método pode levar a conclusões diferentes, dependendo do pesquisador. Assim, torna-se importante que o método gráfico seja complementado por testes objetivos. Um teste bastante citado na literatura é o de Shapiro \& Wilk (1965), baseado na regressão das observações ordenadas contra os valores das estatísticas de ordem da distribuição padronizada assumida. Comparações entre os diversos testes para normalidade são feitas em Shapiro et al. (1968). Outros testes são o teste de qualidade de 
ajuste utilizando o Qui-quadrado e o teste de distâncias de Kolmogorov-Smirnov (Campos, 1983).

De acordo com Johnson \& Wichern (1999), a preocupação relacionada à normalidade multivariada deve ser concentrada na verificação da normalidade uni e bivariada, tendo em vista que nestes casos é possível fazer verificações gráficas acompanhadas de testes específicos. A verificação da normalidade bivariada pode ser feita através de uma técnica simples: se observações são geradas de uma distribuição normal multivariada, cada distribuição bivariada deve ser normal e os contornos da densidade constante devem ser elipses e, portanto, o gráfico de pontos deve estar de conformidade com esta estrutura. Assim, para os casos com $p$ variáveis, o número de verificações a serem realizadas é $p(p-1) / 2+p=p(p+1) / 2$.

Observa-se que as marginais da distribuição normal multivariada resultam em distribuições normais univariadas. O oposto não ocorre, ou seja, a normalidade univariada e a bivariada das distribuições marginais não garante a normalidade multivariada. Portanto, os testes de normalidade univariados e bivariados servem para refutar a hipótese de multinormalidade, mas não podem ser considerados válidos para a não rejeição da hipótese.

Testes para normalidade multivariada, baseados na generalização dos testes univariados, ou seja, os testes da curtose multivariada, o de simetria, o teste de Shapiro \& Wilk multivariado, além das extensões dos testes de Kolmogorov-Smirnov e Cramer-von-Mises, são apresentados por Malkovich \& Afifi (1973). Nenhum dos testes apresentados tem distribuição nula exata conhecida e, portanto, os valores críticos são obtidos através de simulações.

Os testes de Kolmogorov-Smirnov e de Cramer-von-Mises utilizam o fato de que, se o vetor $\boldsymbol{Y}$ com $p$ elementos segue uma distribuição normal multivariada, ou seja, ${ }_{p} Y_{1} \sim N_{p}\left(\mu_{o}, \Sigma_{0}\right)$ então

$$
V=\left(Y-\mu_{0}\right)^{\prime} \Sigma^{-1}\left(Y-\mu_{0}\right) \sim \chi_{p}^{2}
$$

Assim, utilizando as variáveis amostrais transformadas

$$
V_{j}=\left(Y_{j}-\bar{Y}\right)^{\prime} S^{-1}\left(Y_{j}-\bar{Y}\right), j=1, \ldots, n,
$$


em que $\overline{\boldsymbol{Y}}$ e $\boldsymbol{S}$ são, respectivamente, o vetor de médias e a matriz de variâncias amostrais, os testes de Cramer-von-Mises e de Kolmogorov-Smirnov podem ser utilizados para verificar se os vetores $V_{j}$ 's têm uma distribuição de Qui-quadrado com $p$ graus de liberdade.

Assim, a estatística de teste de Crámer-von-Mises (CM) é dada por

$$
C M=\int\left[S(V)-F_{p}(V)\right]^{2} d F_{p}(V)
$$

em que $S(V)$ é a função de distribuição acumulada amostral baseada em $V_{1}, V_{2}, \ldots, V_{n}$ e $F_{p}(V)$ é a função distribuição acumulada da distribuição de Qui-quadrado com $p$ graus de liberdade $\left(\chi_{p}^{2}\right)$.

A estatística de Kolmogorov-Smirnov (KS) é calculada obtendo-se o máximo das diferenças entre a função distribuição acumulada observada e a função distribuição acumulada empírica, ou seja,

$$
K S=\max _{V}\left|S(V)-F_{p}(V)\right| .
$$

O procedimento para a realização do teste generalizado de Shapiro-Wilk segue os seguintes passos:

a) Considera-se inicialmente o vetor de observações $\boldsymbol{Y}_{\boldsymbol{m}}$ tal que

$$
\left(Y_{m}-\bar{Y}\right)^{\prime} A^{-1}\left(Y_{m}-\bar{Y}\right)=\max _{1 \leq j \leq n}\left(Y_{j}-\bar{Y}\right)^{\prime} A^{-1}\left(Y_{j}-\bar{Y}\right)
$$

em que $A=\sum_{j=1}^{n}\left(Y_{j}-\bar{Y}\right)\left(Y_{j}-\bar{Y}\right)^{\prime}$;

b) Obtém-se as estatísticas $U_{j}=\left(Y_{m}-\bar{Y}\right)^{\prime} A^{-1}\left(Y_{j}-\bar{Y}\right), j=1,2, \ldots, n$;

c) Ordenam-se as estatísticas $U_{j}$, denotando-as por $U_{(1)}, U_{(2)}, \ldots, U_{(n)}$;

d) A estatística de teste é dada por

$$
W^{*}=\frac{\left[\sum a_{j} U_{(j)}\right]^{2}}{\left(\boldsymbol{Y}_{\boldsymbol{m}}-\bar{Y}\right)^{\prime} A^{-1}\left(Y_{m}-\bar{Y}\right)}
$$

em que $a_{j}$ são os valores tabelados por Shapiro-Wilks.

Valores pequenos de $W^{*}$ indicam não normalidade multivariada.Valores críticos para o teste foram obtidos por simulação. 
Assim como no caso das medidas de assimetria e curtose univariadas, as medidas Generalizadas de Assimetria e Curtose (Kattree \& Naik, 2000) podem ser utilizadas para se determinar a normalidade multivariada.

A assimetria multivariada $\left(\beta_{1, p}\right)$, que é obtida a partir da generalização da definição da assimetria univariada, é dada por

$$
\beta_{1, p}=E\left\{(y-\mu)^{\prime} \Sigma^{-1}(y-\mu)\right\}^{3} .
$$

O mesmo ocorre para a Curtose multivariada $\left(\beta_{2, p}\right)$, cuja fórmula é dada por

$$
\beta_{2, p}=E\left\{(y-\mu) \Sigma^{-1}(y-\mu)\right\}^{2} .
$$

Sabe-se que, para a distribuição normal multivariada, a assimetria é nula, ou seja, $\beta_{1, p}=0$ e a curtose é dada por $\beta_{2, p}=p(p+2)$. Assim, o procedimento para se estimar a assimetria e a curtose generalizada de um conjunto de dados multivariados as seguintes fórmulas são utilizadas:

$$
\begin{aligned}
& \hat{\beta}_{1, p}=\frac{1}{n^{2}} \sum_{i=1}^{n} \sum_{j=1}^{n} g_{i j}^{3} \quad \text { em que } g_{i j}=\left(y_{i}-\bar{y}\right)^{\prime} S_{n}^{-1}\left(y_{j}-\bar{y}\right) \\
& \hat{\beta}_{2, p}=\frac{1}{n} \sum_{i=1}^{n} g_{i i}^{2}=\frac{1}{n} \sum_{i=1}^{n} d_{i}^{4} \text { em que } d_{i}=\sqrt{g_{i i}}
\end{aligned}
$$

Observa-se na fórmula (10) que $d_{i}$ é a distância quadrada amostral de Mahalanobis entre $\boldsymbol{y}_{i}$ e $\bar{y}$.

Estas medidas são não-negativas e espera-se que, para uma distribuição normal multivariada, $\hat{\beta}_{1, p}$ seja próximo de zero. Se há um afastamento da simetria esférica (correlação nula e variâncias iguais), então $\hat{\beta}_{1, p}$ será grande.

Além disso, para grandes amostras tem-se que

$$
\begin{aligned}
& \kappa_{1}=\frac{n \hat{\beta}_{1, p}}{6} \sim \chi_{[p(p+1)(p+2) / 6]}^{2} \\
& \kappa_{2}=\frac{\hat{\beta}_{2, p}-p(p+2)}{\sqrt{8 p(p+2) / n}} \sim N(0,1)
\end{aligned}
$$


Assim, para testar a assimetria e a curtose multivariadas de um conjunto de dados, as estatísticas $\boldsymbol{\kappa}_{\mathbf{1}}$ e $\boldsymbol{\kappa}_{\mathbf{2}}$ são utilizadas. Se ambas as hipóteses não forem rejeitadas, a teoria normal para vários testes sobre vetor de médias ou matriz de covariâncias pode ser usada. Porém, verifica-se que testes sobre médias são sensíveis à falta de simetria $\left(\beta_{1, p}\right)$ enquanto que testes sobre a matriz de covariâncias são influenciados pela curtose $\left(\beta_{2, p}\right)$. Programas para a obtenção da curtose e assimetria multivariada e os testes referentes aos valores obtidos são apresentados em Khattree \& Naik (1996).

Kankainen el al. (2003) verificam a possibilidade de substituir o vetor de médias e a matriz de dispersão usual (matriz de variâncias e covariâncias), respectivamente, pela mediana de Oja (Oja, 1983) e a matriz de dispersão estimada baseada nessa mediana (Visuri et al., 2000; Ollila et al., 2003) na discussão da multinormalidade através dos testes de simetria e curtose (Mardia, 1970). O argumento dos autores é que, para a realização do teste, torna-se necessária uma transformação inicial dos dados utilizando o vetor de médias e a matriz de covariâncias amostrais estimados pelos dados. As estatísticas utilizadas para testar a simetria e a curtose multivariadas comparam a variação medida pelo terceiro e quarto momentos em relação ao segundo momento, gerando assim a necessidade de uma medida mais robusta para o vetor de médias e para a matriz de covariâncias. Os autores mostram que a utilização desse tipo de matriz proporciona melhores resultados do que aqueles obtidos com a matriz de variâncias e covariâncias usual.

Muitos outros testes têm sido discutidos com o intuito de se verificar a normalidade multivariada. Dentre eles, destaca-se o proposto por Székely \& Rizzo (2005), que é baseado nas distâncias euclidianas entre os elementos amostrais. De acordo com os autores, o teste apresentado é invariante sob rotação e é de simples utilização, sendo tão poderoso quanto o teste da simetria e curtose generalizada apresentado por Mardia (1970).

Observa-se, entretanto, que em alguns conjuntos de dados, as pressuposições são claramente violadas, como, por exemplo, quando uma ou mais 
variáveis são medidas obtidas de contagens ou ainda quando se utilizam escalas ordinais. Nesses casos, basta verificar se as variáveis com essas características atendem às pressuposições da normalidade univariada. Caso isso não ocorra para alguma dessas variáveis, a análise multivariada desses dados deve ser realizada utilizando técnicas alternativas.

\subsection{Testes de aleatorização uni e multivariados}

O desenvolvimento de testes de permutação ocorreu na década de 30 para problemas de duas amostras, regressão linear simples e delineamentos em blocos, em que é necessário apenas assumir a intercambialidade dos erros dentro de certos subconjuntos (Welch, 1990). Os testes de aleatorização podem ser considerados como casos especiais dos testes de permutação, para populações finitas, e a utilização desses testes na análise de variância tem sido aceita com resultados consistentes. Welch (1990) descreve cinco passos para a construção de testes de permutação, ou seja, construção do modelo, descrição da hipótese nula, invariância, suficiência e o teste de permutação, aplicando-o para delineamentos em blocos aleatorizados completos e experimentos fatoriais.

Considerando que um dos problemas da inferência estatística é delinear testes de significância exatos quando a forma da distribuição de probabilidade é desconhecida, Wald \& Wolfowitz (1944) obtêm um teorema geral para a distribuição limite de formas lineares no universo das permutações das observações, aplicando-o numa série de estatísticas, dentre elas o coeficiente de correlação de Spearman, o teste para dependência entre duas variáveis de Pittman, a análise de variância em blocos aleatórios e o $T^{2}$ de Hotteling. Sabe-se que, considerando um conjunto de permutações das observações, com cada uma delas sendo igualmente provável sob a hipótese a ser testada, um teste exato no nível de significância $\alpha$ pode ser obtido, escolhendo-se uma 
proporção das permutações como região crítica e que para alguns testes, esse pode ser a única maneira de obter testes exatos de significância.

Uma generalização para o teste $\mathrm{t}$ aplicada a dados multivariados é apresentada por Arnold (1964), para dados com distribuições normais bivariadas, retangular e dupla exponencial. O autor verifica haver pouca discrepância entre o nível de significância do teste quando se considera que a suposição de normalidade é válida para o conjunto de dados e o valor de significância obtido considerando todas as permutações de cada amostra igualmente prováveis, para as amostras provenientes de populações com distribuição retangular e dupla exponencial.

Bell \& Sen (1984) discutem testes de aleatorização, sua estrutura, e, mais detalhadamente, testes para hipóteses de invariância, incluindo testes de independência multivariada, e testes envolvendo postos.

Em Mielke et al. (1981), os autores apresentam um teste não-paramétrico de postos univariado baseado em procedimentos de permutação, com dados multivariados, em que a transformação dos dados multivariados em univariados é feita através do cálculo das distâncias entre pontos. O teste apresentado pelos autores é relacionado ao teste de Wilcoxon-Mann-Withney, no caso de dois grupos, e o teste de Kruskal-Wallis, para mais de dois grupos. Mielke \& Iyer (1982) desenvolvem o método para a análise de dados multivariados num delineamento em blocos casualizados e em Berry \& Mielke (1984) é apresentado um programa computacional para o cálculo dos valores-p, que é denominado procedimento de permutação multi-resposta (multiresponse permutation procedure - MRPP).

Vários livros têm sido publicados recentemente discutindo e apresentando a teoria, as utilizações e exemplos relacionados aos testes de permutação, podendo ser destacados os livros de Edgington (1995), Good (2000) e Pesarin (2001). Nesse último, um método de combinação de testes não-paramétricos é apresentado, que depende, naturalmente, das hipóteses que estão verificadas, em que as combinações dos valores- $p$ individuais, referentes a cada uma das hipóteses independentes, são feitas pelos métodos considerados em Hedges \& Olkin (1985). 


\subsection{Testes não-paramétricos multivariados utilizando transformações de dados separadamente, para cada uma das variáveis}

A mediana multivariada, também denominada mediana componentwise, formada pelo vetor das medianas das variáveis individuais, foi tomada como base nos trabalhos em que foram utilizados testes não-paramétricos multivariados até meados da década de 80. Não foram encontradas, até essa época, discussões relativas à utilização de outros tipos de mediana para dados com várias variáveis. Testes não-paramétricos bivariados e multivariados foram discutidos por vários autores, especialmente na década de 70 e meados da década de 80, alguns deles baseados na teoria apresentada por Puri \& Sen (1971). Alguns trabalhos esparsos foram encontrados antes dessa época. Um dos primeiros trabalhos nessa área é o de Wald \& Wolfowitz (1944), que apresentaram uma modificação ao teste $T^{2}$ de Hotelling, baseada em permutações dos dados originais. Chung \& Fraser (1958) apresentam um teste de aleatorização para análise de dados multivariados com duas amostras, no qual a escolha das estatísticas foi feita intuitivamente, com intenção de obter valores simples de serem manipulados e sensíveis em relação aos tipos de resultados a serem esperados sob a hipótese alternativa. Sejam $p$ variáveis medidas em $m$ observações $\left(x_{1 j}, \ldots, x_{p j}\right), j=1,2, \ldots, m$ da primeira amostra e $n$ observações $\left(y_{1 k}, \ldots, y_{p k}\right), k=1, \ldots, n$, da segunda amostra e $N=n+m$. Considera-se, sob a hipótese nula, que as amostras são provenientes de uma mesma população e, assim, os postos são atribuídos aos elementos amostrais de forma conjunta. Se $r_{i j}$ são os postos atribuídos aos elementos da primeira amostra e $s_{i j}$, aos elementos amostrais da segunda amostra, consideram-se os valores $r_{i j}{ }^{\prime}=r_{i j}-(N+1) / 2$ e $s_{i j}{ }^{\prime}=s_{i j}-(N+1) / 2$, Chung \& Fraser (1958) propuseram as estatísticas $T_{1}=\sum_{i=1}^{p}\left|\sum_{j=1}^{m} r_{i j}{ }^{\prime}\right|$ e $T_{2}=\sum_{i=1}^{p}\left(\sum_{j=1}^{m} r_{i j}{ }^{\prime}\right)^{2}$ para testar as diferenças entre os dois grupos. Para facilitar a obtenção dos valores críticos do teste, pode-se tomar $m=\min (m, n)$ e, ainda, se $p=1$, os testes baseados nas estatísticas $T_{1}$ e $T_{2}$ equivalem ao teste de Wilcoxon-Mann-Whitney. O teste proposto é simples de ser implementado, mesmo para grandes amostras, utilizando um conjunto restrito de permutações dos dados nos dois grupos, mas pode não ser adequado nos casos em que 
existem correlações significativas entre as variáveis. Uma extensão ao teste de Wilcoxon, que utiliza em sua construção as correlações entre as variáveis, é apresentada por Bradley et al. (1971), que consideram não apenas um teste de aleatorização baseado nos valores originais como também estatísticas obtidas a partir de transformações dos dados através dos postos, como no teste de Wilcoxon, e nos escores normais. Seja $\bar{X}_{k}=\left(\bar{x}_{k}^{(1)}, \ldots, \bar{X}_{k}^{(p)}\right)$ o vetor $\mathrm{p}$ dimensional de médias referente ao grupo ou tratamento $k$ ( $k=1,2), S$ a matriz quadrada de dimensão $p$ de variâncias e covariâncias amostrais e $T^{2}$ é a estatística de Hotteling (Johnson \& Wichern, 1998), a estatística de teste, quando se utilizam os dados originais, é dada por

$$
B^{2}=\frac{n m}{N}\left(\bar{x}^{(1)}-\bar{x}^{(2)}\right) S^{-1}\left(\bar{x}^{(1)}-\bar{x}^{(2)}\right)=\frac{(N-1) T^{2}}{N-2+T^{2}}
$$

No caso em que os dados originais são substituídos por seus postos, atribuídos de forma individual para cada variável, a estatística $\mathrm{B}^{2}$ pode ser escrita como

$$
B_{r}^{2}=\frac{12}{(N+1) n m}\left(P_{1}-1 \frac{n(N+1)}{2}\right) R^{-1}\left(P_{1}-1 \frac{n(N+1)}{2}\right)
$$

em que o elemento $i(i=1, \ldots, p)$ do vetor $P_{1}$ são obtidos pela soma dos postos do grupo 1 para a variável $i$ e $R$ é a matriz de correlação de postos. Quando se tomam os escores normais no lugar dos dados originais, outras simplificações ocorrem.

Discussões teóricas a respeito de testes multivariados para uma, duas e três ou mais amostras, incluindo distribuição assintótica das permutações, eficiência assintótica dos testes e regiões de confiança, são apresentadas em Tamura (1966), Sen (1967), Sen \& Puri (1967), Puri \& Sen (1967), Puri \& Sen (1968), Sen (1969), dentre outros. Essa teoria é apresentada de forma mais completa e detalhada em Puri \& Sen (1971).

Testes não-paramétricos para dados bivariados, focalizados no problema de locação para duas amostras são apresentados por Fryer (1970). Considerando a hipótese nula de igualdades das funções de distribuições bivariadas para as variáveis $X$ e $Y$ quando se consideram duas amostras, ou seja, $F_{1}(x, y)=F_{2}(x, y)$, três estatísticas são apresentadas, uma para cada hipótese alternativa (diferenças irrestritas, diferenças em uma única direção para ambas as variáveis e diferença em direções opostas para as 
variáveis consideradas). Feita a transformação dos dados originais em seus postos, considerando cada variável separadamente e os grupos conjuntamente, seja $r_{s}$ a correlação de postos amostral (correlação de Spearman), $S_{i}=s_{i}+n(N+1) / 2(i=1,2)$ e, ainda, $s_{1}$ a soma dos postos para a variável $X$ e $s_{2}$ a soma dos postos para a variável $Y$. Assim, considerando a hipótese nula $H_{0}: F_{1}(x, y)=F_{2}(x, y)$, que equivale à hipótese dada por $H_{0}:(\delta, \lambda)=(0,0)$ e a hipótese alternativa geral $H_{a}: F_{2}(x, y)=F_{1}(x-\delta, y-\lambda)$, as estatísticas de teste são dadas por

$$
\begin{aligned}
& t_{1}=\left[\frac{\left(1-r_{s}^{2}\right) n m(N+1)}{12}\right]^{-1}\left[S_{1}^{2}+S_{2}^{2}-2 r_{s} S_{1} S_{2}\right](\delta \text { e } \lambda \text { irrestritos }) \\
& t_{2}=\left[\frac{n m(N+1)\left(1+r_{s}\right)}{6}\right]^{-1 / 2}\left[S_{1}+S_{2}\right] \quad(\delta, \lambda>0 \text { ou } \delta, \lambda<0) \\
& t_{3}=\left[\frac{n m(N+1)\left(1-r_{s}\right)}{6}\right]^{-1 / 2}\left[S_{1}-S_{2}\right](\delta>0 \text { e } \lambda>0) \text { ou }(\delta<0 \text { e } \lambda>0)
\end{aligned}
$$

Os autores discutem a distribuição assintótica de $t_{1}, t_{2}$ e $t_{3}$, mostrando ainda que existe uma relação entre as estatísticas $\left(t_{1}=t_{2}{ }^{2}+t_{3}{ }^{2}\right)$, o que indica maior poder das estatísticas $t_{2}$ e $t_{3}$ em relação à $t_{1}$ em suas hipóteses alternativas específicas. Generalizações para mais do que duas amostras são observadas em Puri \& Sen (1971).

Boyett \& Shuster (1977) discutem um método não-paramétrico bivariado com hipótese alternativa unilateral na análise de dados multivariados dando ênfase a aplicações na área da saúde, que pode ser utilizado, por exemplo, nas comparações de drogas com placebos. Para a efetivação do método proposto calculam-se os valores da estatística $t$ usual de diferença entre médias para cada uma das variáveis envolvidas e o seu valor máximo $\left(t_{\max }\right)$. Em seguida, considerando que o grupo com a nova droga contém $n$ elementos, de um total de $N$, são obtidas todas as amostras possíveis de tamanho $n$, calculando-se para cada uma delas o $t_{\text {max }_{i}}, i=1, \ldots, C_{N}^{n}$. Considerando $\#\left(t_{\max _{i}} \geq t_{\max }\right)$ como o número de valores $t_{\max _{i}}$ maiores do que $t_{\max }$, o valor-p será dado pela proporção $\#\left(t_{\max _{i}} \geq t_{\max }\right) / C_{N}^{n}$ para o caso em que a hipótese alternativa seja a de que o tratamento é melhor do que o placebo para ao menos uma das variáveis. 
Para a hipótese de que o tratamento é melhor do que o placebo para todas as variáveis, o valor-p será dado por $\#\left(t_{\max _{i}} \leq t_{\max }\right) / C_{N}^{n}$. Caso o número de combinações seja proibitivo, pode-se utilizar uma amostra aleatória das combinações possíveis. É possível perceber que o procedimento não leva em conta a interdependência dos componentes (variáveis) de forma explícita e tem sua base nos testes de comparações múltiplas.

Uma outra alternativa é proposta por Dietz \& Killeen (1981), que definem um teste não-paramétrico multivariado para tendência monotônica, apresentando aplicações a testes de drogas farmacêuticas. Os autores estendem o teste univariado de Mann (1945) para o caso multivariado. Considerando a matriz de dados $\boldsymbol{X}$ em que cada coluna contém uma das $p$ variáveis e cada linha representa os dados observados nos tempos $1,2, \ldots, n$, os postos são atribuídos aos dados de forma independente para cada variável, (coluna), obtendo-se a matriz $\boldsymbol{P}$. A estatística de teste multivariado proposta é obtida através da combinação das $p$ estatísticas univariadas de Mann $\boldsymbol{K}_{i}(i=1, \ldots, p)$ calculadas independentemente, dada pela forma quadrática $\boldsymbol{K}^{\prime} S^{-1} \boldsymbol{K}$ sendo $\boldsymbol{K}=$ $\left(\boldsymbol{K}_{1}, \ldots, \boldsymbol{K}_{p}\right)$ e $\boldsymbol{S}^{-1}$ a inversa da matriz de variâncias e covariâncias amostral obtida a partir dos dados originais. Entretanto, devido ao uso da matriz de variâncias e covariâncias amostrais relativa aos dados originais, pode fazer com que o teste fique muito sensível a dados discrepantes, podendo tornar o teste falho em algumas situações. Os autores mostram que tal estatística tem distribuição assintótica $\chi_{p}^{2}$. Dietz (1982) discute um teste semelhante na forma, que generaliza o teste dos sinais e o teste de Wilcoxon, originariamente desenvolvido para uma amostra e uma variável, para duas ou mais variáveis. Como no trabalho anterior (Dietz \& Killeen, 1981), vetores das estatísticas obtidas para cada uma das variáveis separadamente são combinados com a matriz de variâncias e covariâncias dessas mesmas variáveis.

Katz \& McSweeney (1980) apresentam uma extensão multivariada do teste de Kruskal-Wallis, derivando a distribuição de referência para grandes amostras da estatística de teste, além de fornecer fórmulas simples para a obtenção da estatística de teste. Procedimentos para a realização de testes de comparações múltiplas são apresentados e comparados. A técnica apresentada pelos autores para a obtenção da 
estatística de teste da análise de variância multivariada (MANOVA) não-paramétrica é uma dada em Puri \& Sen (1971). Os autores apresentam a técnica sob a forma mais clara, com a explicitação de fórmulas e testes de maneira simples e objetiva. A estatística de teste $H_{M}$, proposta por Katz \& McSweeney (1980), é comparada com o valor de Qui-quadrado com $p(c-1)$ graus de liberdade. Os autores apresentam também testes de comparações múltiplas multivariadas, baseados em contrastes, generalizando o teste univariado de Scheffé.

Ampliando o conceito de testes multivariados para mais do que dois grupos, Zwick (1985) apresenta um procedimento não-paramétrico multivariado em que os dados são transformados em postos, de forma independente para cada uma das variáveis, e calcula-se uma estatística baseada no traço de Pillai. Assim, considerando $p$ variáveis, $c$ grupos ou tratamentos, $n_{i}(i=1, \ldots, c)$ amostras em cada grupo, com $N=\sum_{i=1}^{c} n_{i}$ e a matriz de dados transformados $R$, com $N$ linhas e $p$ colunas, obtém-se a matriz de variâncias e covariâncias amostrais total $S_{R}=\left\{s_{i j}\right\}, i, j=1, \ldots, p$. Essa matriz pode ser subdividida na matriz de hipóteses $\left(H_{R}\right)$ e na de erros residuais $\left(E_{R}\right)$, de tal forma que $S_{R}=H_{R}+E_{R}$ e o traço de Pillai $V$ é dado por $V=\operatorname{traço}\left(H_{R} S_{R}^{-1}\right)$. A estatística de teste, dada por $(N-1) V$ é comparada com o valor de Qui-quadrado com $p(c-1)$ graus de liberdade. Para efetuar os testes de comparações múltiplas utilizou-se a técnica proposta por Katz \& McSweeney (1980). Zwick (1985) mostra ainda a relação desse teste com o traço de Pillai para a análise multivariada de um delineamento inteiramente casualizado (one-way) e que, para $p=1$, o teste equivale ao de Kruskal-Wallis e para $p$ $=1$ e $c=2$, tem-se a aproximação normal do teste de Wilcoxon-Mann-Withney. Da forma explicitada no referido artigo, apenas é possível obter os valores- $p$ aproximados através do Qui-quadrado e não há nenhuma menção à maneira como tratar casos em que se têm poucas amostras e variáveis. Nessas situações, considerando o caso univariado, Pontes (2000) indica que a aproximação não é adequada. Essa mesma constatação é feita por Schwertman (1982), considerando o caso multivariado.

Outra formulação para esse teste é dada em Schwertman (1984), em que são apresentados dois testes, denominados teste multivariado da mediana para várias amostras (MMMT - multivariate multisample median test) e teste multivariado da soma 
de postos (MMRST - multivariate multisample rank sum test), sendo o último equivalente ao teste discutido em Katz \& McSweeney (1980) e Zwick (1985), todas elas sendo versões não-paramétricas baseadas no traço de Pillai. As formas apresentadas por Schwetman (1984) e Zwick (1985) são mais simples de serem manipuladas devido ao fato das matrizes serem de dimensões menores. Porém, para a realização de testes de comparações múltiplas, a versão apresentada por Katz \& McSweeney (1980) é mais adequada. No caso do teste multivariado da mediana, utiliza-se a mesma formulação que é utilizada para a estatística do teste multivariado da soma de postos, ou seja, o autor propõe uma única estatística $L_{N}=\sum_{i=1}^{c} n_{i}\left(T_{i}-\bar{T}\right) V^{-1}\left(T_{i}-\bar{T}\right)$ para ambos os testes. $\mathrm{O}$ que modifica entre um teste e outro é a definição dos vetores $T$, e, conseqüentemente, do seu vetor de médias, e a matriz de variâncias e covariâncias $V$, que são adaptadas ao teste da mediana.

Comparações entre métodos paramétricos e não-paramétricos são feitas por Ittenbach et all (1993), que apresentam um exemplo utilizando quatro técnicas para a análise de dados multivariados com quatro variáveis e três grupos ou tratamentos, cada um deles com 35 elementos amostrais. As análises efetuadas foram: análise de variância multivariada paramétrica, análise de variância não-paramétrica multivariada, análise de variância não-paramétrica para as variáveis separadamente e regressão logística multinomial. As análises multivariadas, paramétrica e não-paramétrica, apresentaram resultados semelhantes. O procedimento não-paramétrico utilizado pelos autores baseouse em Zwick (1985).

Bhapkar (1984) discute os métodos utilizados para a realização de testes não-paramétricos de escala e locação univariados e multivariados, quando se consideram vários grupos ou tratamentos, resumindo e apresentando algumas discussões a respeito desses métodos. Outras versões para os testes multivariados para uma, duas ou mais amostras podem ser encontradas nos trabalhos de Spurrier (1988), Randles \& Peters (1990), Peters \& Randles (1990), Peters \& Randles (1991), Um \& Handles (1998), Munzel \& Brunner (2000), dentre outros. 
Partindo de uma premissa um pouco diferente, Park et al. (2001) propõem um teste não-paramétrico com alternativa unilateral para dados multivariados, tomando por base as estatísticas univariadas padronizadas. Assim, considerando a hipótese nula de igualdade dos parâmetros de locação e a hipótese alternativa de que ao menos um dos parâmetros de locação é estritamente maior do que 0 , seja a estatística univariada $T_{i}$ (i = $1, \ldots, \mathrm{p})$, com média $\mu_{i}$ e desvio padrão $\sigma_{i}$, a estatística proposta pelos autores considera o máximo entre os $p$ testes univariados baseados no valor normalizado de $T_{i}$.

Chama a atenção nos trabalhos apresentados nessa seção o fato de não haver nenhuma menção à mediana multivariada. Os autores supõem que o vetor de médias das variáveis transformadas em postos de forma individual é uma medida central adequada. Observa-se ainda que, no caso de não haver empates, o vetor de médias das variáveis transformadas equivale ao vetor de medianas individuais das variáveis originais.

\subsection{Mediana multivariada}

Considerando-se a variável aleatória $X$, contínua, define-se a mediana $M d$ como o lugar geométrico tal que $\operatorname{Pr}(X<M d)=0,5$. No caso discreto com $N$ valores $x_{i}$ $(i=1, \ldots, N)$ equiprováveis, são utilizadas as estatísticas de ordem $x_{(i)}$. Assim, para $N$ ímpar, a mediana é bem estabelecida, sendo dada pelo valor de ordem $(N+1) / 2$, ou seja, $x_{([N+1 / 2])}$. Quando o número de valores é par, convencionou-se que a mediana é o ponto médio entre os valores de ordem $N / 2$ e $(N+2) / 2$, ou seja, $M d=\left[x_{(N / 2)}+x_{([N+2] / 2)}\right] / 2$. Entretanto, qualquer valor entre $x_{(N / 2)}$ e $x_{([N+2] / 2}$ pode ser considerado como o ponto mediano de um conjunto com $N$ dados ( $N$ par).

No caso multivariado, a definição de uma medida de posição multivariada não é tão simples como no caso univariado. Os trabalhos iniciais focalizando a análise de dados multivariados através de métodos não-paramétricos indicam a utilização de uma medida mediana equivalente, em sua forma, à média multivariada, ou seja, um vetor de valores constituído pelas medianas das variáveis individuais. Assim, 
considerando $p$ variáveis com medianas individuais dadas por $\mathrm{Md}_{\mathrm{k}}(\mathrm{k}=1, \ldots, \mathrm{p})$, o vetor de medianas, denominado mediana componentwise ou simplesmente mediana multivariada, é dado $\boldsymbol{M e d}_{\boldsymbol{c}}=\left(M d_{1}, M d_{2}, \ldots, M d_{p}\right)$.

Essa mediana multivariada, formada pelo vetor composto das medianas individuais, pode não ser adequada devido ao fato de não ser invariante ou afim invariante sob rotação. Assim, considerando que o vetor de medianas das variáveis tomadas isoladamente não reflete o valor mediano para o caso multivariado, têm-se buscado formas alternativas de definir uma mediana multivariada. Dentre elas merecem destaque a mediancenter ou centro-mediano (Gower, 1974) e a mediana de Oja (Oja, 1983).

Dados $n$ pontos com $p$ coordenadas $P_{i}\left(\mathrm{x}_{11}, x_{i 2}, \ldots, x_{i p}\right), i=1,2, \ldots n$, referentes aos eixos retangulares, Gower (1974) definiu o centro-mediano como sendo o ponto $M\left(\mathrm{~m}_{1}, m_{2}, \ldots, m_{p}\right)$ tal que $\sum_{i=1}^{n} \Delta\left(P_{i} M\right)$ seja mínimo, sendo $\Delta\left(P_{i} M\right)$ é a distância entre $P_{i}$ e $M$. Como se está trabalhando com distâncias, o centro-mediano é afetado por mudanças de escala e recomenda-se a padronização das variáveis antes da sua utilização. O centro-mediano difere do centróide (ponto médio multivariado) pois este minimiza a distância quadrática, ou seja, minimiza $\sum_{i=1}^{n} \Delta^{2}\left(P_{i} M\right)$.

O centro-mediano é único para mais de uma dimensão e se $\theta_{i}$ é o ângulo entre $M P_{i}$, tem-se que $\sum_{i=1}^{n} \cos \theta_{i}=0$, ou seja, $M$ é invariante para qualquer localização dos pontos $P_{i}$ sobre os raios $M P_{i}$. Em uma dimensão tem-se que $\sum_{i=1}^{n} \cos \theta_{i}=\sum_{i=1}^{n} \operatorname{sinal}\left(x_{i}-m\right)=0$, ou seja, o número de sinais positivos é igual ao número de sinais negativos em relação ao ponto mediano e recai-se na mediana tradicional em uma dimensão. Gower (1974) apresenta um algoritmo interativo para a obtenção do centro-mediano, baseado na interpretação mecânica de que $M$ está em equilíbrio sob forças unitárias nas direções $M P_{i}$ tomando como estimativa inicial do centro mediano o ponto $M_{0}$ (centróide).

Brown (1983) investiga as propriedades assintóticas do centro-mediano, cujas equações de estimativas têm um aspecto angular. O autor utiliza o centro-mediano 
no desenvolvimento de testes angulares, análogos aos testes de sinais em uma direção, possibilitando testar tanto a mudança de locação numa direção fixa, como globalmente em qualquer das duas direções sendo análogos aos testes uni e bilaterais da locação univariada. Apresenta ainda um teste angular para $k$ amostras.

Oja (1983) apresenta uma generalização dos conceitos de medidas de locação, escala, simetria e curtose para o caso multivariado baseados no volume obtido a partir de um simplex de dimensão $p$. Dados $x_{1}=\left(x_{11}, \ldots, x_{1 p}\right)^{\prime}, \ldots, x_{p+1}=\left(x_{p+1,1}, \ldots, x_{p+1, p}\right)^{\prime}$, pontos no espaço $R^{p}$ que determinam um simplex $p$-dimensional, o volume deste simplex é dado por $\Delta\left(x_{1}, \ldots, x_{k+1}\right)=a b s[1 / k !(\operatorname{det} A)]$ sendo $A$ uma matriz cujas colunas são formadas pelos vetores $x_{i}(i=1, . ., k)$ com o acréscimo do primeiro elemento igual a 1 . Se $k=1$ (caso univariado), $\Delta\left(x_{1}, x_{2}\right)$ é a distância entre os pontos $x_{1}$ e $x_{2}$ em $R$ e no caso bivariado $(k=2) \Delta\left(x_{1}, x_{2}, x_{3}\right)$ é a área do triângulo determinado por $x_{1}, x_{2}$ e $x_{3}$ em $R^{2}$. Seja $X_{1}, \ldots, X_{k}$ uma amostra aleatória de tamanho $k$ da população $P$ e sejam as funções $\mu_{\alpha}: \mathfrak{I} \rightarrow$ $\mathfrak{R}^{\mathrm{k}}, 0<\alpha<\infty$ então $E\left\{\left[\Delta\left(X_{1}, \ldots, X_{k}, \mu_{\alpha}(P)\right)\right]^{\alpha}\right\}=\inf _{\mu \in \mathfrak{R}^{k}} E\left\{\left[\Delta\left(X_{1}, \ldots, X_{k}, \mu\right)\right]^{\alpha}\right\}$ define uma classe de medidas de locação, onde $\mathfrak{I}$ uma classe de distribuições de probabilidade. As funções $\mu_{\alpha}$ são medidas de locação nos modelos simétricos e se o valor $\mu_{\alpha}(P)(\alpha>1)$ existe, ele é único. Como casos especiais são consideradas uma generalização da média $\mu_{2}(P)$ e uma nova generalização da mediana $\mu_{1}(P)$. Seja $x_{1}, . ., x_{n}$ uma amostra observada da população $P$, estimativas naturais $\hat{\mu}_{\alpha}$ de $\mu_{\alpha}(P)$ são dadas por

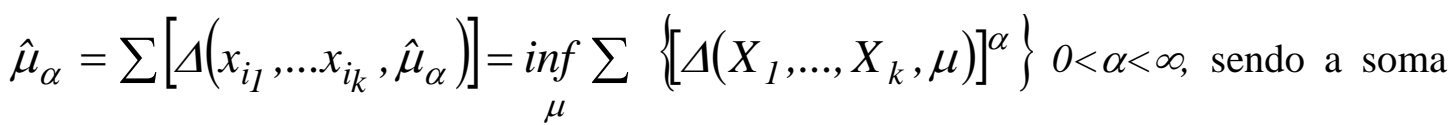
sobre $1 \leq i_{1}<\ldots<i_{k} \leq n$. A estimativa $\hat{\mu}_{2}$ é um vetor de médias amostrais e $\hat{\mu}_{1}$ a mediana amostral. No caso da mediana ( $\alpha=1$ ), tem-se algumas vezes um ponto e outras vezes um conjunto convexo no qual a mediana pode ser selecionada. Assim, a mediana de Oja (1983), também denominada mediana espacial, é definida como o ponto $M$ ou os pontos que minimizam a soma dos volumes dos simplexes formados por $k$ pontos e o ponto $M$. 
A partir da mediana de Oja, muitos trabalhos foram publicados discutindo testes e propriedades. Testes de sinais bivariados e testes multivariados para uma amostra são apresentados por Oja \& Nyblom (1989) e Hettmansperger et al. (1997), respectivamente. Métodos multivariados para os postos e sinais espaciais, para uma e duas amostras, são discutidos por Möttönen \& Oja (1995). A eficiência de testes multivariados utilizando a mediana de Oja é discutida em Möttönen et al. (1998). Testes multivariados não-paramétricos para blocos aleatorizados completos são apresentados em Möttönen et al. (2003). Choi \& Marden (2002) discutem testes para efeitos principais e interações num esquema fatorial 2x2 para um delineamento em blocos casualizados.

Plachky \& Rukhin (1999), Visuri et al. (2000), Nadar et al. (2003), Ollila et al. (2003) apresentam estimativas para a matriz de covariâncias baseadas em postos ou sinais.

Com o intuito de obter valores medianos invariantes sob rotação e transformações afins, e ainda simples de serem obtidas computacionalmente, Chakraborty \& Chaudhuri (1996) e Chakraborty et al. (1998) discutem técnicas de transformação e retransformação sobre a mediana de Oja, que são aplicadas por Randles (2000), num teste multivariado de sinais. Ainda buscando um estimador para a mediana multivariada, Hettmansperger \& Randles (2002) propõem a utilização de um caso especial de estimador simples de ser calculado, mas que, não possui as propriedades desejáveis de existência e unicidade, apesar de serem invariantes.

\subsection{Combinação de testes independentes e testes de independência}

Considerando $p$ variáveis independentes com hipóteses nulas $H_{0 i}$ $(i=1, \ldots, p)$ e ainda um nível de significância $u_{i}$ para a estatística $t_{i}$ obtida dos valores observados, várias técnicas são descritas por Birnbaum (1954) para a combinação desses testes de significância independentes. Caso as variáveis não sejam independentes, os $t_{i}$ 's devem ser funções das variáveis originais, de tal forma que essas novas variáveis sejam 
estatisticamente independentes. O autor verifica ainda que não existe um único método ótimo sob todas as condições.

Vários testes foram propostos para a combinação dos níveis de significância, dentre eles os métodos baseados na distribuição uniforme, método do Quiquadrado inverso e o método da normal inversa (Hedges \& Olkin, 1985).

Um dos métodos de combinação de resultados baseado na distribuição Uniforme foi proposto em 1931 por Tippett. Dadas as probabilidades de significância (valores p) $u_{1}, \ldots, u_{p}$ independentes, então cada um deles tem uma distribuição uniforme sob a hipótese nula $\mathrm{H}_{0}$. Supondo que $u_{(1)}$ seja o mínimo entre todos os valores de $u_{i}$, um teste de $\mathrm{H}_{0}$ ao nível de significância $\alpha$ é obtido a partir da comparação entre $u_{(1)}$ com $1-(1-\alpha)^{1 / k}$, ou seja, rejeita-se $H_{0}$ se $u_{(1)}<1-(1-\alpha)^{1 / k}$. O teste proposto é um procedimento monótono com região de aceitação convexa. Uma generalização desse teste foi proposta por Wilkinson (1951) na qual, ao invés de usar o menor valor-p, utiliza-se o $r$-ésimo menor $u_{(r)}$. Assim, $u_{(r)}$ menor que um valor crítico $p_{r, \alpha}$ implica que pelo menos $r$ dos valores- $p$ são menores que $p_{r, \alpha}$. Assim, pode-se utilizar tanto um valor crítico $p_{r, \alpha}$ para $u_{(r)}$ como também um número crítico $m_{r, \alpha}$ de valores-p que são menores que um nível $\alpha$ fixo, como discutido originalmente por Wilkinson (1951). Como $u_{i}$ tem distribuição uniforme no intervalo [0,1] então (Mood et al., 1974, p. 251265)

$$
f_{u_{r}}(t)=\frac{k !}{(r-1) !(k-r) !}[F(t)]^{r-1}[1-F(t)]^{k-r} f(t)
$$

Sendo $B(r, k-r+1)=\Gamma(r) \Gamma(k-r+1) / \Gamma(k+1), \quad \Gamma(k-r+1)=(k-r) !$, $\Gamma(r+k-r+1)=\Gamma(k+1)=k !, \Gamma(r)=(r-1) !, \quad f(t)=I_{[0,1]}(t)$ e ainda $F(t)=t$ para $t \in[0,1]$, a expressão de $f_{u_{r}}(t)$ pode ser reescrita na forma

$$
f_{u_{r}}(t)=\frac{1}{B(r, k-r+1)} t^{r-1}(1-t)^{k-r} I_{[0,1]}(t)
$$

Assim, percebe-se que $u_{(r)}$ tem distribuição Beta, com parâmetros $r$ e $k$ $r+1$ e assim, tabelas podem ser obtidas. Esse tipo de procedimento tem a vantagem de 
não depender de observações extremas, mas, por outro lado, devido ao fato desse teste não ter uma região de aceitação convexa, ele não pode ser utilizado na combinação de estatísticas de teste que são membros da família exponencial a um parâmetro.

Procedimentos baseados no método do Qui-quadrado inverso, como o de Fisher (1932) e o de Fisher ponderado (Good, 1955) são os mais utilizados na combinação de estudos independentes. Assim, dados k estudos independentes e os valores-p $u_{1}, \ldots, u_{k}$, esse procedimento utiliza a conexão entre as distribuições uniforme e de Qui-quadrado na qual, dada a variável aleatória $U$ com distribuição uniforme, então, a variável transformada - $\log U$ tem distribuição de Qui-quadrado com dois graus de liberdade. Baseando-se no produto dos valores- $p$, tem-se que, se cada hipótese nula $H_{0 i}$ é verdadeira, cada termo do segundo membro da igualdade

$$
T=-2 \log \left(u_{1} u_{2} \ldots u_{k}\right)=-2 \log u_{1}-2 \log u_{2}-\ldots-2 \log u_{k}
$$

tem distribuição de Qui-quadrado com dois graus de liberdade e, portanto, a variável $T$ tem distribuição de Qui-quadrado com 2k graus de liberdade. Assim, a hipótese nula $H_{0}$ é rejeitada se $T=-2 \sum_{i=1}^{k} \log u_{i}$ for maior ou igual a um valor tabelado $C$ obtido a partir da cauda superior da distribuição de Qui-quadrado com $2 k$ graus de liberdade. Uma modificação ao procedimento de Fisher (1932), proposta por Good (1955) e denominada método ponderado de Fisher, utiliza pesos para cada um dos valores-p. Assim, dados os pesos $v_{1}, v_{2}, \ldots, v_{k}$, escolhidos a priori, a estatística para o teste é dada por $T_{w}=u_{1}^{v_{1}} u_{2}^{v_{2}} \ldots u_{k}^{v_{k}}$. A vantagem desse método é que torna possível ao pesquisador atribuir maiores pesos a estudos considerados mais sensíveis, mas ao mesmo tempo duas novas dificuldades são criadas: a forma de atribuição dos pesos e a obtenção da distribuição de $T_{w}$. A distribuição exata de $T_{w}$ nos casos em que os pesos $v_{1}, v_{2}, \ldots, v_{k}$ são distintos foi obtida por Good (1955) e a sua distribuição acumulada é dada por

$$
\operatorname{Prob}\left\{T_{w} \leq q\right\}=\sum_{i=1}^{k} \frac{q^{1 / v_{i}}}{a_{i}} \text {, em que } a_{i}=\frac{1}{v_{i}^{k-1}} \prod_{\substack{j=1 \\ j \neq i}}^{k}\left(v_{i}-v_{j}\right) .
$$

Outro procedimento para combinação de valores- $p$ é o método da normal inversa, onde cada valor-p é tranformado no seu escore normal correspondente, ou seja, 
dado que $\Phi(x)$ é a função de distribuição acumulada normal padronizada, define-se $Z_{\mathrm{i}}$ de tal forma que $u_{i}=\Phi\left(Z_{i}\right)$ ou ainda, $Z_{i}=\Phi^{-1}\left(u_{i}\right)$. Se a hipótese nula $\mathrm{H}_{0}$ é verdadeira, a estatística $Z=\sum_{i=1}^{k} Z_{i} / \sqrt{k}$ tem distribuição normal padrão e $\mathrm{H}_{0}$ é rejeitada se Z é maior que o valor tabulado da distribuição normal padrão.

Littell \& Folks (1974) utilizam a eficiência relativa de Bahadur para discutir os métodos de combinação de testes independentes, mostrando que o teste de Fisher é no mínimo tão eficiente quanto os outros testes. Berk \& Cohen (1979) mostram que outros métodos, além do método de Fisher, são assintoticamente ótimos. Por outro lado, quando são dados pesos diferentes para cada estatística a ser combinada, os autores sugerem alguns métodos de combinação que são ótimos do ponto de vista da eficiência de Bahadur.

As vantagens e limitações de vários métodos de combinações de estudos independentes são discutidas por Rosenthal (1978), que conclui que o método de Fisher é aplicável nos casos em que o número de estudos seja menor ou igual a cinco. Para casos em que o número de estudos supera esse valor, outros métodos são mais aconselháveis, como, por exemplo, os métodos do u médio ou o do Z médio. No primeiro, a estatística é obtida retirando-se 0,5 da média dos valores-p e multiplicandose o resultado por $\sqrt{12 N}$, lembrando que, como a distribuição dos $\mathrm{u}_{\mathrm{i}}$ 's é uniforme, a variância populacional de u é $1 / 12$. No segundo método, os valores-p são convertidos, inicialmente, em valores da distribuição normal e então é efetuado um teste $t$ sobre a média dos valores de $Z$.

Rosenthal \& Rubin (1979) realizam comparações de níveis de significância através de um método simples no qual são obtidos, inicialmente, os valores- $p\left(u_{i}\right)$ e os seus respectivos desvios normais padrões $\left(Z_{i}\right)$ para os k experimentos a serem testados. Toma-se então a estatística $\sum_{i=1}^{k}\left(Z_{i}-\bar{Z}\right)^{2}$, em que $\bar{Z}$ é a média aritmética simples dos $Z_{i}$ 's, $i=1, \ldots, k$ que tem distribuição assintótica $\chi^{2}$ com $k-1$ graus de liberdade. Outra possibilidade apontada pelos autores é a utilização de contrastes destes valores- $p$. Na mesma direção, Rosenthal \& Rubin (1982) discutem testes para 
comparações dos efeitos de estudos independentes, apresentando também a possibilidade de utilização de contrastes desses efeitos para serem testados.

A comparação de oito métodos de combinação de valores-p é feita por Folks (1984). Os métodos comparados são: o da transformação integral de probabilidade, o método de Tippett-Wilkinson, o método de Fisher (denominado FisherPearson), o método de Lancaster, o método de Liptak-Stouffer, o método de GoodZelen, o método de George-Mudholkar e o método de Edgington. Apresentando cada método e utilizando um exemplo, o autor destaca o método de Tippett-Wilkinson, baseado no menor nível de significância dentre os estudos realizados, e o método de Fisher.

Outras discussões a respeito do tema aparecem em Berk \& Cohen (1979), Hedges \& Olkin (1985) e Gianotti (2004), dentre outros.

Para a utilização dos testes discutidos nesta seção, é necessária a verificação da independência dos vetores de dados cujos valores-p ou estimativas dos parâmetros deseja-se combinar. Na maior parte dos casos, a utilização desses métodos é feita para combinação de resultados de experimentos feitos em locais e/ou épocas diferentes e a independência não é verificada formalmente. Um teste paramétrico clássico utilizado para a verificação de independência entre dois pares de vetores é baseado na partição da matriz de covariâncias amostrais $\boldsymbol{S}$. Assim, a hipótese de independência entre os pares de vetores $\boldsymbol{x}_{\boldsymbol{i}}^{(1)}$ e $\boldsymbol{x}_{\boldsymbol{i}}^{(2)}(i=1, \ldots, N)$, com dimensões $p$ e $q$ e matrizes de covariâncias $\boldsymbol{S}_{11}$ e $\boldsymbol{S}_{22}$, respectivamente, obtidos da partição do vetor $\mathrm{x}_{\mathrm{i}}$, de dimensão $\mathrm{p}+\mathrm{q}$ e matriz de covariâncias $\mathrm{S}$, é testada utilizando-se a estatística $\mathrm{W}_{\mathrm{N}}$ (Tashiken et al., 2003), definida por

$$
W_{N}=\frac{|S|}{\left|S_{11}\right|\left|S_{22}\right|}
$$

Uma estatística análoga a essa, só que na versão não-paramétrica, foi apresentada por Puri \& Sen (1971), na qual os vetores de dados são substituídos por seus postos, atribuídos separadamente para cada variável (componentwise ranks). Assim, considerando $\mathrm{R}, \mathrm{R}_{11}$ e $\mathrm{R}_{22}$ as matrizes de covariâncias dos postos, equivalentes às matrizes $\mathrm{S}, \mathrm{S}_{11}$ e $\mathrm{S}_{22}$, a estatística de teste é dada por 


$$
W_{R}=\frac{|R|}{\left|R_{11}\right|\left|R_{22}\right|}
$$

Sob $H_{0}$, tem-se que $-n W_{R}$ tem distribuição assintótica qui-quadrado, com pxq graus de liberdade. Méier (1997) obtém a normalidade assintótica do teste de independência através de postos. Gieser \& Randles (1997), Tashiken et al. (2003) apresentam outras versões para testar a independência entre dois vetores, baseados em outras de atribuições de postos. Puri \& Sen (1971) apresentam também testes para independência entre pares de vetores.

\subsection{Testes multivariados baseados na distância entre os dados}

As distâncias, denominadas medidas de dissimilaridade (ou similaridade, dependendo do ponto de vista que se olha a situação) são bastante difundidas na análise de dados, em especial de dados ecológicos. Clarke (1993) apresenta uma discussão extensa sobre análise multivariada não-paramétrica de mudanças em estruturas de comunidades, obtendo, dentre outros, testes para diferenças temporais e espaciais. Num dos exemplos apresentados, o autor discute o uso de testes de permutação numa análise de variância inteiramente casualizada baseada nos postos das similaridades entre as $n$ amostras $i$ e $j(i=1, \ldots, n-1 ; j=2, \ldots, n ; i<j)$, correspondente aos elementos abaixo da diagonal da matriz de similaridades, em que a maior similaridade tem posto 1 . A estatística de teste utilizada por Clarke (1993) é $R=\left(\bar{r}_{B}-\bar{r}_{W}\right) /(M / 2)$ em que $M=n(n-1) / 2$, e $\bar{r}_{B}$ e $\bar{r}_{W}$ são, respectivamente, as médias de postos entre e dentro das amostras.

Um teste estatístico para a diferença entre as distribuições espaciais de duas populações, baseado numa generalização do teste de Cramér-von Mises e que usa métodos de permutação para obtenção de valores-p é apresentado em Syrjala (1996). 
Outros trabalhos, como os de Schilling (1986) e Henze (1988), para o problema multivariado com duas amostras, envolvem comparações das proporções dos $\mathrm{k}$ vizinhos mais próximos, no qual as observações e seus vizinhos pertencem à mesma amostra. Se considerarmos a variável $Z$, cujos valores $Z_{i}(i=1, \ldots n, n+1, \ldots, N ; N=n+m)$, os valores das amostras combinadas, sendo os primeiros $n$ elementos correspondentes aos elementos da primeira amostra, e $N_{r}\left(Z_{i}\right)$ o r-ésimo vizinho mais próximo de $Z_{i}$, ou seja, é o ponto que satisfaz as desigualdade $\left|Z_{v}-Z_{i}\right|<\left|Z_{j}-Z_{i}\right|$ para exatamente $\mathrm{r}-1$ valores de $v(1 \leq v \leq n$ e $v \neq i)$. A estatística de teste é dada por $T_{n, k}=\sum_{i=1}^{n} \sum_{r=1}^{k} I_{i}(r)$, em que $I_{i}(r)$ é a variável indicadora que assume valores iguais a 1 se $Z_{i}$ e $N_{r}\left(Z_{i}\right)$ pertencem à mesma amostra e 0 em outros casos. Observa-se que o símbolo | . | identifica uma norma em $\Re^{p}$, em que $p$ é o número de variáveis. Valores grandes de $T_{n, k}$ leva à rejeição da hipótese nula de igualdade entre os grupos e os autores obtêm a distribuição assintótica para essa estatística, mas a implementação computacional da mesma exige a determinação de todos os vizinhos mais próximos, o que requer algoritmos eficientes. Em Schilling (1986), valores críticos baseados na métrica euclidiana foram obtidos para alguns valores de $k$ e $p$.

Legendre \& Anderson (1999) propõem uma análise de dados multivariados denominada análise de redundância baseada em distâncias ( $d b-R D A)$. Inicialmente, são calculadas as $N$ distâncias (dissimilaridades) entre os elementos amostrais $\left(d_{i j}\right)$. Para realizar a análise de coordenadas principais toma-se a matriz $\Delta$ cujos elementos $\delta_{i j}(i, j=1, \ldots, N)$ são dados por $\delta_{i j}=a_{i j}-\bar{a}_{i}-\bar{a}_{j}+\bar{a}, a_{i j}=\frac{1}{2} d_{i j}^{2}$ e as médias $\bar{a}_{i}, \bar{a}_{j}$ e $\bar{a}$ são, respectivamente, referentes à linha $i$, coluna $j$ e total da matriz $A=\left\{a_{i j}\right\}$ obtida a partir da matriz de distâncias. Calculam-se os autovalores e autovetores da matriz $\Delta$ e obtém-se, a partir deles, os eixos das coordenadas principais. Finalmente, é feita a análise de redundância sobre a matriz com os elementos das coordenadas principais utilizando-se uma outra matriz com variáveis binárias (dummy) correspondente à matriz de delineamento. O método descrito pelos autores apresenta 
problemas relacionados aos autovalores da matriz $\Delta$ que podem não ser todos positivos. Métodos de correção destes autovalores são apresentados.

McArdle \& Anderson (2001) mostram que o método proposto por Legendre \& Anderson (1999) não têm erros do tipo I consistentes e propõem a utilização da subdivisão da variação total na própria matriz de distâncias. Metodologias semelhantes são propostas por Gower \& Krzanowski (1999) e Krzanowski (2002), nos quais um tratamento matemático mais adequado é apresentado, sob a denominação de análise de distâncias (analysis of distance).

Anderson (2001) propõe um método não-paramétrico baseado em testes de permutação para a análise de variância multivariada, cuja estatística de teste é multivariada, análoga à razão $\mathrm{F}$ de Fisher e é calculada diretamente de qualquer distância simétrica ou matriz de dissimilaridade, com os valores-p obtidos usando permutações. De acordo com a autora, em estudos ecológicos, a necessidade da utilização de métodos não-paramétricos é bastante acentuada pelo fato de que as variáveis medidas em geral não seguem distribuições normais. Por outro lado, os testes da MANOVA não são possíveis de serem realizados nos casos em que o número de variáveis é maior do que o número de unidades amostrais, o que não é incomum em aplicações ecológicas. Nessa situação tem-se uma matriz de covariâncias singular e, portanto, com variância generalizada nula, o que impede a aplicação de alguns testes da MANOVA.

Em Anderson (2001), o método não-paramétrico proposto para testar diferenças entre grupos em geral é baseado em medidas de distâncias (dissimilaridade) entre pares de observações multivariadas individuais ou seus postos. Uma estatística é construída para comparar essas distâncias entre observações dentro de um mesmo grupo versus aquelas em diferentes grupos, seguindo a estrutura conceitual da análise de variância utilizando então permutações das observações para obter a probabilidade associada com a hipótese nula de não diferença entre grupos. O método não-paramétrico descrito utiliza a idéia de que a soma de quadrados entre os pontos e seus centróides é igual à soma de quadrados das distâncias entre pontos, dividida pelo número de pontos, ou seja, uma subdivisão aditiva das somas de quadrados pode ser obtida para qualquer 
distância diretamente da matriz de distâncias, sem calcular as posições centrais dos grupos. Essa propriedade se reveste de importância especialmente quando se utilizam distâncias em que o cálculo de uma posição central pode ser problemático, como é o caso da medida semi-métrica de Bray-Curtis. Assim, é possível obter a subdivisão diretamente das distâncias entre-pontos. Portanto, para realização do teste, calcula-se uma matriz de distâncias entre todos os pares de observações a partir da matriz dos dados originais e obtêm-se as somas de quadrados $S S_{T}=\frac{1}{N} \sum_{i=1}^{N-1} \sum_{j=i+1}^{N} d_{i j}^{2}$ e $S S_{W}=\frac{1}{n} \sum_{i=1}^{N-1} \sum_{j=i+1}^{N} d_{i j}^{2} \varepsilon_{i j}$, observando que $N$ é o número total de observações e $d_{i j}$ a distância entre as observações $i$ e $j(i, j=1, \ldots, N)$ e ainda $\varepsilon_{i j}$ toma o valor 1 se a observação $i$ e a observação $j$ estão no mesmo grupo; em outros casos, ele toma o valor 0 . Obtida a variação entre grupos $S S_{B}\left(S S_{B}=S S_{T}-S S_{W}\right)$, uma pseudo razão F para testar a hipótese multivariada é $F=\left[S S_{B} /(c-1)\right] /\left[S S_{W} /(N-c)\right]$. Uma distribuição da estatística $F$ sob a hipótese nula pode ser criada, entretanto, usando permutações das observações (Edgington, 1995; Manly, 1997). Supondo que a hipótese nula é verdadeira e os grupos não diferem em termos de suas composições e/ou suas abundâncias relativas de espécies então, as observações multivariadas podem ser trocadas entre os diferentes grupos. Para cada uma dessas $M$ permutações, um valor da estatística $F\left(F^{\#}\right)$ é calculado e comparado com o valor de $F$ obtido a partir do ordenamento original e o valor-p é dado por $P=\left(n^{\circ} d e F^{\#} \geq F\right) / M$. O número de resultados possíveis para a estatística de teste, dado por $N R P=(c n) ! /\left[c !(n !)^{c}\right]$, pode crescer rapidamente e assim utiliza-se um subconjunto aleatório de todas as possíveis permutações. A única suposição do teste é que as observações sejam intercambiáveis entre os grupos sob a hipótese nula verdadeira, ou seja, as observações são independentes e têm distribuições similares. O teste proposto é sensível às diferenças de dispersão dos pontos, mesmo se as medidas de locação não diferirem e assim, cuidados devem ser tomados na interpretação dos resultados dos testes de significância. 


\subsection{Análise de Componentes Principais (PCA) e assuntos correlacionados}

A análise de componentes principais (principal component analysis PCA) é uma das mais antigas técnicas multivariadas e seu tratamento matemático já é bem difundido, não sendo necessária nenhuma nova discussão a respeito desse tema específico. A análise de componentes principais é uma técnica que tem o propósito de analisar estruturas de covariâncias e correlações, baseada nas raízes (ou valores) características e nos vetores gerados a partir delas, em matrizes simétricas positivas definidas. No sentido mais geral, a técnica de componentes principais é um método de transformar variáveis correlacionadas em outro grupo de variáveis não correlacionadas, servindo ainda para a obtenção de combinações lineares das variáveis originais com variabilidade relativamente grande (ou pequena, dependendo do propósito), além de ser uma ferramenta para a redução da dimensionalidade dos dados. Pode-se ver ainda que a análise de componentes principais pode ser vista como um fim por si só ou como um passo intermediário para a análise subsequente dos dados. É nesse segundo sentido que ela será utilizada no presente trabalho.

De uma forma geral, considerando um vetor aleatório $X=\left(X_{1}, \ldots, X_{p}\right)$ ' e, sem perda de generalidade, que $\mathrm{E}[\mathrm{X}]=0$. A matriz de covariâncias de $\mathrm{X}$, quadrada de dimensão p, dada por $\mathrm{E}\left[\mathrm{XX}^{\prime}\right]=\Sigma$ é uma matriz simétrica positiva definida. Considere a combinação linear $\mathrm{U}=\mathrm{a}^{\prime} \mathrm{X}$, com $a \in \mathfrak{R}^{p}$ e tal que a variância de $\mathrm{U}$ seja a maior possível, sob a restrição (arbitrária) que a’a $=1$. Pela decomposição espectral, a matriz de covariâncias $\Sigma$ pode ser escrita como

$$
\Sigma=\sum_{j=1}^{p} \lambda_{j} \beta_{j} \beta_{j}^{\prime}=\beta \Lambda \beta^{\prime}
$$

em que $\beta=\left(\beta_{1}, \ldots, \beta_{p}\right)$ é uma matriz ortogonal de dimensão $\mathrm{p}, \Lambda=\operatorname{diag}\left(\lambda_{1}, \ldots, \lambda_{p}\right)$ e os autovalores ou raízes características $\lambda_{\mathrm{j}}$ são ordenados, ou seja, $\lambda_{1} \geq \lambda_{2} \geq \ldots . \lambda_{\mathrm{p}}$. Devido à ortogonalidade de $\beta$, tem-se que $\beta^{\prime} \Sigma \beta=\Lambda$. Como $\beta_{1}, \ldots, \beta_{\mathrm{p}}$ formam uma base de $\mathfrak{R}^{\mathrm{p}}$, o vetor a pode ser escrito como $a=\sum_{i=1}^{p} \alpha_{i} \beta_{i}=\alpha^{\prime} \beta$ para algum $\alpha=\left(\alpha_{1}, \ldots, \alpha_{\mathrm{p}}\right)^{\prime}$. Sendo $\beta$ ortogonal, $\alpha^{\prime} \alpha=1$ e a variância de a'X é menor ou igual que $\lambda_{1}$. Tomando a = 
$\beta_{1}$, tem-se que $\operatorname{var}\left(\beta_{1}{ }^{\prime} X\right)=\beta_{1}{ }^{\prime} \Sigma \beta_{1}=\lambda_{1}$ e define-se a variável aleatória $U_{1}=\beta_{1}{ }^{\prime} X$ como o primeiro componente principal de X. A obtenção dos outros componentes é feita com a restrição adicional de não correlação do próximo componente $U_{i}$ com os componentes anteriormente obtidos $\left(U_{1}, \ldots, U_{i-1}\right)$. Assim, os componentes principais de $\mathrm{X}$ são definidos como vetores aleatórios p-variados $U=\left(U_{1}, \ldots, U_{p}\right)=\beta$ 'X, no qual as colunas de $\beta$ são os vetores característicos de $\Sigma$. Adicionalmente, a matriz de covariâncias de U é diagonal, cujos elementos são os autovalores $\lambda_{\mathrm{i}}$, dada por

$$
\operatorname{Cov}(U)=E\left(U U^{\prime}\right)=\beta^{\prime} \Sigma \beta=\Lambda
$$

Pode-se verificar que a variância total de $\mathrm{X}$ é dada pela soma dos elementos diagonais da matriz $\Lambda$, que é invariante quando se utiliza a transformação utilizada na obtenção dos componentes principais. Outras discussões a respeito dos componentes principais podem ser vistas em Mardia et al. (1979), Flury (1988), Johnson \& Wichern (1995), dentre outros.

A técnica de obtenção de componentes principais foi desenvolvida para variáveis em que não há separação dos dados ou elementos amostrais em grupos. Entretanto, em muitas situações experimentais, grupos pré-estabelecidos são formados, como ocorre na análise de variância e, para esses casos, Flury (1984) desenvolve uma metodologia, denominada análise de componentes principais comuns (common principal components - CPC). Boyk (2002) estende o modelo para dar maior abrangência de utilização do método, incluindo os casos em que os autovalores das matrizes de covariâncias, referentes aos $c$ grupos, são modelados levando em conta a possibilidade de multiplicidade e as relações entre autovalores das $c$ populações. Krzanowski (2002b) apresenta uma revisão geral do método e aplicações. Como método geral, tem-se que dadas $c$ amostras de tamanho $n_{i}(i=1, \ldots, c)$ com vetores de médias $\bar{X}_{i}$ e matrizes de covariâncias $\boldsymbol{S}_{\boldsymbol{i}}$, obtém-se a estimativa de $\mathbf{L}$, que minimiza M, em que

$$
M=\sum_{i=1}^{c} n_{i}\left[\sum_{\substack{j=1 \\ j \neq i}}^{c}\left(L^{\prime} S_{j} L\right)\right] .
$$


tomando, em seguida, $\boldsymbol{D}_{\boldsymbol{i}}=\boldsymbol{L}^{\prime} \boldsymbol{S}_{\boldsymbol{i}} \boldsymbol{L}$ e então utilizamos a transformação $\boldsymbol{Y}=\boldsymbol{L}^{\prime} \boldsymbol{X}$, em que $\boldsymbol{L}^{\prime} \boldsymbol{S}_{\mathrm{i}} \boldsymbol{L} \cong \operatorname{diag}\left(\boldsymbol{D}_{\boldsymbol{i}}\right)$ e $\boldsymbol{L} \boldsymbol{} \boldsymbol{L}=\boldsymbol{I}$. O modelo é considerado adequado se, dado $\mathrm{E}_{\mathrm{i}}=\operatorname{diag}\left(\mathrm{D}_{\mathrm{i}}\right)$, a matriz de correlações $R_{i}=E_{i}^{-1 / 2} L^{\prime} S_{i} L E_{i}^{-1 / 2}$, aproxima-se de uma matriz diagonal ou, mais formalmente, utilizando-se a estatística $T=\sum_{i=1}^{c} n_{i} \ln \left|S_{i}^{-1}\left(L^{\prime} D_{i} L\right)\right|$, que tem distribuição de Qui-quadrado com $p(p-1)(g-1) / 2$ graus de liberdade. Flury (1988) apresenta discussões teóricas e aplicações do método em modelos multivariados.

Segundo Rao (1952), considerando $(s+p)$ variáveis correlacionadas $Y^{(1)}, \ldots, Y^{(s)}, Y^{(s+1)}, \ldots, Y^{(s+p)}$ para as quais amostras de tamanho $n_{1}, n_{2}, \ldots, n_{k}$ são avaliadas para $k$ populações, um possível objetivo é buscar saber se as diferenças entre $k$ grupos caracterizados por $(s+p)$ medidas pode ser explicada pelas variações em $s$ funções lineares destas medidas. Seja a transformação linear definida por $X=M Y$, onde $X$ e $Y$ são matrizes de dimensões $N \times(s+p)$ e $M$ é uma matriz $(s+p) \times(s+p)$. As $s$ primeiras linhas são definidas pelos coeficientes de interesse e os coeficientes de $X^{(s+1)}$ $, \ldots, X^{(s+p)}$ são escolhidos arbitrariamente sujeitos à condição de que o $|M| \neq 0$, condição esta necessária para garantir que a transformação seja biunívoca. O problema é reduzido à consideração da dispersão das variáveis $X^{(s+1)}, \ldots, X^{(s+p)}$ quando aquela devido a $X^{(1)}, \ldots, X^{(s)}$ é removida. Considerando as matrizes $(s+p) \times(s+p)$ de dispersão total $(S)$, entre tratamentos $(B)$ e dentro de tratamentos ou erro $(W)$, a partição da soma de quadrados da análise de variância é dada por $S=B+W$. A matriz quadrada $W^{S}$, de dimensão $s$, das somas de produtos devida ao erro para as variáveis $X^{(1)}, \ldots, X^{(s)}$ a serem eliminadas é obtida a partir da partição da matriz $W$, de tal forma que

$$
W=\left[\begin{array}{cc}
W_{s X s}^{s} & W_{p x s}^{s p} \\
W_{s x p}^{p s} & W_{p x p}^{p}
\end{array}\right]
$$

A matriz de somas de produtos do erro para $X^{(s+1)}, \ldots, X^{(s+p)}$ quando corrigida para $X^{(1)}, \ldots, X^{(s)}$ é dada por $W^{(s+1, \ldots, s+p / 1, \ldots, s)}=W^{(p / s)}=W^{(p s)}-W^{(s p)}\left(W^{s}\right)^{-1} W^{s p}$. Uma outra maneira de obter a matriz $W^{(p / s)}$ é iniciar pela matriz completa $W_{s+p, s+p}$ e reduzi-la $s$ vezes pelo método de condensação pivotal começando pelo elemento $W_{11}$. A matriz referente à soma dos desvios da hipótese mais o erro $\left(S^{(p / s)}\right)$ pode ser obtida, 
substituindo-se a matriz $W$ pela matriz $S$. Assim, a estatística de teste de Wilks será dada por $W(p / s) / S(p / s)$ e o número de graus de liberdade para $W(p / s)$ e $S(p / s)$ são $[N-(c-1)$ - (s-1)] e $[N-s-1]$, respectivamente.

Dempster (1963a, 1963b) descreve o método stepwise de análise de variância multivariada baseado nas variáveis principais resultantes da análise de componentes principais, generalizando o método delineado por Rao (1952). No primeiro trabalho é apresentada a distribuição teórica de métodos de significância para dados multivariados através de métodos geométricos. No segundo, o método stepwise é descrito e ilustrado, estendendo para a aplicação de combinações lineares de variáveis resultantes da análise de componentes principais. Assim, o critério único de Wilks para averiguação de diferenças entre grupos ou tratamentos é substituído por uma sequência de critérios, cada um dos quais testado separadamente, pois, segundo Dempster (1963b), não há razão para acreditar que um simples critério possa ter ótima sensibilidade contra todas as falhas da hipótese nula devida a diferenças entre os vetores de médias. A opção alternativa, na qual substitui-se o critério único por testes realizados em cada uma das $p$ variáveis separadamente, não é satisfatória, pois em geral os critérios são dependentes e, portanto, difíceis de interpretar na sua forma conjunta. Além disso, esses critérios são insensíveis a efeitos associados às combinações lineares das $p$ variáveis, mas não fortemente associados às variáveis individuais.

Dempster (1963b) advoga a escolha dos critérios ordenados através da análise de componentes principais, de tal forma que as primeiras variáveis usadas na ordenação sejam suspeitas, a priori, de terem os maiores desvios da hipótese nula, ou seja, são mais sensíveis ao critério de teste, e pode-se esperar que o procedimento de teste seja mais sensitivo do que a estatística de Wilks $(\Lambda)$, na qual os pesos dos valores $P_{i}$ são iguais, sejam eles sensíveis ou não à hipótese em estudo. A idéia central da análise de componentes principais é encontrar certas combinações lineares das $p$ variáveis dadas que são importantes, no sentido de ter maior variabilidade relativa a um critério padrão. Essas combinações lineares são denominadas variáveis principais e serão consideradas as análises de variâncias sobre estas novas variáveis. Quando as variáveis principais são utilizadas como entrada para o procedimento de teste stepwise, estamos realmente 
testando na ordem se as principais variáveis mostram desvios da hipótese nula. O método proposto por Dempster (1963b) é útil mesmo nos casos em que $n-k<p$ (posto $(W)<p$ ) e nestes casos os $P_{i}$ são definidos e não nulos somente para $i=1, . ., n-k$ e somente um subconjunto das variáveis pode ser incorporado. Finalmente, um aspecto técnico importante do método stepwise baseado nas variáveis principais que merece menção é o fato de que ele permanece aplicável quando o número de variáveis é maior do que o número de observações. Ainda, utilizando-se do fato de que $P_{1}, \ldots, P_{r}$ são independentes de $S$ e, consequentemente, dos autovalores $\left(\lambda_{1}, \lambda_{2}, \ldots\right)$, calculados a partir da matriz $S$, pode-se ainda desejar combinar os níveis de significância de $P_{1}, P_{2}, \ldots, P_{r}$ para obter um nível de significância geral. 


\section{METODOLOGIA}

As alternativas apresentadas na literatura para a resolução de problemas que envolvam a análise de variância multivariada, no caso não-paramétrico, podem ser resumidas em quatro grupos:

a) transformação dos dados através da atribuição de postos de forma independente para cada variável e aplicação dos testes usuais da análise de variância multivariada aos dados transformados;

b) obtenção de medidas de posição multivariadas (medianas de Liu, Oja, centro-mediano, etc.) e de testes a serem aplicados aos postos referenciados por estas medidas;

c) transformação dos dados multivariados em univariados utilizando-se as distâncias entre as observações ou entre as observações e uma medida central, incluindo a possibilidade de escolha da distância a ser utilizada, que seja mais adequada ao tipo de dado envolvido; quando se utiliza uma medida central, recai-se no problema de escolha da mediana adequada;

d) utilização da composição de testes univariados não-paramétricos em cada uma das variáveis em estudo e composição desses resultados numa estatística única.

No presente trabalho serão apresentadas algumas alternativas e/ou complementações aos itens (a) e (d).

Para testes envolvendo medianas multivariadas diferentes da mediana formada pelo vetor das medianas das variáveis consideradas isoladamente (mediana componentwise), não serão feitas discussões de testes alternativos já que esse tema vem 
sendo bastante explorado na literatura. Além disso, as medianas obtidas partem de conceitos interessantes, mas não suficientemente amplos para serem consideradas medidas de locação ideais no plano, no espaço e no hiper-plano.

No caso da transformação de dados multivariados em distâncias, existem implementados softwares para a realização de comparações entre grupos, com a utilização de testes de permutação.

Como complementação ao item (a), serão discutidas a construção de tabelas, utilizando as permutações sistemáticas, para a obtenção de valor-p exato, e de permutações aleatórias, para calcular valores-p aproximados, para os testes multivariados baseados na soma dos postos de amostras multivariadas, de acordo com Schwertman (1985), complementando os testes com as comparações múltiplas.

Outras sugestões serão analisadas, buscando a composição dos resultados obtidos para as variáveis individuais. Para esse fim, discute-se a forma de composição de resultados através de técnicas conhecidas como meta-análise e também os resultados obtidos utilizando uma metodologia stepwise baseada nas variáveis principais, calculadas a partir dos componentes principais (Dempster, 1963b).

No caso da transformação inicial dos dados utilizando distâncias (item c), será discutida e implementada uma alternativa, onde os postos são atribuídos aos pontos baseados na distância desses à uma origem arbitrária, em contraposição àquela que se baseia nos postos obtidos a partir da distância entre as observações componentes da amostra. Em ambos os casos a estatística de teste é calculada comparando-se os postos das distâncias entre grupos e das distâncias intra-grupos.

Comparações com os métodos existentes serão feitas com a utilização de dados simulados.

\subsection{Notação}

Inicialmente, é necessária a introdução de uma notação para os dados e matrizes utilizados neste trabalho. A análise de variância multivariada (MANOVA) 
refere-se ao teste de médias de várias populações numa situação em que várias variáveis são medidas ao mesmo tempo, ou seja, são feitas inferências sobre várias médias populacionais. Essa técnica é uma generalização direta do caso univariado para o caso em que se tem mais do que uma variável resposta. Em sua forma mais simples, consideram-se $c$ grupos ou populações de onde são extraídas amostras aleatórias. Seja $n_{i}$ o número de elementos amostrais extraídos da população $i(i=1,2, \ldots, c)$. Os valores observados da variável $X$ de uma amostra $i$ podem ser escritos na forma de um vetor, ou seja, $X_{i}=\left(X_{i 1}, X_{i 2}, \ldots, X_{i n_{i}}\right)$.

É possível incluir mais de uma variável para o estabelecimento de diferenças entre grupos ou tratamentos e a análise se torna multivariada, levando em conta, além das diferenças individuais de cada variável, a inter-relação existente entre as variáveis estudadas. Obviamente, o número de variáveis a serem estudadas é limitado, já que é impossível abranger todas as avaliações que são responsáveis pelas diferenças individuais e/ou entre grupos. Além disso, a inclusão de variáveis no estudo deve ser feita de forma criteriosa. Uma análise inicial dos dados, com a verificação das interrelações (correlações) entre variáveis é necessária, já que a inclusão de variáveis de forma indiscriminada pode levar a complicações desnecessárias (por exemplo, variáveis fortemente correlacionadas pode levar à não-singularidade da matriz de variâncias e covariâncias). Assim, para a análise multivariada, considera-se:

p: número de variáveis a serem envolvidas no estudo;

$n_{i}$ : número de amostras no grupo $i, i=1, \ldots, c$;

$N=\sum_{i=1}^{c} n_{i}:$ número total de amostras;

$\boldsymbol{X}_{i j}=\left(\mathrm{X}_{\mathrm{ij}}^{(1)}, \ldots, \mathrm{X}_{\mathrm{ij}}{ }^{(\mathrm{p})}\right)$ : observações multivariadas, representadas por um vetor aleatório $p \times 1$;

$\boldsymbol{X}$ : matriz de observações $p \times N$ em que cada linha representa uma observação multivariada, ou seja, 


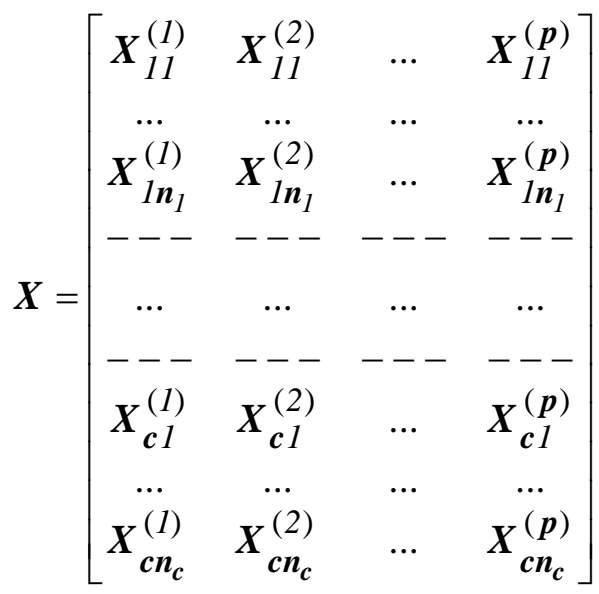

$\overline{\boldsymbol{X}}=\left\lfloor\begin{array}{llll}\overline{\boldsymbol{X}}^{(1)} & \overline{\boldsymbol{X}}^{(2)} & \Lambda & \overline{\boldsymbol{X}}^{(\boldsymbol{p})}\end{array}\right\rfloor$ : vetor de médias amostrais, em que $\bar{X}^{(k)}=\frac{1}{N} \sum_{i=1}^{c} \sum_{j=1}^{n_{i}} X_{i j}^{(k)}, k=1,2, \ldots, p ;$

$S=\left\{s^{\left(k k^{\prime}\right)}\right\}$ em que $s^{\left(k k^{\prime}\right)}=\frac{1}{N-1} \sum_{i=1}^{c} \sum_{j=1}^{n_{c}}\left(X_{i j}^{(k)}-\bar{X}^{(k)}\right)\left(X_{i j}^{\left(k^{\prime}\right)}-\bar{X}^{\left(k^{\prime}\right)}\right)$, $k, k^{\prime}=1, \ldots, p$ : matriz simétrica $p \mathrm{X} p$ de variâncias e covariâncias amostrais.

$R_{P}=\left\{r_{P}^{\left(k k^{\prime}\right)}\right\}$, em que $r_{P}^{\left(k k^{\prime}\right)}=\frac{s^{\left(k k^{\prime}\right)}}{\sqrt{s^{(k k)}} \sqrt{s^{\left(k^{\prime} k^{\prime}\right)}}}:$ matriz simétrica $p \times p$ de coeficientes de correlação de Pearson amostrais;

$\mu=\left\{\mu^{(k)}\right\}=E(X)$ : vetor de médias populacionais;

$\sum=\left\{\sigma^{\left(k k^{\prime}\right)}\right\}=E\left[(X-\mu)(X-\mu)^{\prime}\right]$ : matriz simétrica $p \times p$ de variâncias e covariâncias populacionais;

$\rho=\left\{\rho^{\left(k k^{\prime}\right)}\right\}$, em que $\rho^{\left(k k^{\prime}\right)}=\frac{\sigma^{\left(k k^{\prime}\right)}}{\sqrt{\sigma^{(k k)}} \sqrt{\sigma^{\left(k k^{\prime}\right)}}}$ : matriz simétrica $p \times p$

de coeficientes de correlação de Pearson populacionais;

$Z=\left\{Z_{1}, Z_{2}, \ldots, Z_{p}\right\}$ onde $Z_{i}=\frac{X_{i}-\mu_{i}}{\sqrt{\sigma_{i i}}}:$ vetor $p \times 1$ de variáveis padronizadas. 
A análise de variância multivariada tem como finalidade verificar se os vetores de médias populacionais são significativamente diferentes e, caso sejam, quais os componentes destes vetores diferem significativamente. As suposições do modelo são:

a) $X_{\lambda 1}, X_{\lambda 2}, \ldots, X_{\lambda n_{\lambda}}$ é uma amostra aleatória de tamanho $n_{\lambda}$ de uma população com vetor de médias $\mu_{\lambda}, \lambda=1,2, \ldots, c$. As amostras aleatórias de diferentes populações são independentes;

b) todas as populações têm uma matriz de covariâncias comum $\sum$;

c) cada população é normal multivariada (esta pressuposição pode ser relaxada na presença de amostras de tamanho grande utilizando-se o teorema do limite central).

Na análise de variância multivariada não-paramétrica, não é necessária a pressuposição da multinormalidade dos dados ou mesmo relacionar a distribuição amostral dos dados a qualquer outra distribuição teórica. Apenas pressupõe-se que as amostras são provenientes de uma mesma distribuição e que as amostras obtidas são independentes. Além disso, as inferências não são feitas sobre os parâmetros e sim sobre a distribuição.

\subsection{Materiais e Métodos}

Os dados utilizados no presente trabalho serão obtidos principalmente a partir de simulações. Serão simulados dados provenientes de distribuições normais com algumas variâncias diferentes, distribuições normais contaminadas com dados discrepantes (outliers), distribuições exponenciais e distribuições de contagem para as variáveis em estudo.

Utilizar-se-ão também dados com distribuições diferentes para cada variável, visando verificar a adequabilidade dos métodos nestas situações. 


\subsubsection{Método 1}

Dada uma amostra de $N$ elementos, nos quais foram feitas medidas em $p$ variáveis, a transformação dos dados em postos é feita de forma independente em cada uma das variáveis $\mathrm{X}^{(1)}, \ldots, \mathrm{X}^{(p)}$, obtendo-se assim um vetor de postos $R=\left(R^{(1)}, \ldots, R^{(p)}\right)$ para cada elemento amostral. A estatística de teste é uma adaptação do teste de Wilks aos dados transformados em postos (Zwick, 1985). Assim, em cada uma das p variáveis é feita a transformação dos dados em postos de forma individual. Esse tipo de transformação em postos considera que, para sua realização não é necessária a admissão de uma mediana multivariada que agregue todos os dados de forma multivariada, ou seja, considera-se o vetor de medianas composto pelas medianas individuais relativas a cada uma das variáveis.

Katz \& McSweeney (1980) apresentam uma extensão multivariada do teste de Kruskal-Wallis, derivando a distribuição de referência para grandes amostras da estatística de teste, além de fornecer fórmulas simples para a obtenção da estatística de teste. Procedimentos para a realização de testes de comparações múltiplas são apresentados e comparados. A técnica apresentada pelos autores para a obtenção da estatística de teste da MANOVA não-paramétrica é aquela dada em Puri \& Sen (1971). Os autores apresentam a técnica sob a forma mais clara, com a explicitação de fórmulas e testes de maneira simples e objetiva.

Considerando $c$ grupos ( $c$ amostras aleatórias independentes) em que são medidas $p$ variáveis e seja $X_{i j}{ }^{(k)}, j=1, . ., n_{i} ; i=1, \ldots, c$ e $k=1, \ldots, p$, onde $n_{i}$ é o tamanho da $i$ ésima amostra e seja $N=n_{1}+\ldots+n_{k}$. Para cada elemento das amostras existe um vetor de observações da forma $X_{i j}=\left(X_{i j}{ }^{(1)}, \ldots, X_{i j}{ }^{(k)}\right)^{\prime}$. Se $F_{i}(X)$ representa a função distribuição acumulada multivariada de $X_{\mathrm{i}}$, uma hipótese de interesse frequente é dada por $H_{0}: F_{1}(X)$ $=\ldots=F_{c}(X)$ que, em muitos estudos, reduz-se à hipótese de igualdade dos parâmetros de locação, ou seja, $H_{0}: \mu_{1}=\ldots=\mu_{c}$, onde $\mu_{i}$ é um vetor $p$ dimensional, que constitui o parâmetro de locação da distribuição da $i$-ésima amostra.

Nos casos em que $F_{i}(X)$ são normais multivariadas, com média $\mu_{i}$ e matriz de covariâncias $\Sigma$, o teste da hipótese pode ser efetuado através de algum dos 
critérios paramétricos conhecidos, ou seja, a maior raiz característica (Teste de Roy), o traço de Hotelling-Lawley, a razão de verossimilhança de Wilks ou ainda o traço de Pillai. Para a verificação da multinormalidade multivariada, Mardia (1975), dentre outros, apresenta algumas técnicas com a utilização da curtose e assimetria multivariada. Em relação à homogeneidade das matrizes de variâncias e covariâncias dos grupos, Harris (1975) apresenta um teste, análogo ao teste de Bartlett univariado, mas a utilização deste teste está restrita às situações em que a multinormalidade foi detectada. Nos casos em que as suposições para a utilização da análise de variância multivariada (MANOVA) paramétrica não ocorrem ou ainda nos casos em que as amostras são pequenas para que o teste seja adequado, as técnicas não-paramétricas podem ser uma opção interessante.

O teste não-paramétrico análogo à MANOVA requer somente que as distribuições $F_{1}(X), \ldots, F_{c}(X)$ sejam contínuas. O uso desta técnica pode ser questionável no caso em que se tem variáveis em escalas com dois ou três pontos, indicando assim violação da suposição de continuidade. Entretanto, este tipo de violação só se torna importante quando desejamos trabalhar com distribuições assintóticas. Observa-se ainda que a hipótese nula é agora tratada em termos de medianas e não de médias como no caso paramétrico, sendo pois uma extensão do teste de Kruskal-Wallis. O procedimento para a realização do teste é o seguinte:

a) para cada uma das $p$ variáveis, ordenam-se os dados, independentemente dos grupos, de 1 a $N$, sendo 1 para o menor valor, 2 para o segundo menor e assim por diante, até o valor $N$ para o maior valor; no caso de empates (igualdade de observações), calcula-se a média dos postos correspondentes; desta maneira, cada $X_{i j}^{(k)}$ é substituído por seu respectivo posto $R_{i j}{ }^{(k)}$, em que $1 \leq R_{i j}{ }^{(k)} \leq N$;

b) calcula-se $\bar{R}_{i}^{(k)}$ que são as médias dos postos dentro de cada grupo $i$, para cada variável $k$; sob $H_{0}$, que pode ser escrita como sendo $H_{0}: E\left(\bar{R}_{1}^{k}\right)=. .=E\left(\bar{R}_{c}^{k}\right), E\left(\bar{R}_{i}^{k}\right)=(N+1) / 2$; 
c) obtém-se o vetor linha $V$, referentes aos (c-1) grupos e a cada uma das $p$ variáveis, totalizando (c-1)p elementos; os desvios do último grupo são obtidos a partir dos $(c-1)$ grupos anteriores; o vetor $V$ é tal que $V=\left(V_{1}^{\prime}, \ldots, V_{p}^{\prime}\right)^{\prime}, V_{i}=\left\lfloor\bar{R}_{1}^{(k)}-(N+1) / 2, \ldots, \bar{R}_{c-1}^{(k)}-(N+1) / 2\right\rfloor ;$

d) a matriz de variâncias e covariâncias é quadrada e simétrica, com (c1)p linhas ou colunas.

e) a estatística de teste é dada por $H_{M}=V^{\prime} \Sigma_{V}^{-1} V$ onde $\mathrm{V}$ é um vetor linha

A técnica apresentada por Katz \& McSweeney (1980) é simplificada, do ponto de vista computacional, em Schwertman (1984). Considerando o problema de testar a igualdade de $c(c>=2)$ funções de distribuição contínuas, $F_{1}, F_{2}, \ldots, F_{c}$ que têm a mesma forma geral, mas podem ter parâmetros diferentes. Os autores apresentam a adaptação para o caso multivariado de dois procedimentos para testar a igualdade das funções de distribuição, um baseado no teste da mediana (Teste da Mediana de BrownMood), aqui denominado de teste da mediana multivariado, e outro no teste de KruskalWallis, que usa a soma dos postos que será denominado Kruskal-Wallis multivariado. Ambos os procedimentos, como no caso do trabalho de Katz \& McSweeney (1980) são baseados nos trabalhos de Puri \& Sen (1971).

Em ambos os procedimentos, a estatística $L_{N}$ para testar a igualdade de funções de distribuições contínuas é dada pela soma das formas quadráticas balanceadas, ou seja, $L_{N}=\sum_{i=1}^{c} n_{i}\left(T_{i}-\bar{T}\right) V^{-1}\left(T_{i}-\bar{T}.\right)$, em que $\bar{T}=\sum_{i=1}^{c} n_{i} T_{i} /\left(\sum_{i=1}^{c} n_{i}\right)$. O procedimento denominado teste da mediana multivarido não será discutido no presente trabalho.

Assim, no caso de teste de Kruskal-Wallis multivariado, obtém-se os postos individualmente para cada variável, e seja $T_{i}(i=1, \ldots, c)$ um vetor $p$-dimensional de postos médios para cada uma das $p$ respostas multivariadas na $i$-ésima amostra, $c$ é o número de populações amostradas, $n_{i}$ é o tamanho da $i$-ésima amostra, $V$ é a matriz de dispersão do vetor de postos e $T$. é o vetor de postos médios para os dados combinados 
com todas as amostras. Seja $V(k, l)=\frac{1}{N} \sum_{i=1}^{c} \sum_{j=1}^{n_{i}}\left(r_{i j}^{(k)}-\bar{r}_{. .}^{(k)}\right)\left(r_{i j}^{(l)}-\bar{r}_{i j}^{(l)}\right), \quad$ o elemento da matriz de dispersão, no qual $r_{i j}^{\left({ }^{(a)}\right.}$ é o posto da j-ésima unidade experimental na i-ésima amostra, $a$-ésima resposta multivariada; $r_{. .}{ }^{(a)}$ é o posto médio da $a$-ésima resposta multivariada para todas as amostras combinadas e $N=\sum_{i=1}^{c} n_{i}$.

Quando a hipótese nula de que as funções distribuições $F_{1}, F_{2}, \ldots, F_{c}$ são idênticas é verdadeira, espera-se que as médias dos postos das várias amostras sejam aproximadamente iguais e desvios substanciais da igualdade é refletido em $\left(T_{i}-T\right)$. O fator $n_{i}$ dá importância maior àqueles desvios baseados em amostras grandes. Portanto, grandes valores de $\mid T_{i}-T$. levam a grandes valores de $L_{N}$ e à rejeição da hipótese de funções de distribuição idênticas.

Quando há somente duas populações a serem comparadas $(c=2)$, as simplificações conduzem a $L_{N}=\frac{n_{1}\left(n_{1}+n_{2}\right)}{n_{2}}\left(T_{1}-\bar{T} \text {. }\right)^{\prime} V^{-1}\left(T_{1}-\bar{T}\right.$. $)$. Pode ser verificado ainda que, se $n_{i}=n$ para todo $i=1, \ldots, c$, o valor máximo da estatística $L_{N}$ é $n c p\left(1-\frac{n^{2}-1}{n^{2} c^{2}-1}\right)$.

Para a obtenção do valor-p, calcula-se inicialmente a estatística de teste para os dados transformados em postos $\left(\mathrm{W}_{0}\right)$. Permutam-se os elementos amostrais (e não as variáveis) e calcula-se, para cada matriz obtida a partir dessa permutação, o valor da estatística $\mathrm{W}_{\mathrm{i}}$. O valor-p obtido simplesmente calculando-se a proporção de valores da estatística, obtida a partir das permutações, que sejam menores ou iguais à estatística gerada pelos dados originais, ou seja,

$$
\text { Valor-p }=\#\left(W_{i} \leq W_{0}\right) /(\# \text { permutações })
$$

No caso de pequenas amostras é possível obter o valor-p exato. No caso de grandes amostras, além da aproximação usual através da distribuição de Quiquadrado, é possível obter os valores- $p$ aproximados, utilizando uma amostra aleatória das possíveis permutações dos dados e em cada uma delas calcular a estatística desejada.

Assim, por exemplo, no delineamento inteiramente aleatorizado, são dadas $N$ amostras, divididas em $c$ grupos com tamanhos $n_{1}, \ldots, n_{c}$, respectivamente, 
$N=\sum_{i=1}^{c} n_{i}$. O elemento amostral k, e seu respectivo posto, pode ser escrito como um vetor de $p$ componentes $X_{k}=\left(X_{k}^{(1)}, \ldots, X_{k}^{(p)}\right), \quad R_{k}=\left(R_{k}^{(1)}, \ldots, R_{k}^{(p)}\right), \quad k=1, \ldots$, $n_{1}, n_{1}+1, \ldots, n_{1}+n_{2}, \ldots, N$, sendo os primeiros $n_{1}$ componentes provenientes da população 1 , os $n_{2}$ seguintes da população 2 e assim por diante. As permutações são feitas sobre os elementos amostrais $X_{k}$. Como as trocas de posições dentro dos grupos não afetam o resultado, existem $N P=N ! / n_{1} ! \ldots n_{C}$ ! permutações possíveis dos elementos amostrais. Para cada uma das NP permutações obtidas, a estatística de teste é calculada e o valor-p é então obtido através do procedimento descrito anteriormente.

\subsubsection{Método 2}

A medodologia para a obtenção de variáveis não relacionadas a partir da utilização do método de componentes principais na combinação das variáveis originais é discutida em Dempster (1963a, 1963b), baseada na sugestão de Rao (1952).

De acordo com Rao (1952), sejam $x_{1}, \ldots, x_{s}, x_{s+1}, \ldots, x_{s+p}(s+p)$ variáveis correlacionadas para as quais amostras de tamanho $n_{1}, n_{2}, \ldots, n_{c}$ são avaliadas para $c$ populações. Se as diferenças entre médias destas $(s+p)$ variáveis são testadas, então, teste de Wilks, por exemplo, pode ser utilizado. Um problema importante que ocorre em biometria é testar se as variáveis $x_{s+1}, \ldots, x_{s+p}$ apresentam diferenças relacionadas às populações quando as diferenças devidas as variáveis $x_{1}, \ldots, x_{s}$ são retiradas.

Assim, se $\mathrm{y}_{1}, \ldots, \mathrm{y}_{\mathrm{s}+\mathrm{p}}$ são as $(\mathrm{s}+\mathrm{p})$ variáveis, consideram-se $\mathrm{L}_{1}, \ldots \mathrm{L}_{\mathrm{s}}$ as $\mathrm{s}$ funções lineares destas medidas

$$
\begin{aligned}
& L_{1}=m_{1,1} y_{1}+\ldots+m_{1, p+s} y_{p+s} \\
& L_{s}=m_{s, 1} y_{1}+\ldots+m_{s, p+s} y_{p+s}
\end{aligned}
$$

É possível então trocar as $(\mathrm{s}+\mathrm{p})$ variáveis $\mathrm{y}_{1}, \ldots, \mathrm{y}_{\mathrm{s}+\mathrm{p}}$ por $\mathrm{x}_{1}, \ldots, \mathrm{x}_{\mathrm{s}+\mathrm{p}}$ definidas por

$$
x_{1}=L_{1} ; \ldots ; x_{s}=L_{s}
$$




$$
\begin{aligned}
& x_{s+1}=m_{s+1,1} y_{1}+\ldots+m_{s+1, p+s} y_{p+s} \\
& L_{s}=m_{s+p, 1} y_{1}+\ldots+m_{s+p, p+s} y_{p+s}
\end{aligned}
$$

Os coeficientes de $X_{S+1}, \ldots, X_{S+p}$ são escolhidos arbitrariamente sujeitos à condição de que o determinante $\left|m_{i j}\right|[i, j=1, \ldots,(s+p)]$ seja diferente de zero. Esta última condição assegura que a transformação de $y$ para $x$ leva a uma correspondência biunívoca. Novamente o problema é reduzido a considerar as diferenças em $x_{s+1}, \ldots, x_{s+p}$ quando aquelas devido a $x_{1}, \ldots, X_{S}$ são removidas. O teste proposto é independente dos coeficientes utilizado para definir o conjunto $x_{s+1}, \ldots, x_{s+p}$ de tal forma que, em problemas práticos, eles podem ser convenientemente escolhidos. Em todos estes casos, o problema é analisar a dispersão das variáveis $x_{S+1}, \ldots x_{S+p}$ quando a dispersão devida a $x_{1}, \ldots, X_{S}$ é removida.

Seja $\left(\mathrm{S}_{\mathrm{ij}}\right)=\left(\mathrm{Q}_{\mathrm{ij}}\right)+\left(\mathrm{W}_{\mathrm{ij}}\right)(\mathrm{i}, \mathrm{j}=1, \ldots, \mathrm{S}+\mathrm{p})$ a análise de dispersão para todas as $(\mathrm{s}+\mathrm{p})$ variáveis devido aos desvios da hipótese e erro com os graus de liberdade $n^{\prime}=q+\left(n^{\prime}-q\right)$. A matriz de somas de produtos $(s \times s)$ devida ao erro para as variáveis $x_{1}, \ldots, X_{S}$ a serem eliminadas é $W=\left\{W_{i j}\right\}$ e sua inversa é representada por $W^{-1}=\left\{W^{\mathrm{ij}}\right\}$. $\mathrm{A}$ matriz de somas de produtos do erro para $x_{S+1}, \ldots, x_{S^{+} p}$ quando corrigida para $x_{1}, \ldots, x_{S}$ é dada por $W(s+1, \ldots, s+p / 1, \ldots s)$ ou simplesmente $W(p / s)$, em que

$$
\begin{gathered}
W(p / s)=Z_{W}-\left[\begin{array}{ccc}
W_{1, s+1} & \ldots & W_{s, s+1} \\
\ldots & \ldots & \ldots \\
W_{1, s+1} & \ldots & W_{s, s+p}
\end{array}\right]\left[\begin{array}{ccc}
W^{11} & \ldots & W^{1 s} \\
\ldots & \ldots & \ldots \\
W^{s 1} & \ldots & W^{s s}
\end{array}\right]\left[\begin{array}{ccc}
W_{1, s+1} & \ldots & W_{1, s+p} \\
\ldots & \ldots & \ldots \\
W_{s, p+1} & \ldots & W_{s, s+p}
\end{array}\right] \\
\text { para } Z_{W}=\left[\begin{array}{ccc}
W_{s+1, p+1} & \ldots & W_{s+1, s+p} \\
\ldots & \ldots & \ldots \\
W_{s+p, p+1} & \ldots & W_{s+p, s+p}
\end{array}\right] .
\end{gathered}
$$

Esta forma, que envolve o cálculo de um produto de matrizes triplo parece ser conveniente. Outra maneira de obter a matriz $W(p / s)$ é começar com a matriz completa $\left(W_{i j}\right)(i, j=1,2, \ldots, s, s+1, \ldots, s+p)$ e reduzi-la s vezes pelo método de condensação pivotal começando pelo elemento $W_{11}$. Substituindo $W$ por $S$ tem-se a fórmula para calcular a matriz de somas de produtos devido a "desvios da hipótese + erro" para $x_{S+1}, \ldots x_{S+p}$ quando corrigida para $x_{1}, \ldots, x_{S}$, representada por $S(p / s)$. Assim, o critério de 
teste será dado por $\mathrm{W}(\mathrm{p} / \mathrm{s}) / \mathrm{S}(\mathrm{p} / \mathrm{s})$. Os graus de liberdade para $W(p / s)$ serão $\left(n^{\prime}-q-s\right)$ e para $S(p / s)$ são ( $\left.n^{\prime}-s\right)$, tal que em notação padrão os parâmetros associados com $\Lambda$ são $n=n^{\prime}-s, p=p$ e $q=q$. O teste pode ser realizado normalmente.

Assim, supondo que $V_{1}, V_{2}, \ldots, V_{p}$ denotam as p variáveis dadas e $U_{1}, U_{2}$, ..., $U_{r}$ quaisquer combinações lineares de $V_{1}, V_{2}, \ldots, V_{p}$, isto é, $U=A V$ em que $U^{\prime}=\left[U_{1} U_{2}\right.$ $\left.\ldots U_{r}\right], V^{\prime}=\left[\begin{array}{llll}V_{1} & V_{2} \ldots V_{p}\end{array}\right]$ e $A$ é uma matriz de coeficientes qualquer de dimensão $r \times p$. Utilizando a partição da matriz de dispersão total $S=B+W$, então $A S A^{\prime}, A B A^{\prime}$ e $A W A^{\prime}$ são, respectivamente, as matrizes de dispersão total, entre e dentro de células de $U_{1}$, $U_{2}, \ldots, U_{r}$. Em particular, quando $r=1$, ocorre a decomposição da análise de variância usual para uma combinação linear qualquer de $V_{1}, V_{2}, \ldots, V_{p}$. Segue-se o procedimento de Gram-Schimidt para a diagonalização de cada uma das três matrizes, $B, W$ e $S$. Assim, dadas $T_{B}, T_{W}$ e $T$, matrizes triangulares de dimensão $p$, com todos os valores da diagonal unitários e todos os valores abaixo da diagonal nulos, as matrizes $B, W$ e $S$ podem ser diagonalizadas de forma a se obterem as matrizes $D_{B}=T_{B} S_{B} T_{B}{ }^{\prime}, D_{W}=T_{W} S_{W} T_{W}{ }^{\prime}$ e $D=$ TST'. Denotando os i-ésimos elementos da diagonal de $D_{B}, D_{W}$ e $D$ por $d_{i i}{ }^{(B)}, d_{i i}{ }^{(W)}$ e $d_{i i}$ respectivamente, $(i=1, \ldots, p)$, é possível calcular $P_{i}=d_{i i}{ }^{(W)} / d_{i i}, \quad Q_{i}=d_{i i}{ }^{(B)} /\left(d_{i i}{ }^{(B)}+d_{i i}{ }^{(W)}\right)$ e $R_{i}=\left(d_{i i}{ }^{(B)}+d_{i i}{ }^{(W)}\right) / d_{i i}$. Se qualquer denominador for nulo, os correspondentes $P_{i}, Q_{i}$ e $R_{i}$ devem ser considerados como indefinidos.

O procedimento de diagonalização é feito em $p$-1 estágios. No primeiro estágio, substitui-se a matriz de dispersão original $S$ por uma matriz $S_{.1}$ de dimensão $p$-1 com elementos $s_{i j .1}=s_{i j}-s_{1 i} s_{1 j} / s_{11}$ para $i=2,3, \ldots, p$ e $j=2,3, \ldots, p$. No segundo estágio a mesma operação é repetida em $S_{.1}$ para a obtenção da matriz $S_{.12}$ de dimensão $p$-2, cujos elementos são $s_{i j .12}=s_{i j .1}-s_{2 i .1} s_{2 j} ~_{1} / s_{22.1}$, para $i=3, \ldots, p ; j=3, \ldots, p$. Da mesma forma,

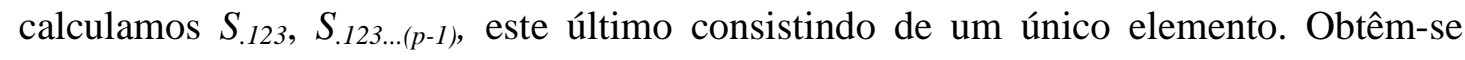
assim $d_{11}, \ldots, d_{p p}$, que são os primeiros elementos diagonais de $S, S_{.1}, \ldots, S_{.12 \ldots(p-1)}$, respectivamente.

No procedimento stepwise geral primeiro escolhe-se um conjunto de variáveis $U=A V$ e depois calculamos as matrizes de dispersão total e dentro $A S A^{\prime}$ e $A W A^{\prime}$ para obter $d_{11}{ }^{(W)}, d_{22}{ }^{(W)}, \ldots, d_{r r}{ }^{(W)}$ e $d_{11}, d_{22}, \ldots, d_{r r}$. A estatística obtida através do procedimento stepwise é definida por $P_{i}=d_{i i}{ }^{(W)} / d_{i i}$ para $i=1,2, \ldots, r$. Em geral, $r=p$, mas 
em alguns casos o posto da matriz $S$ é menor que $p$ e existem somente $r$ valores não nulos na diagonal e nesse caso apenas $r$ quantidades $P_{1}, \ldots, P_{r}(r<p)$ podem ser definidas. Observa-se que $P_{1}$ é simplesmente a razão entre as somas de quadrados dentro e total para a variável $U_{1}$. Para $i>1$, as quantidades $d_{i i}$ e $d_{i i}{ }^{(W)}$ podem ser consideradas como a soma de quadrados total e residual, respectivamente, de $U_{i}$ depois de retirados os efeitos lineares associados a $U_{1}, \ldots, U_{i-1}$. Assim, $P_{i}, i>1$, é a razão entre as somas de quadrados dentro e total depois que os efeitos associados a $U_{1}, U_{2}, \ldots, U_{i-1}$ forem removidos.

Diferentes escolhas de $U$ levam a sequências $P_{1}, \ldots, P_{r}$ diferentes. Uma análise de componentes principais é uma maneira de analisar uma matriz de dispersão para obter um conjunto de variáveis $U_{1}, U_{2}, \ldots$ as quais serão denominadas variáveis principais. Dada uma matrix de dispersão S e uma matriz positiva definida pré-escolhida $K$, resolve-se a equação $\operatorname{det}(S-\lambda K)=0$, obtendo-se os autovalores $\lambda_{1}, \lambda_{2}, \ldots, \lambda_{r}$ em que $r$ $=$ posto $(S)$ e $\lambda_{1} \geq \lambda_{2} \geq \ldots \geq \lambda_{r}$. Em seguida, para cada $\lambda_{i}$ resolvem-se as equações $a_{i}(S$ $\left.\lambda_{i} K\right)=0$ obtendo-se o autovetor p-dimensional $a_{i}$. As variáveis $U_{i}=a_{i} V$ são as variáveis principais e os correspondentes $\lambda_{i}$ são as variâncias dos componentes principais. Há uma diferente análise de componentes principais para cada escolha de $K$, mas em geral $K=I$ ou $K=\operatorname{diag}(S)$ e, neste último caso, tem-se $\operatorname{det}(R-\lambda I)=0$ sendo $R$ a matriz de correlações calculada a partir de $S$. Espera-se que as variáveis principais $U_{1}, U_{2}, \ldots$ resultantes dos maiores autovalores sejam as únicas combinações lineares de $V_{1}, V_{2}, \ldots, V_{p}$ de alguma importância prática. Assim, uma possível escolha para $U$ pode ser baseada nas variáveis principais.

A proposta não-paramétrica baseada nesta sequência de critérios pode ser efetuada com duas modificações à proposta original. A primeira é utilizar, na obtenção dos componentes principais, a matriz de correlações amostrais dos postos. Essa matriz, tem elementos diagonais iguais a 1 e elementos fora da diagonal equivalentes ao coeficiente de correlação de Spearman entre as variáveis. A segunda modificação requer a transformação das variáveis principais através de seus respectivos postos seguida da aplicação do teste de Kruskal-Wallis aos valores transformados, para cada uma das novas variáveis. A combinação dos níveis de significância individuais pode levar à 
composição de um nível de significância geral para o que será denominado teste de Kruskal-Wallis Multivariado.

Para realizar a discussão do método dos componentes principais para a obtenção da estatística de teste entre variáveis independentes, é necessário fazer, inicialmente, uma revisão sobre a matriz de variâncias e covariâncias para dados transformados em postos e o seu relacionamento com a matriz de correlação para esses mesmos tipos de dados. A diagonal principal da matriz de correlação de postos tem todos os seus valores iguais a 1, enquanto que fora dessa diagonal, ela é formada por valores obtidos pelo coeficiente de correlação de Spearman. O coeficiente de correlação de Spearman é considerado o competidor ou substituto não-paramétrico do coeficiente de correlação de Pearson. Considerando $\mathrm{N}$ pares de dados tomados sobre $N$ indivíduos e sejam $R_{i 1}$ e $R_{i 2}$ os postos do indivíduo $i$ para as variáveis 1 e 2, respectivamente, a fórmula mais conhecida para o cálculo da estimativa desse coeficiente é dada por

$$
r_{S}=1-\frac{6 \sum_{i=1}^{N} d_{i}^{2}}{N^{3}-N}
$$

Em (1), $d_{i}=R_{i}^{(k)}-R_{i}^{(\lambda)}$ é a diferença entre os postos das variáveis $k$ e $\lambda$ referente ao indivíduo $i$. A ordem em que tomamos a diferença não é importante, pois para a obtenção do coeficiente é calculada a soma dos quadrados das diferenças.

Pode-se verificar que a fórmula acima é obtida a partir da fórmula do coeficiente de correlação de Pearson aplicada aos postos das variáveis, depois de feitas as substituições e simplificações possíveis. Assim, considere a fórmula do coeficiente de correlação amostral de Pearson aplicada aos postos dos dados, lembrando que

$$
\begin{aligned}
\bar{R}^{(t)} & =\frac{N+1}{2} ; R^{(t)}=\sum_{i=1}^{N} R_{i}^{(t)} ; t=k, \lambda \\
s^{(k)^{2}} & =s^{(\lambda)^{2}}=\frac{1}{N-1} \sum_{i=1}^{N}\left(R_{i}-\bar{R}\right)^{2}=\frac{1}{N-1}\left\{\sum_{i=1}^{N} R_{i}^{2}-N\left(\frac{N+1}{2}\right)^{2}\right\}
\end{aligned}
$$


sabendo-se que $\sum_{i=1}^{N} R_{i}^{2}=1^{2}+2^{2}+\ldots+N^{2}=\frac{N(N+1)(2 N+1)}{6}$ e ainda que a diferença que aparece entre chaves é equivalente a $\left[\frac{N(N+1)(2 N+1)}{6}-\frac{N(N+1)^{2}}{4}\right]=\frac{N(N-1)^{2}}{12}$, tem-se que

$$
s^{2}=\frac{N(N+1)}{12}
$$

Portanto, a variância é igual para todas as variáveis envolvidas, pois todas elas têm o mesmo conjunto de postos e é dada pela fórmula (34).

Assim, o coeficiente de correlação de Spearman pode ser escrito como

$$
r_{S}=\frac{s^{(k \lambda)}}{s^{(k)} s^{(\lambda)}}=\frac{s^{(k \lambda)}}{\sqrt{[N(N+1] / 12} \sqrt{[N(N+1)] / 12}}=\frac{12}{N(N+1)} s^{(k \lambda)}
$$

mas

$$
\begin{aligned}
& S^{(k \lambda)}=\frac{1}{N-1} \sum_{i=1}^{N}\left\{\left[R_{i}^{(k)}-\frac{N+1}{2}\right]\left[R_{i}^{(\lambda)}-\frac{N+1}{2}\right]\right\} \\
& s^{(k \lambda)}=\frac{1}{N-1}\left\{\sum_{i=1}^{N} R_{i}^{(k)} R_{i}^{(\lambda)}-\frac{N(N+1)^{2}}{4}\right\}
\end{aligned}
$$

Substituindo (38) em (36), tem-se

$$
\begin{aligned}
& r_{S}=\frac{1}{N-1}\left\{\frac{12}{N(N+1)} \sum_{i=1}^{N} R_{i}^{(k)} R_{i}^{(\lambda)}-\frac{12 N(N+1)^{2}}{4 N(N+1)}\right\} \\
& r_{S}=\frac{1}{N-1}\left\{\frac{12}{N(N+1)} \sum_{i=1}^{N} R_{i}^{(k)} R_{i}^{(\lambda)}-3(N+1)\right\}
\end{aligned}
$$

Por outro lado, partindo da fórmula (32), tem-se que

$$
\begin{aligned}
& r_{S}=1-\frac{6 \sum_{i=1}^{N} d_{i}^{2}}{N^{3}-N}=1-\frac{6 \sum_{i=1}^{N}\left(R_{i}^{(k)}-R_{i}^{(\lambda)}\right)^{2}}{N\left(N^{2}-1\right)} \\
& r_{S}=\frac{1}{N-1}\left\{(N-1)-\frac{6 \sum_{i=1}^{N}\left[R_{i}^{(k) 2}+R_{i}^{(\lambda) 2}-2 R_{i}^{(k)} R_{i}^{(\lambda)}\right]}{N(N+1)}\right\}
\end{aligned}
$$




$$
\begin{gathered}
r_{S}=\frac{1}{N-1}\left\{(N-1)-\frac{12\left(\sum_{i=1}^{N} R_{i}^{2}-\sum_{i=1}^{N} R_{i}^{(k)} R_{i}^{(\lambda)}\right)}{N(N+1)}\right\} \\
r_{S}=\frac{1}{N-1}\left\{(N-1)-\frac{12}{N(N+1)}\left[\frac{N(N+1)(2 N+1)}{6}-\sum_{i=1}^{N} R_{i}^{(k)} R_{i}^{(\lambda)}\right]\right\} \\
r_{S}=\frac{1}{N-1}\left\{\frac{12}{N(N+1)} \sum_{i=1}^{N} R_{i}^{(k)} R_{i}^{(\lambda)}-3(N+1)\right\}
\end{gathered}
$$

Portanto, o coeficiente de correlação de Spearman é obtido pela utilização dos postos no lugar dos valores originais na fórmula do coeficiente de correlação de Pearson. Verifica-se que:

a) se $\quad R_{i}^{(k)}=R_{i}^{(1)}, \forall i=1, \ldots, N$, tem-se que $\sum_{i=1}^{N} R_{i}^{(k)} R_{i}^{(\lambda)}=\sum_{i=1}^{N} R_{i}^{2}$ e,

$$
S^{(k \lambda)}=\frac{1}{N-1}\left\{\frac{N(N+1)(2 N+1)}{6}-\frac{N(N+1)^{2}}{4}\right\}=\frac{N(N+1)}{12}=s^{2},
$$

assim, $r_{S}=1$, ou seja, as variáveis são perfeita e positivamente correlacionadas;

b) se $R_{i}^{(k)}=N-R_{i}^{(\lambda)}+1, \forall i=1, \ldots, N$, tem-se que $r_{s}=-1$ tendo em vista que

$$
\begin{aligned}
\sum_{i=1}^{N} R_{i}^{(k)} R_{i}^{(\lambda)}=\sum_{i=1}^{N} R_{i}^{(k)}\left[N-R_{i}^{(k)}+1\right]=N \sum_{i=1}^{N} R_{i}^{(k)}-\sum_{i=1}^{N} R_{i}^{(k)} R_{i}^{(K)}+\sum_{i=1}^{N} R_{i}^{(k)} \\
=\frac{N(N+1)^{2}}{2}-\frac{N(N+1)(2 N+1)}{6}
\end{aligned}
$$

e $s^{(k \lambda)}=\frac{1}{N-1}\left\{\frac{N(N+1)^{2}}{4}-\frac{N(N+1)(2 N+1)}{6}\right\}=\frac{-N(N+1)}{12}=-s^{2}$

Das relações existentes entre o coeficiente de correlação de Spearman e as variâncias e covariâncias dos dados transformados em postos, decorre que as matrizes de correlação $(\boldsymbol{R})$ e de covariâncias $(\boldsymbol{S})$ são diretamente correlacionadas de forma que

$$
R=\frac{12}{N(N+1)} S \quad \text { ou } S=\frac{N(N+1)}{12} R
$$


De acordo com Johnson \& Wichern (1996), a análise de componentes principais é uma técnica de análise multivariada que permite explicar uma estrutura de variâncias e covariâncias de um conjunto de variáveis, em geral complicada, através de algumas (às vezes, poucas) combinações lineares dessas variáveis. Em geral o objetivo é diminuir a dimensionalidade do conjunto de variáveis com o objetivo de facilitar a interpretação da interdependência entre elas, mas em alguns casos a análise de componentes principais é somente um meio para a obtenção de outros objetivos na pesquisa. A análise de componentes principais é baseada na obtenção dos autovalores e autovetores de uma matriz. Assim, antes de discutir os componentes principais propriamente ditos, deve-se fazer uma rápida discussão sobre a obtenção e propriedades dos autovalores e autovetores.

Dada uma matriz quadrada $\mathbf{A}$, e considerando a equação $\mathbf{A u}=\lambda \mathbf{u}$, sendo $\mathbf{u}$ um vetor e $\lambda$ um escalar, a condição para que existam $\lambda$ e $\mathbf{u}$ (para $\mathbf{u} \neq \mathbf{0}$ ) é que o determinante da matriz (A - $\lambda \mathbf{I})$ seja nulo. De outra forma, pode-se dizer que para a existência de valores não nulos de $\lambda$ e $\mathbf{u}$ é necessário que a matriz (A - $\lambda \mathbf{I})$ seja singular. Assim, basta resolver a equação $|\mathbf{A}-\lambda \mathbf{I}|=\mathbf{0}$, denominada equação característica, obtendo os valores de $\lambda$. Se $\mathbf{A}$ é de ordem $n$, obtém-se uma equação polinomial em $\lambda$ de ordem $\mathrm{n}$, com $\mathrm{n}$ raízes $\lambda_{1}, \lambda_{2}, \ldots, \lambda_{\mathrm{n}}$, que são denominadas raízes características, autovalores ou $\lambda$-raízes. A cada autovalor $\lambda_{i}(i=1, \ldots, n)$, corresponde um autovetor $\mathbf{u}_{\mathbf{i}}$ satisfazendo a equação $\mathbf{A} \mathbf{u}_{\mathbf{i}}=\lambda_{\mathbf{i}} \mathbf{u}_{\mathbf{i}}$. Os vetores $\mathbf{u}_{1}, \mathbf{u}_{2}, \ldots, \mathbf{u}_{\mathbf{n}}$ são denominados vetores característicos ou autovetores.

Algumas propriedades importantes dos autovalores e autovetores devem ser enunciadas, considerando que a matriz $\mathbf{A}$ tem um autovalor $\lambda$ :

a) para a obtenção dos autovalores da potência de uma matriz, considera-se a equação $\mathbf{A u}=\lambda \mathbf{u}$ e pré-multiplica-se os dois membros da igualdade por $\mathbf{A}^{\mathrm{k}-1}$; assim, tem-se, por recorrência, que $\mathbf{A}^{\mathrm{k}} \mathbf{u}=\mathbf{A}^{\mathrm{k}-}$ ${ }^{1} \lambda \mathbf{u}=\lambda \mathbf{A}^{\mathrm{k}-1} \mathbf{u}=\lambda \mathbf{A}^{\mathrm{k}-2}(\mathbf{A u})=\lambda^{2}\left(\mathbf{A}^{\mathrm{k}-2} \mathbf{u}\right)=\ldots=\lambda^{\mathrm{k}} \mathbf{u}$, ou seja, $\mathrm{o}$ autovalor de $\mathbf{A}^{\mathrm{k}}$ é $\lambda^{\mathrm{k}}$; se $\mathbf{A}$ é singular, $k$ é positivo e se $\mathbf{A}$ é não 
singular, $k$ pode ser positivo ou negativo; em particular, se $\mathbf{A}$ é nãosingular, o autovalor de $\mathbf{A}^{-1}$ é $1 / \lambda$;

b) para a obtenção dos autovalores da multiplicação de um escalar $c$ por uma matriz, basta lembrar que $c \mathbf{A u}=c \lambda \mathbf{u}=(\mathrm{c} \lambda) \mathbf{u}$, ou seja, $c \lambda$ é o autovalor de $c \mathbf{A}$;

c) dado um polinômio em $\mathbf{A}, f(\mathbf{A})$, como consequência dos itens (a) e (b), $f(\lambda)$ é um autovalor de $f(\mathbf{A})$;

d) a soma dos autovalores de uma matriz é igual ao seu traço e o produto deles é igual a seu determinante, ou seja, $\sum_{i=1}^{n} \lambda_{i}=\operatorname{tr}(A)$ e $\prod_{i=1}^{n} \lambda_{i}=\operatorname{det}(\boldsymbol{A})=|\boldsymbol{A}|$

Do item (b) pode-se estabelecer que o relacionamento direto existente entre as matrizes de covariâncias e de correlação de postos, ou seja, $R=\frac{12}{N(N+1)} \boldsymbol{S}$ indica que os autovalores são relacionados da mesma forma e seus autovetores das duas matrizes são iguais. Considerando $\lambda_{\mathrm{i}}$ e $\delta_{\mathrm{i}}$ como os auto-valores das matrizes $\boldsymbol{R}$ e $\boldsymbol{S}$, respectivamente, pode-se verificar que $\quad \sum_{i=1}^{n} \lambda_{i}=\operatorname{tr}(\boldsymbol{R})=\boldsymbol{p} \quad$ e $\sum_{i=1}^{n} \delta_{i}=\operatorname{tr}(S)=p[N(N+1)] / 12$.

Propriedades importantes ocorrem quando se consideram matrizes simétricas e reais, como é o caso das matrizes $\boldsymbol{R}$ e $\boldsymbol{S}$. Os autovalores dessas matrizes são reais e seus autovetores são ortogonais, ou seja, dados dois autovalores de matrizes reais e simétricas $\lambda_{\mathrm{i}}$ e $\lambda_{\mathrm{j}}$, cujos autovetores são, respectivamente, $\mathbf{u}_{\mathbf{i}}$ e $\mathbf{u}_{\mathbf{j}}$, tem-se que $\mathbf{u}_{\mathbf{i}}{ }^{\prime} \mathbf{u}_{\mathbf{j}}=0$, para $\mathrm{i} \neq \mathrm{j}$. Além disso, é possível mostrar que toda matriz simétrica $\mathbf{A}$ é diagonalizável pois, considerando a igualdade $\mathbf{A} \mathbf{U}=\mathbf{U D}, \mathbf{D}$ uma matriz diagonal, existe $\mathbf{U}^{-1}$ e portanto $\mathbf{A}=\mathbf{U D U}^{-1}$. Observa-se que podem ser obtidos, de uma matriz simétrica, autovetores ortogonais entre si. Normalizando tais vetores substituindo os vetores $\mathbf{u}$ por $\left(\left(1 / \sqrt{\boldsymbol{u}^{\prime} \mathbf{u}}\right) \boldsymbol{u}\right.$ e organizando-os na matriz $\mathbf{U}$, tem-se uma matriz ortogonal e portanto, U'AU = D com U’U = I e essa é a forma canônica sob similaridade ortogonal. 
Outra forma de decomposição de uma matriz simétrica é denominada decomposição espectral de A. Sabendo-se que $\mathbf{U}$ é ortogonal, tem-se que $I=U^{\prime} U=U U^{\prime}=\sum_{i=1}^{n} u_{i} u_{i}{ }^{\prime}, \quad$ então $\quad A=A \sum_{i=1}^{n} u_{i} u_{i}{ }^{\prime}=\sum_{i=1}^{n} A u_{i} u_{i}{ }^{\prime}=\sum_{i=1}^{n} \lambda_{i} u_{i} u_{i}{ }^{\prime}$. Essas propriedades dos autovalores e autovetores serão utilizadas na discussão dos componentes principais da matriz de variâncias e covariâncias e da matriz de correlação para os dados transformados em postos.

O processo de obtenção dos componentes principais é puramente matemático, sem a necessidade de estabelecer qualquer discussão a respeito da distribuição dos dados que estão sendo estudados. A análise de componentes principais é uma técnica multivariada cujo objetivo é, em geral, reduzir a dimensionalidade do conjunto de dados. Entretanto, no presente trabalho os componentes principais serão utilizados para analisar uma matriz de dispersão de forma a produzir um conjunto de novas variáveis, denominadas variáveis principais, não correlacionadas entre si, que são combinações lineares das variáveis originais.

Assim, considerando a matriz $\mathbf{X}$, obtida a partir de um conjunto de $N$ observações em $p$ variáveis, sua matriz de dispersão quadrada $\mathbf{S}_{\mathbf{0}}$, de dimensão $p$ e uma matriz positiva definida $\mathbf{K}_{0}$, de mesma dimensão de $\mathbf{S}_{0}$, resolve-se a equação $\left|\boldsymbol{S}_{\boldsymbol{o}}-\lambda \boldsymbol{K}_{\boldsymbol{o}}\right|=0$ e obtém-se os autovalores $\lambda_{1}, \lambda_{2}, \ldots, \lambda_{\mathrm{r}}\left(\lambda_{1} \geq \lambda_{2} \geq \ldots . \lambda_{\mathrm{r}}\right)$, em que $r=$ $\operatorname{posto}\left(\boldsymbol{S}_{\boldsymbol{o}}\right)$. Em seguida, para cada $\lambda_{\mathrm{i}}$, resolve-se a equação $\boldsymbol{a}_{\boldsymbol{i}}\left(\boldsymbol{S}_{\boldsymbol{o}}-\lambda_{\boldsymbol{i}} \boldsymbol{K}_{\boldsymbol{o}}\right)=0$. As variáveis $\mathbf{U}_{\mathrm{i}}=\mathbf{a}_{\mathrm{i}} \mathbf{X}$ são denominadas variáveis principais e os $\lambda_{\mathrm{i}}$ 's correspondentes denominam-se variâncias dos componentes principais. A escolha da matriz $\mathbf{K}_{\mathbf{0}}$ é arbitrária, mas em geral $\mathbf{K}_{\mathbf{0}}=\mathbf{I}$ ou $\mathbf{K}_{\mathbf{0}}=\operatorname{diag}\left(\mathbf{S}_{\mathbf{0}}\right)$ (matriz diagonal com os mesmos elementos diagonais de $\mathbf{S}_{\mathbf{o}}$ ). No segundo caso, tem-se a equação $\left|\boldsymbol{R}_{\boldsymbol{o}}-\lambda\right|=0$, ou seja, os autovalores e autovetores são obtidos da matriz de correlações calculada a partir da matriz $\mathbf{S}_{\mathbf{0}}$.

Quando é feita a transfomação dos dados originais em postos, de forma individual, são obtidas a matriz de variâncias e covariâncias de postos $\mathbf{S}$ e a matriz de correlações de postos $\mathbf{R}$. Como conseqüência das propriedades dos autovetores e autovalores de uma matriz simétrica positiva definida, os componentes principais 
obtidos a partir da matriz de correlações $\boldsymbol{R}$ são os mesmos calculados a partir da matriz $\boldsymbol{S}$, quando não ocorrem empates. Essa invariância dos componentes principais não ocorre quando se utilizam os dados originais.

Observa-se que a transformação em postos discutida nesse trabalho é a transformação de postos de Wilcoxon, ou seja, o menor elemento tem posto 1, o segundo menor tem posto 2, e assim por diante, que é adequada na maior parte dos casos em que se procura discutir diferenças de parâmetros de locação entre populações.

Substituindo as variáveis por seus postos, dois fatos interessantes ocorrem:

a) as matrizes de variâncias e covariâncias e a de correlações são substituídas, respectivamente, pelas matrizes de variâncias e covariâncias de postos e pela matriz de correlações de Spearman; nesse caso, os elementos da diagonal principal de ambas as matrizes são iguais, ou seja, $r_{i i}=r_{i^{\prime} j^{\prime}}$ e $s_{i i}=s_{i^{\prime} j^{\prime}}$;

b) pelo fato dos elementos da diagonal principal da matriz de covariâncias, que são as variâncias dos postos, serem todos iguais, os autovalores e, conseqüentemente, os autovetores obtidos a partir de cada uma dessas matrizes são iguais.

Assim, não é necessária a discussão sobre qual das matrizes deve ser utilizada, pois ambas levam aos mesmos resultados e ainda, a homogeneidade de variâncias, que é uma das pressuposições da análise da variância, é observada.

A autenticidade dessas duas afirmações pode ser verificada da seguinte forma:

a) considere a matriz $\mathrm{Y}$, dos dados transformados em postos; as somas dos elementos de cada coluna, que é referente a cada uma das variáveis, são todas iguais a $\mathrm{N}(\mathrm{N}+1) / 2$;

b) as somas dos quadrados dos elementos de cada coluna são iguais a $[N(N+1 / 2)(2 N+1)] / 3$ ou, equivalentemente, a $[N(N+1)(2 N+1)] / 6$; assim, a variância é dada por 


$$
\begin{aligned}
& V_{i i}=\frac{1}{N-1}\left\{\frac{N(N-1)(2 N+1)}{6}-\frac{1}{N}\left[\frac{N(N+1)}{6}\right]^{2}\right\} \\
& V_{i i}=\frac{1}{N-1}\left\{\frac{2 N(2 N+1)-2 N(N+1)^{2}}{12}\right\}=\frac{1}{N-1}\left\{\frac{N(N+1)(N-1)}{12}\right\} \\
& V_{i i}=\frac{N(N+1)}{12}
\end{aligned}
$$

c) para a obtenção das correlações a partir das covariâncias, basta dividir pelas raízes das variâncias das variáveis envolvidas; como todas as variâncias são iguais, a relação $\operatorname{corr}\left(X_{i}, Y_{j}\right)=\operatorname{cov}\left(X_{i}, Y_{j}\right) /[N(N+1) / 2]$ ocorre para todos os elementos das matriz.

Tem-se, portanto, que dada a matriz de variâncias e covariâncias C, quadrada e simétrica de dimensão p, formada pelos elementos $C_{i j}$, os elementos da matriz de correlação de postos $R=\left\{R_{i j}\right\}$ podem ser obtidos simplesmente multiplicandose os elementos $C_{i j}$ por uma constante., ou seja,

$$
R_{i j}=\frac{12}{N(N+1)} C_{i j}
$$

Portanto, dada uma matriz de correlação de postos $\boldsymbol{R}=\left\{R_{i j}\right\}$, os elementos da matriz de covariâncias $\boldsymbol{C}=\left\{C_{i j}\right\}$ podem ser obtidos simplesmente multiplicando-se os elementos $R_{i j}$ por uma constante, ou seja, $C_{i j}=$ $[N(N+1) / 12] R_{i j}$, o que não se obtém quando as variáveis estão na escala original. Além disso, os autovalores dessas duas matrizes são proporcionais e seus autovetores são iguais. 


\section{RESULTADOS E DISCUSSÃO}

A utilização de testes não-paramétricos na análise de dados multivariados tem esbarrado em alguns obstáculos, especialmente devido à falta de programas computacionais que complementem a teoria. Os trabalhos discutidos na revisão bibliográfica mostram a utilização de alguns testes, mas para a obtenção dos valores-p são utilizadas as distribuições assintóticas, mesmo em situações com poucas amostras, em que esta não é adequada. Em Dempster (1963 a, 1963b) é dado um esboço de um algoritmo para a utilização da metodologia empregada, mas não foram encontradas referências a programas elaborados para tal fim. Assim, além da discussão dos testes multivariados não-paramétricos, objetiva-se apresentar alternativas computacionais para a resolução de problemas com a utilização desses métodos alternativos. No presente trabalho são apresentadas algumas alternativas e/ou complementações aos itens transformação dos dados através da atribuição de postos de forma independente para cada variável e aplicação dos testes usuais da análise de variância multivariada aos dados transformados e utilização da composição de testes univariados não-paramétricos em cada uma das variáveis em estudo e composição desses resultados numa estatística única.

Para medianas multivariadas diferentes da mediana formada pelo vetor das medianas das variáveis consideradas isoladamente (mediana componentwise), não serão feitas discussões de testes alternativos já que esse tema vem sendo bastante explorado na literatura. Além disso, as medianas obtidas partem de conceitos interessantes, mas não suficientemente amplos para serem consideradas medidas de locação ideais quando a dimensão é maior do que um. 
Apenas como menção, deve-se retornar ao caso da mediana univariada. Considerando um conjunto de dados ordenados $x_{(1)}, x_{(2)}, \ldots, x_{(N)}$, se $N$ é ímpar, ou seja, para $\mathrm{K}$ inteiro, $N=2 K+1$, a mediana é definida inequivocamente como o valor de ordem $K+1$, ou, equivalentemente, o valor de ordem $(N+1) / 2\left(x_{([N+1] / 2)}\right)$. No caso em que o número de elementos amostrais é par $(N=2 K)$ a mediana é considerada como um valor médio entre os dados de ordem $K$ e $K+1$ ou, equivalentemente, os dados de ordem N/2 e N/2+1. A atribuição da mediana como a média desses valores é arbitrária, ou seja, qualquer valor entre $x_{(K)}$ e $x_{(K+1)}$ satisfaz as condições para ser o valor mediano de um conjunto de dados, mas a escolha do ponto médio, que no caso unidimensional, equivale ao centro do segmento de reta cujos pontos extremos são os mencionados anteriormente, tem sido consensual entre os pesquisadores.

Ampliando esse conceito para o caso bidimensional, considerando o conjunto de vetores de dados bidimensionais $\left(x_{i 1}, x_{i 2}\right), \mathrm{i}=1, \ldots, \mathrm{N}$, se $N$ é ímpar, a mediana é um ponto pertencente ao conjunto de dados, ou seja, $M d_{2}=\left(x_{([N+1] / 2) 1}, x_{([N+1] / 2) 2}\right)$. Se $N$ é par, a mediana pode ser qualquer ponto dentro do plano cujos pontos extremos $\left(x_{(N / 2) 1}\right.$, $\left.x_{(N / 2) 2}\right),\left(x_{(N / 2+1) 1}, x_{(N / 2) 2}\right),\left(x_{(N / 2) 1}, x_{(N / 2+1) 2}\right)$ e $\left(x_{(N / 2+1) 1}, x_{(N / 2+1) 2}\right)$. Assim, existem infinitas pontos que possuem as propriedades necessárias para serem consideradas como o ponto mediano de um conjunto de dados bidimensionais. Esse conceito, considerando um conjunto de pontos num hiperplano $p$-dimensional, indica que a mediana, quando se têm $N$ vetores $p$-dimensionais, correspondentes a cada um dos $N$ pontos amostrais, com $N$ par, a mediana é um ponto qualquer da figura formada pelos $2^{N}$ pontos da forma $\left(x_{(j 1) 1}, \ldots, x_{(j p) p}\right), \operatorname{com} j_{i}=N / 2$ ou $j_{i}=N / 2+1$, para $i=1, \ldots, p$.

\subsection{Exemplo 1. Dados fictícios (dois grupos e duas variáveis)}

Com o intuito de mostrar a falta de adequação dos métodos assintóticos para a obtenção do valor-p na análise multivariada, tomou-se como exemplo inicial dados fictícios numa situação peculiar. Considerando uma amostra de $\mathrm{n}=6$ elementos 
em cujos elementos foram medidas duas variáveis e ainda, dois grupos ou tratamentos. Os postos encontram-se na Tabela 1.

Tabela 1. Dados fictícios para uma amostra com dois grupos.

\begin{tabular}{ccc}
\hline Grupos & Variável $\mathrm{X}_{1}$ & Variável $\mathrm{X}_{2}$ \\
\hline 1 & 1 & 5 \\
1 & 2 & 4 \\
1 & 3 & 6 \\
2 & 4 & 1 \\
2 & 5 & 2 \\
2 & 6 & 3 \\
\hline
\end{tabular}

Na situação proposta, tem-se um total de 6 elementos divididos em dois grupos com três elementos cada. Considerando que os valores que são obtidos para o elemento amostral $i$, dado pelo vetor $\boldsymbol{X}=\left(\boldsymbol{X}_{1}, \boldsymbol{X}_{2}\right)$, não são separáveis devido à suas características intrínsecas, no caso geral o número de configurações possíveis é dado por 6!/(3!3!). Como as amostras têm o mesmo tamanho e as comparações a serem realizadas é bilateral e, além disso, não ocorrem empates, podemos ainda dividir esse número pelo fatorial do número de grupos. Portanto, nesse caso específico, basta tomar 6!/[(3!3!)2!] = 10 configurações. Assim, quando se considera que a aleatorização ocorre entre os elementos amostrais e não nos elementos combinados com as variáveis, na configuração em que ocorre a maior diferença entre os grupos, o valor- $p$ obtido não deverá ser menor que 0,1 . Ou seja, o menor valor-p possível é o mesmo para os casos uni e multivariado devido à indissolubilidade dos termos do vetor $\boldsymbol{X}$.

Iniciando com a situação univariada, considerando separadamente as variáveis $\mathrm{X}_{1}$ e $\mathrm{X}_{2}$ e a comparação entre os testes t para amostras independentes e o teste de Wilcoxon-Mann-Whitney, tem-se que: 
i) tanto para a variável $\mathrm{X}_{1}$ como para a variável $\mathrm{X}_{2}$, o teste $t$ indica diferenças significativas entre os grupos ou tratamentos, com um valor-p igual a 0,021;

ii) para ambas as variáveis, consideradas isoladamente, pelo teste de Wilcoxon-Mann-Whitney obtém-se um valor-p igual a 0,100.

iii) A correlação de Spearman (postos) entre as variáveis $X_{1}$ e $X_{2}$ é 0,600 , mas o teste indica que não é significativa (valor-p $=0,208$ ), o que pode ser explicada pelo pequeno tamanho amostral.

Essa forte discrepância entre os resultados dos testes t e Wilcoxon-MannWhitney, no caso univariado, tende a se acentuar no caso multivariado. Considerando agora as variáveis conjuntamente e utilizando qualquer software estatístico que resolva problemas multivariados, os resultados dos testes multivariados mais comuns (Wilks, Roy, Pillai e Lawley-Hotteling) coincidem, indicando diferenças significativas entre os grupos (valor-p igual a 0,007).

O procedimento de teste, no caso permutacional, é feito considerando cada uma das configurações possíveis. Calcula-se, inicialmente, a estatística do teste de Wilks para o conjunto de dados na sua forma original $\left(W_{c}\right)$. Considerando c grupos, em cada uma das $n ! /\left(n_{1} ! \ldots . n_{c} !\right)$ configurações, a estatística referente ao teste de Wilk $\left(W_{i}\right)$ é calculada. Observa-se que esse número de configurações pode ser reduzido nos casos em que não há empates entre as observações e ainda o tamanho de todas as amostras dos grupos são iguais. Nesse caso, o número de configurações é dado por $n ! /\left(n_{1} ! \ldots n_{c} ! c !\right)$. O valor-p é dado pelo número de valores do teste de Wilks que são menores ou iguais ao valor do mesmo teste para os dados originais, dividido pelo número total de configurações possíveis, ou seja

$$
\text { valor }-p=\frac{\#\left(W_{i} \leq W_{c}\right)}{\left(\begin{array}{c}
n \\
n_{1} \ldots n_{c}
\end{array}\right)}
$$

O número de configurações possíveis, dado por $n ! /\left(n_{1} ! n_{2} ! c !\right)=6 ! /(3 ! 3 ! 2 !)$ = 10. Essas configurações são mostradas na Tabela 2 e para cada uma delas foram feitos os cálculos necessários para a obtenção da estatística de Wilks. Para todas as 
configurações, a matriz de variação total $(H+E)$ não se modifica e o valor do seu determinante é 196. Para a configuração original dos dados, obtém-se o valor 0,0357 para a estatística de Wilks, que é o menor dos dez valores possíveis. Assim, o valor-p para o teste de permutações considerado é igual a 0,10.

Tabela 2. Teste de Wilks para as configurações com dois grupos de três elementos.

Grupos Lambda

$\begin{array}{llllllll}\text { Configurações Variáveis } & 1 & 1 & 1 & 2 & 2 & 2 & \operatorname{Det}(\mathrm{E}) \text { de Wilks }\end{array}$

\begin{tabular}{|c|c|c|c|c|c|c|c|c|c|}
\hline \multirow[t]{2}{*}{1} & $X_{1}$ & 1 & 2 & 3 & 4 & 5 & 6 & 7.00 & 0.0357 \\
\hline & $\mathrm{X}_{2}$ & 5 & 4 & 6 & 1 & 2 & 3 & & \\
\hline \multirow[t]{2}{*}{2} & $\mathrm{X}_{1}$ & 1 & 2 & 4 & 3 & 5 & 6 & 25.67 & 0.1310 \\
\hline & $X_{2}$ & 5 & 4 & 1 & 6 & 2 & 3 & & \\
\hline \multirow[t]{2}{*}{3} & $\mathrm{X}_{1}$ & 1 & 2 & 5 & 3 & 4 & 6 & 137.67 & 0.7024 \\
\hline & $\mathrm{X}_{2}$ & 5 & 4 & 2 & 6 & 1 & 3 & & \\
\hline \multirow[t]{2}{*}{4} & $\mathrm{X}_{1}$ & 1 & 2 & 6 & 3 & 4 & 5 & 175.00 & 0.8929 \\
\hline & $\mathrm{X}_{2}$ & 5 & 4 & 3 & 6 & 1 & 2 & & \\
\hline \multirow[t]{2}{*}{5} & $\mathrm{X}_{1}$ & 1 & 3 & 4 & 2 & 5 & 6 & 149.33 & 0.7619 \\
\hline & $\mathrm{X}_{2}$ & 5 & 6 & 1 & 4 & 2 & 3 & & \\
\hline \multirow[t]{2}{*}{6} & $\mathrm{X}_{1}$ & 1 & 3 & 5 & 2 & 4 & 6 & 149.33 & 0.7619 \\
\hline & $\mathrm{X}_{2}$ & 5 & 6 & 2 & 4 & 1 & 3 & & \\
\hline \multirow[t]{2}{*}{7} & $\mathrm{X}_{1}$ & 1 & 3 & 6 & 2 & 4 & 5 & 74.67 & 0.3810 \\
\hline & $\mathrm{X}_{2}$ & 5 & 6 & 3 & 4 & 1 & 2 & & \\
\hline \multirow[t]{2}{*}{8} & $\mathrm{X}_{1}$ & 1 & 4 & 5 & 2 & 3 & 6 & 102.67 & 0.5238 \\
\hline & $\mathrm{X}_{2}$ & 5 & 1 & 2 & 4 & 6 & 3 & & \\
\hline \multirow[t]{2}{*}{9} & $\mathrm{X}_{1}$ & 1 & 4 & 6 & 2 & 3 & 5 & 177.33 & 0.9048 \\
\hline & $\mathrm{X}_{2}$ & 5 & 1 & 3 & 4 & 6 & 2 & & \\
\hline \multirow[t]{2}{*}{10} & $\mathrm{X}_{1}$ & 1 & 5 & 6 & 2 & 3 & 4 & 177.33 & 0.9048 \\
\hline & $X_{2}$ & 5 & 2 & 3 & 4 & 6 & 1 & & \\
\hline
\end{tabular}


Portanto, considerando o nível de significância igual a 5\%, a hipótese de diferença entre os grupos ou tratamentos não é rejeitada. Esse resultado difere consideravelmente daquele obtido com a utilização dos testes usuais da análise de variância multivariada paramétrica sobre os postos das variáveis, nos quais o valor-p foi igual a 0,007 e, portanto, indicando diferenças significativas ao nível de 5\%. Verifica-se ainda que o resultado do teste de Wilks é equivalente ao teste utilizando o traço de Pillai, indicando um valor-p igual a 0,10 .

No presente caso, o resultado obtido com o teste multivariado é semelhante àquele obtido quando se atribuem postos considerando conjuntamente as variáveis. Nesse caso, atribuem-se postos da forma usual para a primeira variável e, para a segunda variável, os postos são atribuídos na mesma direção, se a correlação entre elas for significativamente positiva, e na direção contrária (menores postos para os maiores valores), se a correlação for negativa. Nesse caso, considerando a configuração 1 como sendo correspondente à configuração original dos dados, o valor-p para o teste de Wilcoxon-Mann-Whitney foi igual a 0,004. Considerando a configuração 2 como a original, obtém-se, para o teste de Wilcoxon-Mann-Whitney, o valor-p igual a 0,200 e, para os testes multivariados, o valor-p igual a 0,235.

Entretanto, não foi possível comprovar teoricamente a compatibilidade dos resultados obtidos dessa maneira com o resultado multivariado. Além disso, o cálculo da estatística numa situação desse tipo, através dos testes de permutações, desrespeita uma condição básica que é a indissolubilidade dos dados de cada indivíduo e ainda, quando as medidas são feitas em mais do que duas variáveis, a atribuição pode tornar-se confusa.

\subsection{Exemplo 2. Dados fictícios (três grupos e três variáveis)}

Nesse segundo exemplo foram considerados três grupos, cada um deles com dois elementos $\left(n_{1}=n_{2}=n_{3}=2\right)$, totalizando $n=6$ elementos amostrais. Como o número de elementos em todas as amostras são iguais, o número de configurações possíveis é dado por 6!/[(2!2!2!)3!] = 15. Assim, o menor valor- $p$ que pode ser obtido, considerando a situação de maior diferença entre os grupos, é $1 / 15=0,06667$. Como no 
exemplo anterior, a pequena amostra utilizada tem apenas finalidade de observação dos resultados já que testes nessas condições não resultam em resultados bem definidos em relação à significância da diferença entre grupos.

Os testes usuais da análise de variância multivariada aplicados indicam contradições em relação aos resultados, havendo significância ao nível de 5\% para o teste de Pillai (valor-p $=0,020$ ) e não havendo para o teste de Wilks (valor-p =0,102). Essa contradição ocorre também quando se consideram os dados permutados e os resultados dos testes referidos em cada uma das 15 configurações obtidas. A Tabela 3 indica essa contradição.

Tabela 3. Resultados do teste de Wilks $\left(\Lambda_{\mathrm{i}}\right)$ e do teste de Pillai $\left(\mathrm{V}_{\mathrm{i}}\right)$ para as configurações considerando três tratamentos, cada um com duas repetições.

\begin{tabular}{cccccc}
\hline Configurações & $\lambda_{1}$ & $\lambda_{2}$ & $\lambda_{3}$ & $\Lambda$ & $\mathrm{V}$ \\
\hline 1 & 0,1669813 & 0,0677962 & 0,1097315 & 0,0012422 & 1,8782609 \\
2 & 0,9922407 & 0,0413551 & 0,6130312 & 0,0251553 & 1,0074534 \\
3 & 0,9061219 & 0,0635926 & 0,9108311 & 0,0524845 & 1,0919255 \\
4 & 0,3269545 & 0,0002580 & 0 & 0 & 1,8385093 \\
5 & 0,3549270 & 0,5272139 & 0,0414914 & 0,0077640 & 1,4869565 \\
6 & 0,5255346 & 0,788418 & 0,1686432 & 0,0698758 & 0,9850930 \\
7 & 0,4455292 & 0,1905297 & 0,0146341 & 0,0012422 & 1,1329193 \\
8 & 0,4825949 & 0,5206334 & 0,5450897 & 0,1369565 & 1,0447205 \\
9 & 0,7393214 & 0,9080867 & 0,8553039 & 0,5742236 & 0,4583850 \\
10 & 0,8382610 & 0,5329357 & 0,4004170 & 0,1788820 & 1,1006211 \\
11 & 0,8473542 & 0,5852524 & 0,1227417 & 0,0608696 & 1,3639752 \\
12 & 0,3067938 & 0,6038559 & 0,0067054 & 0,0012422 & 1,2968944 \\
13 & 0,8914161 & 0,8244249 & 0,4327255 & 0,3180124 & 0,812422 \\
14 & 0,9866281 & 0,9017842 & 0,0684139 & 0,0608696 & 0,991304 \\
15 & 0,1893414 & 0,1500961 & 0,3933978 & 0,0111801 & 1,510559 \\
\hline
\end{tabular}


O teste realizado com as permutações, utilizando o traço de Pillai, é mais consistente. Isso pode ser explicado porque o teste é mais robusto para pequeno tamanho amostral. No caso do teste de Wilks, algumas configurações, que não diferenciam tanto os tratamentos quanto a primeira configuração, resultam em valores menores ou iguais ao da estatística, enquanto que isso não acontece com o teste utilizando o traço de Pillai. Utilizando a estatística de Wilks para obtenção do valor-p através do teste de permutações, obtém-se o valor-p $=3 / 14=0,214286$. Foi retirada a configuração 4 pois o resultado é incoerente. No caso do traço de Pillai, a estatística referente à primeira configuração é a maior dentre as quinze estatísticas obtidas e, portanto, o valor-p é igual a 0,06667. A utilização de combinações de valores-p, através do método de Fisher pode ser uma boa alternativa. Para isso, devemos considerar os resultados individuais que estruturam a construção da estatística de Wilks, como em Dempster (1963b) e calcular, para cada um desses resultados individuais, um valor-p. Os valores-p são então combinados pelo método de Fisher. Assim, considerando a primeira configuração como a que foi obtida no experimento, os valores-p para $\lambda_{1}, \lambda_{2}$ e $\lambda_{3}$ são, respectivamente, 0,06667, 0,26667 e 0,357143. O denominador do último valor-p é 14 devido à inconsistência do resultado da configuração 4. Assim, a estatística combinada dos valores-p é dada por $T=-2 \log \left(p_{1} p_{2} p_{3}\right)=7783641$.

Esse valor é comparado com a distribuição de Qui-quadrado com seis graus de liberdade e obtém-se um valor-p conjunto igual a 0,119735. Observa-se que as estatísticas exatas de Kruskal-Wallis para as três variáveis, analisadas isoladamente, são iguais a $0,0667,0,0667$ e 0,2000 .

\subsection{Exemplo 3. Dados de Anselmo (2005)}

Os dados apresentados neste exemplo referem-se aos fatores psicológicos que podem contribuir com as desordens temporomandibulares (DTM). O objetivo do estudo era verificar a evolução da prevalência dos distúrbios psiquiátricos menores em pacientes portadores de DTM, tratados com aparelhos de superfície oclusal plana e reabilitação oral. As variáveis medidas foram stress psíquico (SP), desejo de morte 
(DM), desconforto (DD), distúrbio do sono (DS), distúrbio psíquico (DP) e saúde geral (SG), sendo que esta última uma combinação das variáveis anteriores. No total, 58 pacientes foram selecionados, 29 de cada sexo, na faixa etária de 21 a 75 anos. Em cada grupo de sexo, metade dos pacientes foi submetida ao tratamento (reabilitação oclusal protética) para DTM e a outra metade, denominada grupo controle, não foi submetido a nenhum tratamento para DTM.

Os pacientes, submetidos ou não ao tratamento, foram entrevistados antes do início do experimento. Após o tratamento feito apenas em um dos grupos, os pacientes foram novamente entrevistados. Assim, tem-se dois valores para cada uma das variáveis, uma ao início e outra ao término do experimento. É possível desta forma saber se houve alteração nas respostas após a aplicação do tratamento, para o grupo que a ele se submeteu, comparando-se com o outro grupo, que em nenhum momento foi tratado.

Assim, 28 pacientes foram submetidos à reabilitação oclusal protética, seja ela com próteses parciais fixa, removíveis ou totais, ou ainda uma combinação de ambos, após a reabilitação foram novamente submetidos à aplicação do QSG. Os outros 30 não foram submetidos à reabilitação protética e responderam novamente ao QSG. Estes grupos serão denominados tratados e não tratados.

Os resultados apresentados são oriundos das respostas dos pacientes ao QSG (Questionário de Saúde Geral de Goldberg), utilizado para a determinação dos distúrbios psiquiátricos menores e do questionário do CETASE - Centro de Estudos e Tratamento das Alterações Funcionais do Sistema Estomatognático, da Faculdade de Odontologia de Piracicaba - Unicamp. Os valores das seis variáveis podem variar de 1,000 a 4,000 e a utilização de testes individuais, baseados na distribuição normal ou $\mathrm{t}$ de Student, pode não ser apropriada. Também no caso multivariado, a aplicação dos testes usuais, baseados nas pressuposições de multinormalidade, homogeneidade das matrizes de variâncias e covariâncias e ausência de pontos discrepantes, pode não ser correta. A tabela 4 mostra o tamanho das amostras e as médias de cada uma das variáveis para cada um dos quatro grupos (feminino tratado, feminino não-tratado, masculino tratado e masculino não-tratado), ao início e ao final do experimento (antes e depois). 
Tabela 4. Tamanho da amostra e médias, para cada grupo, antes e depois do tratamento.

\begin{tabular}{|c|c|c|c|c|c|c|c|c|}
\hline Sexo & Situação & Tempo & $\mathrm{N}$ & SP & $\mathrm{DM}$ & DD & DS & DP \\
\hline \multirow[t]{4}{*}{ Feminino } & Tratados & Antes & 14 & 2,094 & 1,164 & 1,706 & 1,635 & 2,079 \\
\hline & & Depois & 14 & 1,452 & 1,136 & 1,692 & 1,367 & 1,251 \\
\hline & Não tratados & Antes & 15 & 2,189 & 1,491 & 2,160 & 2,004 & 2,207 \\
\hline & & Depois & 15 & 2,178 & 1,571 & 2,000 & 2,068 & 2,320 \\
\hline \multirow[t]{4}{*}{ Masculino } & Tratados & Antes & 14 & 1,757 & 1,260 & 1,675 & 2,161 & 2,437 \\
\hline & & Depois & 14 & 1,678 & 1,086 & 1,815 & 1,696 & 1,686 \\
\hline & Não tratados & Antes & 15 & 2,034 & 1,248 & 1,824 & 2,253 & 2,286 \\
\hline & & Depois & 15 & 2,150 & 1,332 & 1,705 & 2,224 & 2,158 \\
\hline \multirow[t]{4}{*}{ Geral } & Tratados & Antes & 28 & 1,925 & 1,212 & 1,691 & 1,898 & 2,258 \\
\hline & & Depois & 28 & 1,565 & 1,111 & 1,754 & 1,531 & 1,469 \\
\hline & Não tratados & Antes & 30 & 2,111 & 1,370 & 1,992 & 2,128 & 2,246 \\
\hline & & Depois & 30 & 2,164 & 1,452 & 1,852 & 2,146 & 2,239 \\
\hline
\end{tabular}

Os resultados da Tabela 4 já nos dão uma indicação do que ocorre com os valores obtidos para cada uma das variáveis em cada um dos grupos, nos casos dos sexos feminino e masculino, respectivamente. Percebe-se a ação do tratamento, agindo de forma a acelerar as diferenças entre os grupos, tanto pela diminuição ou aumento mais acentuado do valor da variável como pela inversão do efeito que ocorre entre os tratados e não tratados. Estas diferenças serão melhores exploradas quando forem discutidos os testes específicos em cada caso.

Os dados não são adequados para a utilização de testes paramétricos devido ao seu truncamento (só pode assumir valores entre 1 e 4) e a maneira como esses dados são obtidos, ou seja, através de perguntas de questionários às quais são atribuídos valores de 1 a 4, caracteriza a utilização de testes não paramétricos, mais adequados a esse tipo de informação (Pereira, 1999). 
Entretanto, foram feitos os testes para verificar a adequação dos dados à testes paramétricos, ou seja, verificou-se se os resíduos aderem a uma distribuição normal, se a variabilidade dos grupos são homogêneas e se não ocorrem pontos discrepantes (outliers).

Para realizar estas verificações, considera-se a forma como os dados foram obtidos. Inicialmente, o pesquisador buscou elementos dentro das características de faixa etária e sexo, tomando dois grupos separadamente. Assim, nesta etapa do processo não há aleatorização. Em seguida, metade dos pacientes foi escolhida aleatoriamente para fazer parte do grupo que receberia o tratamento, enquanto que a outra metade não receberia. Em seguida duas medidas foram tomadas, antes e depois.

Portanto, o esquema de análise no caso paramétrico é inteiramente casualizado, com parcelas subdivididas. As parcelas referem-se aos grupos de elementos tratados e não tratados, enquanto que as subparcelas são os tempos em que os questionários foram respondidos (antes e depois).

Cada sexo é analisado separadamente e em seguida, comparações entre os sexos para cada caso podem ser realizadas. A tabela 4 mostra os resultados dos testes de Shapiro-Wilk para verificar a normalidade dos resíduos e o de Bartlett referente à homogeneidade de variâncias para cada uma das variáveis, além de informar sobre a presença ou não de valores discrepantes para o sexo masculino.

Verifica-se que, para as variáveis SP, DM, DD e SG não há normalidade dos resíduos e para as variáveis SP e SG foram verificados valores discrepantes. A heterogeneidade das variâncias só ocorre no caso da variável DD.

Assim, no caso dos valores referentes ao sexo masculino, para a maior parte das variáveis (SP, DM, DD e SG) não é aconselhável o uso de testes paramétricos.

No caso do sexo feminino, em todas as variáveis ocorre algum problema em pelo menos uma das pressuposições. Em duas delas, DM e SG, tem-se as três pressuposições não atendidas. Assim como para os dados relativos ao sexo masculino, comprova-se que a utilização de testes baseados na distribuição normal, não são adequados. Portanto, recomenda-se a utilização de testes não-paramétricos em ambos os sexos e em todas as variáveis. 
Tabela 5. Teste de normalidade, homogeneidade de variâncias e indicação da presença de valores discrepantes para as variáveis em estudo - sexo masculino.

\begin{tabular}{lcccc}
\hline Variáveis & & Teste de S-W & Teste de Bartlett & Outliers (S ou N) \\
\hline SP & Estatística & 0,9741 & 2,999 & $\mathrm{~S}$ \\
& Valor-p & $\mathbf{0 , 0 2 7 2}$ & 0,392 & \\
DM & Estatística & 0,9005 & 6,749 & $\mathrm{~N}$ \\
& Valor-p & $<\mathbf{0 , 0 1 0}$ & 0,080 & \\
DD & Estatística & 0,9754 & 10,826 & $\mathrm{~N}$ \\
& Valor-p & $\mathbf{0 , 0 3 3 1}$ & $\mathbf{0 , 0 1 3}$ & \\
DS & Estatística & 0,9805 & 0,559 & $\mathrm{~N}$ \\
& Valor-p & 0,0662 & 0,906 & \\
DP & Estatística & 0,9909 & 6,606 & $\mathrm{~N}$ \\
& Valor-p & $>0,100$ & 0,086 & \\
\hline
\end{tabular}

${ }^{1}$ S-W - Shapiro-Wilk

Tabela 6. Teste de Normalidade, de homogeneidade de variâncias e indicação da presença de valores discrepantes para as variáveis em estudo - sexo feminino.

\begin{tabular}{lcccc}
\hline Variáveis & & Teste de S-W & Teste de Bartlett & Outliers (S ou N) \\
\hline SP & Estatística & 0,9686 & 5,798 & \\
& Valor-p & $<\mathbf{0 , 0 1}$ & 0,122 & S \\
DM & Estatística & 0,8966 & 30,151 & \\
& Valor-p & $<\mathbf{0 , 0 1}$ & $<\mathbf{0 , 0 0 1}$ & S \\
DD & Estatística & 0,9826 & 9,435 & \\
& Valor-p & 0,0943 & $\mathbf{0 , 0 2 4}$ & S \\
DS & Estatística & 0,9287 & 1,736 & \\
& Valor-p & $<\mathbf{0 , 0 1}$ & 0,629 & $\mathrm{~N}$ \\
DP & Estatística & 0,9936 & 22,146 & $\mathrm{~N}$ \\
& Valor-p & $>0,10$ & $<\mathbf{0 , 0 0 1}$ & \\
\hline
\end{tabular}

${ }^{1}$ S-W - Shapiro-Wilk 
Inicialmente, foram feitas as comparações entre elementos dos dois grupos, para cada sexo e conjuntamente, antes da aplicação do tratamento, para saber se o comportamento dos dados permitiria a utilização de uma variável combinando os resultados referentes aos tempos antes e depois. As Tabelas 7, 8 e 9 mostram os resultados dos testes de Wilcoxon-Mann-Whitney (W-M-W) considerando o sexo feminino, o sexo masculino e ambos os sexos conjuntamente, respectivamente.

Tabela 7. Teste de W-M-W comparando os grupos para o sexo feminino - antes.

\begin{tabular}{|c|c|c|c|c|}
\hline \multirow[b]{2}{*}{ Variáveis } & \multicolumn{3}{|c|}{ Média dos Postos } & \multirow[b]{2}{*}{ Valor-p } \\
\hline & NTrat & Trat & Estatística U & \\
\hline SP & 14,77 & 15,25 & 101,5 & 0,889 \\
\hline $\mathrm{DM}$ & 16,20 & 13,71 & 87,0 & 0,421 \\
\hline $\mathrm{DD}$ & 17,33 & 12,50 & 70,0 & 0,131 \\
\hline DS & 16,93 & 12,93 & 76,0 & 0,210 \\
\hline DP & 15,80 & 14,14 & 93,0 & 0,612 \\
\hline
\end{tabular}

Tabela 8. Teste de W-M-W comparando os grupos para o sexo masculino - antes.

\begin{tabular}{|c|c|c|c|c|}
\hline \multicolumn{5}{|c|}{ Média dos Postos } \\
\hline Variáveis & NTrat & Trat & Estatística U & Valor-p \\
\hline SP & 17,07 & 12,79 & 74,0 & 0,180 \\
\hline DM & 15,27 & 14,71 & 101,0 & 0,866 \\
\hline DD & 16,13 & 13,79 & 88,0 & 0,467 \\
\hline DS & 15,57 & 14,39 & 96,5 & 0,722 \\
\hline DP & 13,90 & 16,18 & 88,5 & 0,481 \\
\hline
\end{tabular}

Os testes para todas as variáveis não foram significativos, indicando não haver diferenças entre os grupos (não tratados e tratados) no período antes, tanto para os 
elementos do sexo feminino como para os elementos de sexo masculino e também considerando ambos os sexos conjuntamente. Com a junção dos dois grupos de sexo numa mesma análise, os resultados não se alteram e, ao mesmo tempo, a análise fica mais confiável.

Tabela 9. Valores de interesse para o teste de W-M-W para comparação entre os grupos para ambos os sexos- antes.

\begin{tabular}{lcccc}
\hline \multirow{4}{*}{ Mariáveis } & NTrat & Trat & Estatística U & Valor-p \\
\hline SP & 31,22 & 27,66 & 368,5 & 0,427 \\
DM & 31,22 & 27,66 & 368,5 & 0,405 \\
DD & 32,77 & 26,00 & 322,0 & 0,128 \\
DS & 31,77 & 27,07 & 352,0 & 0,293 \\
DP & 29,03 & 30,00 & 406,0 & 0,832 \\
\hline
\end{tabular}

Assim, devido ao fato de não haver diferenças entre os grupos antes do tratamento, realizou-se a análise alteração, para cada variável, combinando os valores de antes e depois da aplicação dos tratamentos. Essas novas variáveis serão aqui denominadas na sua forma geral como ALT_zz, em que zz pode representar qualquer uma das variáveis originais SP, DM, DD, DS ou DP. Assim, as novas variáveis a serem analisadas são ALT_SP, ALT_DM, ALT_DD, ALT_DS e ALT_DP, que são calculadas subtraindo-se os valores após a aplicação do tratamento dos valores antes da aplicação e dividindo-se o resultado obtido pelo valor antes da aplicação do tratamento, ou seja, para uma variável qualquer tem-se que

$$
\mathrm{ALT} \_\mathrm{zZ}=\left(\mathrm{zZ}_{\text {antes }}-\mathrm{zZ}_{\text {depois }}\right) / \mathrm{zZ}_{\text {antes }}
$$

Observa-se que a variável poderia ser dada na forma percentual, não alterando os resultados a serem obtidos. Os resultados obtidos com as variáveis ALT_zz são semelhantes aos das variáveis não transformadas e as análises dos dados 
transformados encontram-se nas Tabela 10, 11 e 12, para os sexos tomados conjuntamente, sexo feminino e masculino, respectivamente.

Pode ser percebido que as diferenças entre os tratados e não-tratados ocorre em quatro das cinco variáveis, não ocorrendo na variável DD, como ocorreu com os dados originais. Esta repetição dos resultados deve-se ao fato de que antes do tratamento não houve uma variação significativa dos valores das medidas. Observandose o comportamento de cada sexo, separadamente, percebe-se claramente diferenças. Os elementos do sexo feminino responderam melhor ao tratamento do que os do sexo masculino.

Tabela 10. Teste W-M-W entre tratados e não tratados, ambos os sexos - Variáveis ALT_zz.

\begin{tabular}{ccccc}
\hline & Média dos & Postos & & \\
Variáveis & Ntrat (30) & Trat (29) & Estatística U & Valor-p \\
\hline ALT_SP & 34,73 & 23,89 & 263,0 & $\mathbf{0 , 0 1 4}$ \\
ALT_DM & 33,68 & 25,02 & 294,5 & $\mathbf{0 , 0 4 5}$ \\
ALT_DD & 27,08 & 32,09 & 347,5 & 0,262 \\
ALT_DS & 33,68 & 25,02 & 294,5 & $\mathbf{0 , 0 5 0}$ \\
ALT_DP & 37,87 & 20,54 & 169,0 & $<\mathbf{0 , 0 0 1}$ \\
\hline
\end{tabular}

Tabela 11. Teste W-M-W entre tratados e não tratados - sexo feminino - Variáveis ALT_zz.

\begin{tabular}{lcccc}
\hline & Média dos & Postos & & \\
Variáveis & Ntrat (15) & Trat (14) & Estatística U & Valor-p \\
\hline ALT_SP & 10,57 & 19,75 & 38,5 & $\mathbf{0 , 0 0 3}$ \\
ALT_DM & 12,73 & 17,43 & 71,0 & 0,138 \\
ALT_DD & 15,60 & 14,36 & 96,0 & 0,707 \\
ALT_DS & 11,87 & 18,36 & 58,0 & $\mathbf{0 , 0 3 9}$ \\
ALT_DP & 10,70 & 19,61 & 40,5 & $\mathbf{0 , 0 0 4}$ \\
\hline
\end{tabular}


Apenas para as variáveis ALT_DP e ALT_DD os resultados do teste coincidem para ambos os sexos. Para as outras variáveis consideradas, constatam-se diferenças significativas entre tratados e não tratados, enquanto que para o sexo masculino essa diferença não é detectada pelo teste. Para o teste entre os sexos, nenhuma das variáveis foi significativa, conforme ocorreu quando foram observados os resultados separadamente (Tabela 13).

Tabela 12. Valores de interesse para o teste W-M-W entre tratados e não tratados - sexo masculino - Variável ALT_zz.

\begin{tabular}{lcccc}
\hline & Média dos & Postos & & \\
Variáveis & Ntrat (15) & Trat (14) & Estatística U & Valor-p \\
\hline ALT_SP & 14,70 & 15,32 & 100,5 & 0,855 \\
ALT_DM & 13,20 & 16,93 & 78,0 & 0,226 \\
ALT_DD & 17,03 & 12,82 & 74,5 & 0,188 \\
ALT_DS & 13,47 & 16,64 & 82,0 & 0,330 \\
ALT_DP & 10,90 & 19,39 & 43,5 & $\mathbf{0 , 0 0 6}$ \\
\hline
\end{tabular}

Tabela 13. Valores de interesse para o teste $\mathrm{W}-\mathrm{M}-\mathrm{W}$ entre os sexos masculino e feminino e valores-p - Variável ALT_zz.

\begin{tabular}{|c|c|c|c|c|}
\hline \multirow[b]{2}{*}{ Variáveis } & \multicolumn{3}{|c|}{ Média dos Postos } & \multirow[b]{2}{*}{ Valor-p } \\
\hline & Fem & Masc & Estatística U & \\
\hline ALT_SP & 25,90 & 33,10 & 316,0 & 0,105 \\
\hline ALT_DM & 30,71 & 28,29 & 385,5 & 0,583 \\
\hline ALT_DD & 27,21 & 31,79 & 354,0 & 0,305 \\
\hline ALT_DS & 30,28 & 28,72 & 398,0 & 0,730 \\
\hline ALT_DP & 30,59 & 28,41 & 389,0 & 0,629 \\
\hline
\end{tabular}


A análise multivariada dos dados de Anselmo (2005) será feita inicialmente para os pacientes do sexo feminino, excluindo os resultados da variável SG (saúde geral), tendo em vista que ela é obtida por combinação linear das outras variáveis. Tem-se então cinco variáveis, stress psíquico (SP), desejo de morte (DM), desconforto (DD), distúrbio do sono (DS) e distúrbio psíquico (DP). Como não há interesse em discutir os resultados referentes às diferenças entre os tempos (antes e depois), far-se-á apenas a análise das variáveis ALT_SP, ALT_DM, ALT_DD, ALT_DS e ALT_DP. Os resultados dos testes univariados foram apresentados na Tabela 11, indicando que são significativas as diferenças entre tratados e não-tratados para as variáveis ALT_SP, ALT_DS e ALT_DP.

Tabela 14. Coeficiente de correlação de Spearman para as variáveis estudadas e respectivos valores-p.

\begin{tabular}{cccccc}
\hline & ALT_SP & ALT_DM & ALT_DD & ALT_DS & ALT_DP \\
ALT_SP & 1,000 & & & & \\
& & & & & \\
ALT_DM & 0,454 & 1,000 & & & \\
& $(0,013)$ & & & & \\
ALT_DD & 0,291 & 0,169 & 1,000 & & \\
& $(0,125)$ & $(0,382)$ & & & \\
ALT_DS & 0,645 & 0,542 & 0,399 & 1,000 & \\
& $(<0,001)$ & $(0,002)$ & $(0,032$ & & 1,000 \\
ALT_DP & 0,532 & 0,375 & 0,226 & 0,603 & \\
& $(0,003)$ & $(0,045)$ & $(0,238)$ & $(0,001)$ & \\
\hline
\end{tabular}

Obs.: valores-p entre parêntesis.

Entretanto, deve-se observar se existem correlações significativas entre as variáveis. O teste para o coeficiente de correlação de Spearman indica que há correlação significativa, ao nível de 5\% de significância (Tabela 14), entre os pares de variáveis 
ALT_SP e ALT_DM, ALT_SP e ALT_DS, ALT_SP e ALT_DP, ALT_DM e ALT_DS, ALT_DM e ALT_DP, ALT_DD e ALT_DS, ALT_DS e ALT_DP. Essas correlações significativas indicam que a análise dos dados feita de forma individual, não é a mais adequada nesse caso.

A análise de variância multivariada (MANOVA) tende a dar melhores respostas nesses casos. Entretanto, as pressuposições para a realização da análise de variância multivariada nessa situação se constituem obstáculos que podem influenciar nos resultados, podendo mascarar as conclusões que advirão dos testes da MANOVA usual.

Nessas situações, a análise não-paramétrica tende a ser mais adequada, gerando resultados mais consistentes. Foram aplicados os métodos sugeridos na seção 3. Inicialmente, os dados originais foram substituídos por seus postos, com essa atribuição feita de forma isolada para cada variável considerada.

Assim, para cada variável, atribuem-se postos de 1 a 29, sendo 1 para o menor valor, 2 para o segundo menor valor, e assim por diante, até o posto 29 para o maior valor da variável. Empates entre valores das variáveis foram tratados da forma usual, ou seja, atribuiu-se o posto médio das posições relativas dos elementos empatados. As variáveis assim obtidas serão denominadas rAlt_zz.

Foram aplicados os testes multivariados usuais aos dados, com e sem a transformação em postos, ou seja, o traço de Pillai, o teste de Wilks, o traço de Hotelling e a maior raiz característica de Roy, aos valores das variáveis ALT_zz.

Tabela 15. Resultados dos testes de Pillai e de Wilks para os dados transformados em postos e dados originais - variáveis ALT_zz e rALT_zz.

\begin{tabular}{llccc}
\hline Variáveis & Testes & Valor da Estatística & F & Valor-p \\
\hline ALT_zz & Traço de Pillai & 0,51199 & 4,826 & 0,004 \\
& Lambda de Wilks & 0,48801 & 4,826 & 0,004 \\
rALT_zz & Traço de Pillai & 0,54471 & 3,845 & 0,011 \\
& Lambda de Wilks & 0,45529 & 3,845 & 0,011 \\
\hline
\end{tabular}


Como há apenas dois tratamentos ou grupos, todos esses testes indicam os mesmos resultados, equivalentes ao $\mathrm{T}^{2}$ de Hotelling, ou seja, o valor-p para a diferença entre os grupos é 0,004. Assim, ao nível de 1\% de significância, rejeita-se a hipótese de igualdade entre os grupos tratados e não-tratados. Os resultados dos testes de Pillai e de Wilks encontram-se na Tabela 15.

Os resultados mostrados na Tabela 15 indicam discrepâncias entre os valores-p obtidos com os dados transformados em postos em relação aos dados originais, para ambos os testes, quando se consideram conclusões a serem tomadas com um nível de significância de $1 \%$. A verificação da multinormalidade pode ser feita com o teste para a curtose e simetria multivariadas (Mardia, 1970), para o qual utilizou-se um programa em SAS (Khattree \& Naik, 1996). Ambos os testes indicam que a distribuição normal multivariada não é adequada para se estudar os dados tendo em vista que, tanto para o teste da curtose como para o teste de simetria, os valores-p foram menores que 0,0001. Assim, os resultados em que foram utilizados os dados transformados em postos tendem ser mais adequados do que àqueles calculados com os dados originais. Foram então aplicados os dois métodos propostos nesse trabalho aos dados.

Para a aplicação do método 1 , verifica-se inicialmente que o número de configurações que podem ser geradas a partir da permutação dos dados é igual a $29 ! /(15 ! 14 !)=77558760$. A geração de todas a permutações necessárias para o teste exato é proibitiva em termos de tempo computacional e os resultados obtidos com a geração de um grande número de combinações aleatórias têm sido bem aceitos como aproximações dos respectivos valores exatos.

Construiu-se então um programa na linguagem C, com a finalidade de efetuar a geração das combinações requeridas e calcular o valor-p para o teste. O referido programa computacional foi elaborado a partir de uma adaptação para o caso multivariado dos programas apresentados por Pontes (2000), Pontes \& Corrente (2000), Pontes \& Corrente (2001) e Pontes \& Corrente (2005).

Considerando que a aleatorização deve ocorrer para os $n$ elementos amostrais e que, não importando o número de variáveis que estão sendo consideradas, são permutados os indivíduos para a obtenção de cada configuração, o número total de 
configurações possíveis para uma determinada distribuição dos $n$ indivíduos em $c$ grupos de tamanhos $n_{i}(i=1, \ldots, c)$ é dado por $N P=n ! /\left(n_{1} ! n_{2} ! \ldots n_{c} !\right)$. Se os grupos têm todos o mesmo tamanho, ou seja, $n_{i}=m$ para todo $i$, e ainda as comparações a serem feitas são bilaterais, esse número pode ser reduzido para $\left.N P=n ! \Lambda(m !)^{c} c !\right]$. Assim, para pequenas amostras, em que o número de configurações está abaixo de 500000, todas as permutações, de uma forma sistemática, são efetuadas e o valor-p obtido é exato. No caso em que o número de configurações supera esse valor, 39999 configurações aleatórias são construídas pelo programa e o valor-p calculado é aproximado. O cálculo do valor-p é feito da seguinte forma:

a) calcula-se o valor da estatística para os dados transformados em postos na configuração original;

b) para cada configuração obtida, seja na forma sistemática ou na aleatória, calcula-se a estatística de teste de interesse;

c) obtém-se $n c$, que é o número de estatísticas que são maiores ou iguais à estatística da configuração original, no caso do traço de Pillai e o contrário para a estatística referente ao teste de Wilks;

d) no caso sistemático, simplesmente divide-se $n c$ pelo número total de configurações possíveis para a obtenção do valor-p exato;

e) no caso aleatório, o valor-p é obtido por $(n c+1) / 40000$; o acréscimo de uma unidade no numerador e no denominador da razão deve-se ao fato de se considerar o valor original da estatística no cômputo do valor- $p$.

No presente caso, devido ao grande número de permutações requeridas, utilizou-se o método aleatório. Assim, foram calculadas pelo programa, 39999 permutações aleatórias e, para cada uma delas, o valor da estatística do teste de Pillai foi calculada. Deve-se recordar que a estatística do teste de Pillai (traço de Pillai) é dada por

$$
V=\operatorname{tr}\left[E(E+H)^{-1}\right]=\frac{\lambda_{1}}{1+\lambda_{1}}+\frac{\lambda_{2}}{1+\lambda_{2}}+\ldots+\frac{\lambda_{p}}{1+\lambda_{p}}
$$


em que $\boldsymbol{E}$ é a matriz de dispersão dos erros, $\boldsymbol{H}$ é a matriz de dispersão das hipóteses, $\boldsymbol{H}+\boldsymbol{E}$ é a matriz de dispersão total e $\lambda_{i}, i=1, \ldots, p, \lambda_{1} \leq \lambda_{2} \leq \ldots \leq \lambda_{p}$ são os autovalores da matriz $\boldsymbol{E}^{-1} \boldsymbol{H}$.

A estatística para o teste de Wilks (lambda de Wilks) é obtida por

$$
\Lambda=\frac{|E|}{|H+E|}=\frac{1}{1+\lambda_{1}} \times \frac{1}{1+\lambda_{2}} \times \ldots \times \frac{1}{1+\lambda_{c}}
$$

Observa-se que, no caso em que se tomam as permutações, a matriz de dispersão total $\boldsymbol{H}+\boldsymbol{E}$ é fixa para o conjunto de dados observados. Assim, para a obtenção do valor-p permutacional, no caso do teste de Pillai, basta calcular o traço da matriz $\boldsymbol{E}$ e, no caso do teste de Wilks, seu determinante.

Aplicado o programa aos dados do exemplo, tem-se que o valor de $n c$, que é o número de estatísticas que são menores ou iguais à estatística da configuração original, foi igual a 256 para o teste de Pillai, que representa um valor-p igual a 0,0064. Portanto, o tratamento teve efeito significativo sobre o conjunto de variáveis medidas. Como existem apenas dois grupos, o teste de comparações múltiplas não é necessário. O detalhamento dessas diferenças pode ser feito observando as variáveis individualmente, como feito anteriormente. Contrastes multivariados podem ser adaptados, com a utilização do programa, para a obtenção de intervalos de confiança como mostrado em Katz \& McSweeney (1980).

O segundo método explicitado sugere a decomposição da estatística de Pillai. O método sugerido por Dempster (1963a) foi aplicado aos dados de Anselmo (2005). Novamente, as variáveis ALT_SP, ALT_DM, ALT_DD, ALT_DS e ALT_DP foram transformadas, de forma individual, em postos, obtendo-se então as variáveis rALT_SP, rALT_DM, rALT_DD, rALT_DS e rALT_DP, respectivamente.

Para as variáveis transformadas em postos, utilizando-se os programas estatísticos computacionais disponíveis, obteve-se o valor da estatística de Pillai igual a 0,5447122. Decompondo essa estatística de acordo com o método proposto, cinco valores são obtidos, cada um deles referente a uma combinação das variáveis originais que, multiplicados, retornam à variável original. As estatísticas obtidas podem ser testadas separadamente, ou ainda, de acordo com Dempster (1963b) pode-se utilizar 
apenas a maior ou a menor delas na composição do teste. Para os dados do exemplo, tem-se a decomposição apresentada na Tabela 16.

Tabela 16. Valores da decomposição de traço de Pillai e respectivos valores-p.

\begin{tabular}{cccc}
\hline I & $\lambda_{\mathrm{i}}$ & Parâmetros da Distribuição Beta & Valores-p \\
\hline 1 & 0,7577849 & $(27 / 2,1 / 2)$ & 0,0067 \\
2 & 0,8509555 & $(26 / 2,1 / 2)$ & 0,0424 \\
3 & 0,8825422 & $(25 / 2,1 / 2)$ & 0,0801 \\
4 & 0,9743207 & $(24 / 2,1 / 2)$ & 0,4342 \\
5 & 0,9822911 & $(23 / 2,1 / 2)$ & 0,5260 \\
Traço de Pillai & 0,5447122 & & 0,011 \\
\hline
\end{tabular}

Tabela 17. Valores da decomposição de traço de Pillai, resultados obtidos através do programa e respectivos valores-p.

\begin{tabular}{ccccc}
\hline & & \multicolumn{3}{c}{$\#\left(\lambda\right.$ calc $\left._{\mathrm{i}} \geq \lambda_{\mathrm{i}}\right)$} \\
I & $\lambda_{\mathrm{i}}$ ou V & $\begin{array}{c}\text { Valores-p } \\
\text { (Distr.Beta) }\end{array}$ & $\begin{array}{c}\text { ou } \\
\#\left(\lambda \text { calc }_{\mathrm{i}} \leq \mathrm{V}\right)\end{array}$ & $\begin{array}{c}\text { Valores-p } \\
\text { (Programa) }\end{array}$ \\
\hline 1 & 0,7577849 & 0,0067 & 127 & 0,0032 \\
2 & 0,8509555 & 0,0424 & 1069 & 0,0267 \\
3 & 0,8825422 & 0,0801 & 3024 & 0,0756 \\
4 & 0,9743207 & 0,4342 & 17359 & 0,4331 \\
5 & 0,9822911 & 0,5260 & 21743 & 0,5436 \\
Traço de Pillai & 0,5447122 & 0,0110 & 256 & 0,0064 \\
\hline
\end{tabular}


A multiplicação dos $\lambda_{\mathrm{i}}(i=1, \ldots, 5)$ recompõe a estatística de teste denominada traço de Pillai e, se os dados apresentassem as pressuposições para os testes usuais da análise de variância multivariada, esses valores poderiam ser testados através de uma distribuição Beta com parâmetros $(n-c-i+1) / 2$ e (c - i)/2 (Dempster, 1963b), como apresentado na Tabela 16. Tem-se ainda que

$$
\lambda_{1} \times \lambda_{2} \times \lambda_{3} \times \lambda_{4} \times \lambda_{5}=V=0,5447122
$$

Entretanto, como a matriz utilizada foi a matriz obtida a partir da transformação dos dados em postos, obviamente que as pressuposições não foram satisfeitas e assim, as aproximações dos testes individuais, realizadas através da distribuição Beta, não é adequada. Como no método anterior, podemos testar cada um dos valores $\lambda_{i}$ 's obtidos, através dos testes de permutação.

Assim, para cada uma das configurações possíveis, obtém-se a decomposição de acordo com o método explicitado e calculam-se valores $\lambda$ calc $_{\mathrm{i}}$ $(i=1, \ldots, 5)$ que serão comparados com aqueles obtidos na configuração original dos dados. 


\section{CONCLUSÕES}

A utilização de métodos multivariados voltados à análise de variância sempre teve, como ponto fraco, a dificuldade de obtenção de resultados confiáveis nos casos em que as variáveis envolvidas não preenchem os pressupostos necessários para a realização dos testes usuais. Essas situações são comuns nas diversas áreas de pesquisa, como, por exemplo, nas ciências humanas, em que escalas de valores são utilizadas cotidianamente na aplicação de questionários e, as variáveis obtidas a partir dessas escalas, tendem a ser combinadas com outras, em que escalas apropriadas aos testes paramétricos ocorrem. Na ecologia e nas ciências agrárias em geral, inúmeras medidas baseadas em contagens, em escalas proporcionais ou ainda referentes a variáveis ordinais, são utilizadas concomitantemente.

Métodos não-paramétricos univariados válidos para uma grande gama de situações são encontrados na literatura e, mesmo não sendo suficientes para abranger casos de experimentos mais complicados, cumprem um papel importante na resolução de problemas encontrados nas diversas áreas do conhecimento. Ressente-se, obviamente, de programas computacionais mais completos, que focalizem não só a utilização de testes gerais da análise de variância, mas também as comparações múltiplas e obtenção de valores-p para contrastes entre médias (ou medianas) de tratamentos.

O crescimento da capacidade computacional tem sido um aliado importante no crescimento da utilização de métodos não-paramétricos nos diversos campos de pesquisa, mas pouco tem sido feito para solucionar problemas envolvendo múltiplas variáveis.

A metodologia para a utilização da análise de variância multivariada, quando as pressuposições referentes a multi-normalidade dos resíduos, homogeneidade 
das matrizes de variância dos tratamentos e ausência de valores discrepantes (outliers), tem se revelado de grande utilidade nos diversos campos da ciência, mas as exigências para a validade dos testes a ela relacionados têm sido fortes obstáculos na busca de soluções robustas. Em geral, nesse tipo de análise, as pressuposições são relevadas ou enfraquecidas, para que soluções sejam encontradas. Assim, quando ocorrem correlações importantes entre as variáveis, que é bastante comum quando elas são medidas num mesmo indivíduo, o método multivariado se torna uma ferramenta indispensável.

O uso de combinação de testes para cada uma das variáveis exige a independência das mesmas, mas quando isso ocorre, conclusões isoladas são, na maioria das vezes, mais interessantes para futuras utilizações por parte do pesquisador.

Assim, devido às fortes pressuposições requeridas pela análise multivariada paramétrica e a forte demanda advinda do aumento do interesse numa pesquisa mais abrangente, torna-se evidente a necessidade de métodos que combinem as potencialidades da análise de variância multivariada com a amplitude de utilização dos métodos não-paramétricos.

A teoria para a realização de testes não-paramétricos multivariados tem o seu marco no livro de Puri \& Sen (1971), mas o desenvolvimento de métodos e programas computacionais facilmente aplicáveis, como no caso dos testes univariados mais comuns, não ocorreu. Somente alguns métodos, baseados em distâncias entre os dados, tiveram programas computacionais desenvolvidos e têm sido utilizados por muitos pesquisadores.

Nos últimos anos tem crescido o interesse por medidas centrais, em substituição à tradicional mediana obtida pela combinação das medianas obtidas para cada variável separadamente, denominada mediana componentwise ou simplesmente mediana multivariada. Concomitantemente, testes não-paramétricos vêm sendo desenvolvidos para a utilização dessas novas medidas nas comparações entre duas ou mais populações. É crescente o número de trabalhos publicados em revistas especializadas focalizando a teoria e utilização das medianas de Oja (Oja, 1983), o centro mediano (Gower, 1983), dentre outras. Essas medidas, apesar de terem 
propriedades interessantes de invariância afim e de rotação, não são tão simples de serem calculadas e estão longe de serem medidas ideais de localização por serem influenciadas por valores discrepantes. Assim, a discussão dessas medidas no presente trabalho foi feita com o objetivo de informar e ser informado, sem o intuito de utiliza-las na obtenção de métodos multivariados para a verificação de diferenças entre grupos ou tratamentos.

A mesma explicação pode ser aplicada aos métodos multivariado baseados nas distâncias entre os pontos amostrais. Com a transformação dos dados multivariados em distâncias, passa-se do espaço multidimensional para o espaço unidimensional, e testes são construídos para a verificação de diferenças entre a variabilidade entre e dentro de tratamentos ou grupos. Vários métodos já estão implementados em programas computacionais e têm sido aplicados pelos pesquisadores numa gama de problemas relacionados às mais diversas áreas do conhecimento humano, com ênfase na ecologia e ciências sociais.

Métodos não-paramétricos com a utilização da mediana multivariada (componentwise) têm sido aplicados em algumas situações com o uso dos programas computacionais em que os métodos da análise de variância multivariada são disponibilizados, simplesmente substituindo-se os valores originais das variáveis por seus postos, com a atribuição feita isoladamente para cada uma das variáveis em estudo. Esse tipo de procedimento, que tem sua origem no trabalho de Puri \& Sen (1971) e outros correlatos, é bem suportado pela teoria assintótica se o número de elementos amostrados em cada grupo ou tratamento é grande. Entretanto, isso nem sempre ocorre e, nessas situações, o procedimento utilizando a teoria assintótica pode ser falho, levando a falsas conclusões.

Os testes apresentados por Katz \& McSweeney (1980), Schwertman (1984) e Zwick (1985), apesar de serem interessantes do ponto de vista teórico e serem de utilização simples nos casos com grandes amostras, necessitavam de uma complementação computacional para sua utilização em casos com poucas amostras. A utilização de resultados assintóticos tem como pressuposição um grande número de amostras, o que em muitos casos não ocorre. Buscar soluções alternativas para a 
resolução de problemas com poucas amostras em testes multivariados motivou a elaboração de um programa computacional, que pode ser solicitado, através de e-mail, para sua utilização. A linguagem de programação $C$ foi escolhida para tal fim devido sua rapidez de processamento e facilidade em seus comandos. Tentativas utilizando a parte programável de programas comerciais resultaram em programas lentos devido à necessidade de utilização de um número grande de configurações para a realização de testes de permutação. Obviamente que a rapidez de processamento não foi capaz de impedir que o citado programa tivesse limitações devido à impossibilidade de analisar todas as configurações possíveis quando o tamanho das amostras cresce.

Assim, o programa elaborado realiza todas as permutações quando o número de configurações é pequeno, do ponto de vista computacional. É fixado um número máximo para o qual as configurações sistemáticas são obtidas e esse valor pode ser modificado de acordo com a capacidade do computador que vai ser utilizado. Caso o número de configurações seja maior do que o número estipulado, um número fixo permutações aleatórias é utilizado na obtenção o valor-p da estatística de teste. Também esse número de configurações aleatórias pode ser escolhido pelo usuário. Essas configurações aleatórias levam a um valor-p aproximado. Em alguns programas computacionais desenvolvidos com o método de permutações, também um intervalo de confiança é obtido, e o presente programa pode também ser adaptado para a obtenção dos limites desse intervalo.

Através do programa podem ser obtidos os valores-p para os métodos propostos, baseados nos critérios do teste de Wilks e do traço de Pillai, além da técnica de desdobramento da estatística de Wilks em componentes principais, de acordo com Dempster (1963b). Testes de comparações múltiplas baseadas em técnicas semelhantes ao método univariado de Scheffé também podem ser implementados utilizando-se o programa desenvolvido.

A forma que os elementos amostrais são permutados deve estar de acordo com as técnicas de aleatorização requeridas no experimento a ser analisado, sendo sempre enfatizado que são esses elementos e não as variáveis que devem ser trocados de 
posição. Assim a matriz de variação total permanece constante em todas as configurações, o que diminui o esforço computacional.

Os resultados obtidos são promissores, mas a procura por uma estatística mais adequada para a realização de testes considerando os postos deve continuar. Outras situações podem ser também objeto de trabalhos num futuro próximo. Uma delas é a utilização dos componentes principais comuns, que agregam vários grupos ou tratamentos. Essa técnica, desenvolvida por Flury (1984) pode ser utilizada em conjunto com o método da análise de variância multivariada stepwise, apresentada por Dempster (1963a, 1963b).

A metodologia utilizada para a obtenção de níveis de significância exatos (ou aproximados) adotada nesse trabalho pode ser estendida a outros tipos de ensaios, como no caos univariado, bastando verificar como se processa a distribuição dos tratamentos às unidades experimentais e construir as configurações possíveis a partir dessa atribuição inicial. Uma técnica bastante interessante que pode ser utilizada na implementação da técnica nesses tipos de delineamento é a de exclusão dos efeitos de tratamentos que não serão testados, denominada realinhamento dos postos. 


\section{REFERÊNCIAS BIBLIOGRÁFICAS}

ANDERSON, M.J. A new method for nonparametric multivariate analysis of variance. Austral Ecology, v.26, p.32-46, 2001.

ANDREWS, D.F.; GNANADESIKAN, R.; WARNER, J.L. Transformations of multivariate data. Biometrics, v.27, p.825-840, 1971.

ANSELMO, S.M. Fatores psicológicos relacionados às desordens temporomandibulares: avaliação de pacientes submetidos à tratamento com aparelhos oclusais plano e reabilitação oral. Piracicaba, 2005. 87p. Tese (Doutorado) - Faculdade de Odontologia de Piracicaba - UNICAMP.

ARNOLD, H.J. Permutation support for multivariate techniques. Biometrika, v.51, n.1, p.65-70, 1964.

ATKINSON, A.C.; MULIRA H.-M. The stalactite plot for the detection of multivariate outliers. Statistics and Computing, v.3, p.27-35, 1993.

BELL, C.B.; SEN, P.K. Randomization procedures. In: KRISHNAIAH, P.R.; SEN, P.K. (Ed.) Handbook of statistics. New York: Elsevier Science, 1984. v.4, cap.1, p. 1-29.

BERK, R.L.H.; COHEN, A. Asymptotically optimal methods of combining tests. Journal of the American Statistical Association, v.74, n.368, p. 812-814, 1978. 
BERRY, K.J.; MIELKE, P.W. Computation of exact probability for multi-response permutation procedures (mrpp). Communications in Statistics: Simulation and Computation, v.13, n.3, p.417-432, 1984.

BHAPKAR, V.P. Univariate and multivariate multisample location and scale tests. In: KRISHNAIAH, P.R.; SEN, P.K. (Ed.). Handbook of statistics. New York: Elsevier Science, 1984. v.4, cap.2, p. 31-62.

BIRNBAUM, A. Combining independent tests of significance. Journal of the American Statistical Association, v.49, p.559-574, 1954.

BOYETT, J.M.; SHUSTER, J.J. Nonparametric one-sided tests in multivariate analysis with medical applications. Journal of the American Statistical Association, v.72, n.359, p.665-668, 1977.

BOYK, R.J. Spectral models for covariance matrices. Biometrika, v.89, p.159-182, 2002.

BRADLEY, R.A.; PATEL, K.M.; WACKERLY, D.D. Aproximate small-sample distributions for multivariate two-sample nonparmetric tests. Biometrics, v.27, p.515-530, 1971.

BROWN, B.M. Statistical uses of the spatial median. Journal of the Royal Statistical Society, Series B, v.45, n.1, p.25-30, 1983.

CAMPOS, H. de. Estatística experimental não-paramétrica. 4.ed. Piracicaba: FEALQ, 1983. 349p.

CHAKRABORTY, B.; CHAUDHURI, P. On a transformation and re-transformation technique for constructing an affine equivariant multivariate median. Proceedings of the American Mathematical Society, v.124, n.4, p.2539-2547, 1986. 
CHAKRABORTY, B.; CHAUDHURI, P.; OJA, H. Operating transformation retransformation on spatial median and angle test. Statistica Sinica, v.8, p.767-784, 1998.

CHOI, K.; MARDEN, J. Multivariate analysis of variance using spatial ranks. Sociological Methods \& Research, v.30, n.3, p.341-366, 2002.

CHUNG, J.H.; FRASER, D.A.S. Randomization tests for a multivariate two-sample problem. Journal of the American Statistical Association, v.53, p.729-735, 1958.

CLARKE, K.R. Non-parametric multivariate analysis of changes in community structure. Australian Journal of Ecology, v.18, p.117-143, 1993.

CONOVER, W.J. Practical nonparametric statistics. 3.ed. New York: John Wiley, 1999. $584 \mathrm{p}$.

CONOVER, W.J.; IMAN, R.L. Rank transformations as a bridge between parametric and nonparametric statistics.The American Statistician, v.35, n.3, p.124-129, 1981.

DEMPSTER, A.P. Multivariate theory for general stepwise methods. Annals of Mathematical Statistics, v.34, p.873-883, 1963a.

DEMPSTER, A.P. Stepwise multivariate analysis of variance based on principal variables. Biometrics, v.19, p.478-490, 1963b.

DIETZ, E.J. Bivariate nonparametric tests for the one-sample location problem. Journal of the American Statistical Association, v.77, n.377, p.163-169, 1982.

DIETZ, E.J.; KILLEEN, T.J. A nonparametric multivariate test for monotone trend with pharmaceutical applications. Journal of the American Statistical Association, v.78, n.373, 1981.

EDGINGTON, E.S. Randomization tests. 3.ed. New York: Marcel Dekker, 1995. 409p. 
FISHER, R.A. Statistical methods for research workers. 4.ed. Edinburgh: Oliver \& Boyd, 1932. 307 p.

FLURY, B.N. Common principal componentes in k groups. Journal of the American Statistical Association, v.79, n.388, p.892-898, 1984.

FLURY, B.N. Common principal components and related multivariate models. New York: John Wiley, 1988. 258p.

FOLKS, J.L. Combination of independent tests. In KRISHNAIAH, P.R.; SEN, P.K. Handbook of statistics. New York: Elsevier Science, 1984. v.4, cap.6, p.113-121.

FRYER, J.G. On the nonparametric tests of David and Fix for the bivariate two-sample location problem. Journal of the American Statistical Association, v.65, n.331, p.1297-1307, 1970.

GIANNOTTI, J.G. Meta-análise de parâmetros genéticos de características de crescimento em bovinos de corte sob enfoques clássico e bayesiano. Piracicaba, 2004. 86p. Tese (Doutorado) - Escola Superior de Agricultura "Luiz de Queiroz", Universidade de São Paulo.

GIESER, P.W.; RANDLES, R.H. A nonparametric test of independence between two vectors. Journal of the American Statistical Association, v.92, n.438, 1997.

GOOD, I.J. On the weighted combination of significance tests. Journal of the Royal Statistical Society, Series B, v.17, p.264-265, 1955.

GOOD, P. Permutation tests: a practical guide to resampling methods for testing hypotheses. 2.ed. New York: Springer-Verlag, 2000. 270p.

GOWER, J.C. The mediancentre. Applied Statistics, v.23, n.3, p.466-470, 1974.

GOWER, J.C.; KRZANOWKI, W.J. Analysis of distance for structured multivariate data and extensions to multivariate analysis of variance. Applied Statistics, v.48, n.4, p.505-519, 1999. 
HEDGES, L.V.; OLKIN, I. Statistical methods in meta-analysis. New York: Academic Press, 1985. 392p.

HENZE, N. A multivariate two-sample test based on the number of nearest neighbor type coincidences. Annals of Statistics, v.16, n.2, p.772-783, 1988.

HETTMANSPERGER, T.P.; RANDLES, R.H. A practical affine equivariant multivariate median. Biometrika, v.89, n.4, p.851-860, 2002.

HETTMANSPERGER, T.P.; MÖTTÖNEN, J.; OJA, H. Affine-invariant multivariate one-sample signed-rank tests. Journal of the American Statistical Association, v.92, n.440, p.1591-1600, 1997.

HOLLANDER, M.; WOLFE, D.A. Nonparametric statistical methods. 2.ed. New York: John Wiley, 1999. 787p.

HUH, M.-H.; JHUN, M.. Random permutation testing in multiple linear regression. Communications in Statistics: Theory and Methods, v.30, n.10, p.2023-2032, 2001.

ITTENBACH, R.F.; CHAYER, D.E.; BRUININKS, R.H.; THURLOW, M.L.; BEIRRNE-SMITH, M. Adjustment of young adults with mental retardation in community settings: comparison of parametric and nonparametric statistica techniques. American Journal of Mental Retardation, v.97, n.6, p.607-615, 1993.

JOHNSON, R.A.; WICHERN, D.W. Applied multivariate statistical analysis. New Jersey: Prentice-Hall, 1999. 816p.

KANKAINEN, A.; TASKINEN, S.; OJA, H. On Mardia's test of multinormality. http://www.maths.jyu.fi/ ojahannu/files/icorsmars.ps (25 abr. 2005).

KATZ, B.M.; MCSWEENEY, M. A multivariate Kruskal-Wallis test with post hoc procedures. Multivariate Behavoiral Research, v.15, p.281-297, 1980. 
KHATTREE, R.; NAIK, D.N. Applied multivariate statistics with SAS software. 2.ed. Carey: Wiley Interscience; SAS Institute's Book by Users, 1996. 338 p.

KRZANOWSKI, W.J. Multifactorial analysis of distance in studies of ecological community structure. Journal of Agricultural, Biological, and Environmental Statistics, v.7, n.2, p.222-232, 2002a.

KRZANOWSKI, W.J. Orthogonal components for grouped data: review and applications. Statistics in Transition, v.5, n.5, p.759-777, 2002b.

LEGENDRE, P.; ANDERSON, M.J. Distance-based redundancy analysis: testing multispecies responses in multifactorial ecological experiments. Ecological Monographs, v.69, n.1, p.1-24, 1999.

LITTELL, R.C.; FOLKS, J.L. Asymptotically optimal of Fisher's method of combining independent tests II. Journal of the American Statistical Association, v.68, n.341, p.193-194, 1973.

MALKOVICH, J.F.; AFIFI, A.A. On tests for multivariate normality. Journal of the American Statistical Association, v.68, p.176-179, 1973.

MANLY, B.F.J. Multivariate statistical methods: a primer. 2. ed. London: Chapman \& Hall, 1997. 215p.

MANTEL, N.; VALAND, R.S. A technique of nonparametric multivariate analysis. Biometrics, v.26, p.547-558, 1970.

MARDIA, K.V. Measures of multivariate skewness and kurtosis with applications. Biometrika, v.57, n.1, p.519-530, 1970.

MARDIA, K.V. The effect of nonnormality on some multivariate tests and robustness to nonnormality in the linear model. Biometrika, v.58, n.1, p.105-121, 1971. 
MARDIA, K.V.; KENT, J.T.; BIBBY, J.M. Multivariate analysis. London: Academic Press, 1979. 521p.

McARDLE, B.H.; ANDERSON, M.J. Fitting multivariate models to community data: a comment on distance-based redundancy analysis. Ecology, v.82, n.1, p.290-297, 2001.

MEIER, U. On the asymptotic normality of rank tests for independence. Journal of Statistical Planning and Inference, v.61, p.279-296, 1997.

MIELKE, P.W.; IYER, H.K. Permutation techniques for analyzing multi-response data from randomization block experiments. Communications in Statistics: Theory and Methods. v.11, n.13, p.1427-1437, 1982.

MIELKE, P.W.; BERRY, K.J.; BLOCKWELL, P.J.; WILLIAM, J.S. A class of nonparametric test based on multiresponse permutation procedures. Biometrika, v.68, n.3, p.720-724, 1981.

MOOD, A.M.; GRAYBILL, F.A.; BOES, D.C. Introduction to the theory of statistics. 3.ed. Tokyo: McGraw-Hill Kogakusha, 1974. 564 p.

MÖTTÖNEN, J.; OJA, H. Multivariate spatial sign and rank methods. Journal of Nonparametric Statistics, v.5, p.201-213, 1995.

MÖTTÖNEN, J.; HÜSLER, J.; OJA, H. Multivariate nonparametric tests in a randomized complete block design. Journal of Multivariate Analysis, v.85, p.106129, 2003.

MÖTTÖNEN, J.; HETTMANSPERGER, T.P.; OJA, H.; TIENARI, J. On the efficiency of affine invariant multivariate rank tests. Journal of Multivariate Analysis, v.66, p.118-132, 1998. 
MUNDRY, R.; FISCHER, J. Use of statistical programs for nonparametric tests of small samples often leads to incorrect p values: examples from Animal Behaviour. Animal Behaviour, v.56, p.256-259, 1998.

MUNZEL, U.; BRUNNER, E. Nonparametric methods in multivariate factorial designs. Journal of Statistical Planning and Inference, v.88, p.117-132, 2000.

NADAR, M.; HETTMANSPERGER, T.P.; OJA, H. The asymptotic matrix of the Oja median. Statistics \& Probability Letters, v.64, p.431-442, 2003.

NEGRILLO, B.M. Métodos não-paramétricos uni e multivariados. Piracicaba: FEALQ, 1985. 98 p.

OJA, H. Descriptive statistics for multivariate distributions. Statistics \& Probability Letters, v.1, p.327-332, 1983.

OJA, H.; NYBLOM, J. Bivariate sign tests. Journal of the American Statistical Association, v.84, n.405, 1989.

OLLILA, E.; OJA, H.; CROUX, C. The affine equivariant sign covariance matrix: asymptoctic behavior and efficiencies. Journal of Multivariate Analysis, v.87, p.328-355, 2003.

PARK, H-I; NA, J-H.; DESU, M.M. Nonparametric one-sided tests for multivariate data. Sankhyã - Series B, v.63, n.3, p.286-297, 2001.

PEREIRA, J.C.R. Análise de dados qualitativos: estratégias metodológicas para as ciências da saúde, humanas e sociais. São Paulo: EDUSP, 1999. 156p.

PESARIN, F. Multivariate permutation tests: with applications in biostatistics. Chinchester: John Wiley, 2001. 408 p. 
PETERS, D.; RANDLES, R.H. A multivariate signed-rank test for the one-sample location problem. Journal of the American Statistical Association, v.85, n.410, p.552-557, 1990.

PETERS, D.; RANDLES, R.H. A bivariate signed rank test for the two-sample location problem. Journal of the Royal Statistical Society, Series B, v.53, n.2, p.493-504, 1991.

PLACHKY, D.; RUKHIN, A.L. Nonparametric covariance estimation in multivariate distributions. Metrika, v.50, p.131-136, 1999.

PONTES, A.C.F. Obtenção dos níveis de significância para os testes de Kruskal-Wallis, Friedman e comparações múltiplas não-paramétricas. Piracicaba, 2000. 140p. Dissertação (Mestrado) - Escola Superior de Agricultura "Luiz de Queiroz", Universidade de São Paulo.

PONTES, A.C.F.; CORRENTE, J.E. Obtenção de níveis de significância para experimentos em blocos casualizados e comparações múltiplas não-paramétricas. Revista de la Sociedad Argentina de Estadistica, v.1, n.4, p.51-78, 2000.

PONTES, A.C.F.; CORRENTE, J.E. Comparações múltiplas não-paramétricas para o delineamento com um fator de classificação simples. Revista de Matemática e Estatística da UNESP, v.19, p.179-197, 2001.

PONTES, A.C.F.; CORRENTE, J.E. The use of nonparametric contrasts in one-way layouts and random block designs. Journal of Nonparametric Statistics, v.17, n.3, p.335-346, 2005.

PURI, M.L.; SEN, P.K. Nonparametric confidence regions for some multivariate location problems. Journal of the American Statistical Association, v.63, p.13731378, 1968. 
PURI, M.L.; SEN, P.K. Nonparametric methods in multivariate analysis. New York: John Wiley, 1971. 440p.

RANDLES, R.H. A simpler, affine-invariant, multivariate, distribution-free sign test. Journal of the American Statistical Association, v.95, n.452, p.1263-1268, 2000.

RANDLES, R.H.; PETERS, D. Multivariate rank tests for the two-sample location problem. Communications in Statistics: Theory and Methods, v.19, n.11, p.42254238, 1990.

RAO, C.R. Advanced statistical methods in biometric research. New York: John Wiley, 1952. 390p.

RENCHER, A.C. Methods of multivariate analysis. New York: John Wiley, 1995. 627p.

ROSENTHAL, R. Combining results of independent studies. Psychological Bulletin, v.85, n.1, p.185-193, 1978.

ROSENTHAL, R.; RUBIN, D.B. Comparing significance levels of independent studies. Psychological Bulletin, v.86, n.5, p.1165-1168, 1979.

ROSENTHAL, R.; RUBIN, D.B. Comparing effect sizes of independent studies. Psychological Bulletin, v.92, n.2, p.500-504, 1982.

SCHILLING, M.F. Multivariate two-sample tests based on nearest neighbors. Journal of the American Statistical Association, v.81, n.395, p.799-806, 1986.

SCHWERTMAN, N.C. A Monte Carlos study of the $\mathrm{L}_{\mathrm{N}}$ statistic for the multivariate nonparametric median and rank sum tests for two populations. Communications in Statistics - Simulation and Computation, v.11, n.6, p.667-676, 1982. 
SCHWERTMAN, N.C. Multivariate median and rank sum tests. In: KOTZ, S.; JOHNSON, N.L.; READ, C.B. (Ed.). Encyclopedia of statistical sciences. New York: Wiley-Interscience, 1984. v.6, p.85-88.

SEN, P.K. On nonparametric simultaneous confidence regions and tests for the one criterion analysis of variance problem. Annals of the Institute of Statistical Mathematics, v.18, p.319-336, 1966.

SEN, P.K. Nonparametric tests for multivariate interchangeability. Part 1: problems of location and scale in bivariate distributions. Sankhyã - Series A, v.29, p.351-372, 1967.

SEN, P.K. Nonparametric tests for multivariate interchangeability. Part two: the problem of MANOVA in two-way layouts. Sankhyã - Series A, v.31, p.145-156, 1969.

SIMON, G. Multivariate generalization of Kendall's Tau with application to data reduction. Journal of the American Statistical Association, v.72, n.358, p. 367376, 1977.

SHAPIRO, S.S.; WILK, M.B. An analysis of variance test for normality (complete samples). Biometrika, v.52, p.591-611, 1965.

SHAPIRO, S.S.; WILK, M.B.; CHEN, H.J. A comparative study of various tests for normality. Journal of the American Statistical Association, v.63, p.1343-1372, 1968.

SPURRIER, J.D. Generalizations of Steel's treatments-versus-control multivariate sign test. Journal of the American Statistical Association, v.83, n.402, p.471-476, 1988.

SYRJALA, S.E. A statistical test for a difference between the spatial distributions of two populations. Ecology, v.77, n.1, p.75-80, 1996. 
SZÉKELY, G.J.; RIZZO, M.L. A new test for multivariate normality. Journal of Multivariate Analysis, v.93, n.1, p.58-80, 2005.

TAMURA, R. Multivariate nonparametric several-sample tests. Annals of Mathematical Statistics, v.37, p.611-618, 1965.

TASHIKEN, S.; KANKAINEN, A.; OJA, H. Sign test of independence between two random vectors. Statistics \& Probability Letters, v.62, p.9-21, 2003.

THOMPSON, G.L. On intercomponent rank tests for the bivariate two-sample location model. Journal of Statistical Computation and Simulation, v.43, p.103-116, 1992.

TORABI, M.R.; DING, K. Selected measurement and statistical issues in health education evaluation and research. The International Electronic Journal of Health Education, v.1, p.26-38, 1998.

UM, Y.; RANDLES, R.H. Nonparametric tests for the multivariate multi-sample location problem. Statistica Sinica, v.8, p.801-812, 1998.

VISURI, S.; KOIVUNEN, V.; OJA, H. Sign and rank covariance matrices. Journal of Statistical Planning and Inference, v.91, p.557-575, 2000.

VISURI, S.; OLlilA, E.; KOIVUNEN, V.; MÖTTÖNEN, J; OJA, H. Affine equivariant multivariate rank methods. Journal of Statistical Planning and Inference, v.114, p.161-185, 2003.

WALD, A.; WOLFOWITZ, J. Statistical tests based on permutations of the observations. Annals of Mathematical Statistics, v.15, p.358-372, 1944.

WELCH, W.J. Construction of permutation tests. Journal of the American Statistical Association, v.85, n.411, p.693-698, 1990. 
WILKINSON, B.A. A statistical consideration in psychological research. Psychological Bulletin, v.48, p156-158, 1951.

ZWICK, R. Nonparametric ono-way multivariate analysis of variance: a computational approach based on the Pillai-Bartlett trace. Psychological Bulletin, v.97, n.1, p.148152, 1985. 